\title{
Conservative treatment for women with stress incontinence and bladder overactivity
}

Citation for published version (APA):

Berghmans, L. C. M. (2000). Conservative treatment for women with stress incontinence and bladder overactivity. [Doctoral Thesis, Maastricht University]. Universiteit Maastricht. https://doi.org/10.26481/dis.20001201lb

Document status and date:

Published: 01/01/2000

DOI:

$10.26481 /$ dis.20001201lb

Document Version:

Publisher's PDF, also known as Version of record

\section{Please check the document version of this publication:}

- A submitted manuscript is the version of the article upon submission and before peer-review. There can be important differences between the submitted version and the official published version of record.

People interested in the research are advised to contact the author for the final version of the publication, or visit the DOI to the publisher's website.

- The final author version and the galley proof are versions of the publication after peer review.

- The final published version features the final layout of the paper including the volume, issue and page numbers.

Link to publication

\footnotetext{
General rights rights.

- You may freely distribute the URL identifying the publication in the public portal. please follow below link for the End User Agreement:

www.umlib.nl/taverne-license

Take down policy

If you believe that this document breaches copyright please contact us at:

repository@maastrichtuniversity.nl

providing details and we will investigate your claim.
}

Copyright and moral rights for the publications made accessible in the public portal are retained by the authors and/or other copyright owners and it is a condition of accessing publications that users recognise and abide by the legal requirements associated with these

- Users may download and print one copy of any publication from the public portal for the purpose of private study or research.

- You may not further distribute the material or use it for any profit-making activity or commercial gain

If the publication is distributed under the terms of Article $25 \mathrm{fa}$ of the Dutch Copyright Act, indicated by the "Taverne" license above, 


\section{Conservative treatment for women}

\section{with stress incontinence}

and bladder overactivity 
The publication of this thesis was partially realised by financial support of Uroplasty, which is gratefully acknowledged.

Further financial support was generously provided by:

\section{BARD}

BestMedical

Biobedded Systems GmbH

Byk

CodaClin

Coloplast

Dillenburg Medical B.V.

Enral-Nonius

gymna medical revalldation apparatus

KonInklijk Nederlands Genootschap voor Fysiotherapie

MediReva, Medische Speciaalzaken

Medtronic Interstim

Onderzoeksinstituut ExTra

Pharmacla

SCA Hygiene Products B.V.

Stichting Wetenschappelijke Activitelten Maastrichtse Urologie

Uniphy B.V.

Uroplasty

Urosurge

VercomNet

XYTRON Modical B.V.

Yamanouchl Pharma B.V.

'L.C.M. Berghmans, Maastricht 2000

ISBN 90-5681-088-X

Lay-out: Thum Aarts

Cover: A. In de Braekt-Jorissen

Production: Unlgraphic 


\title{
Conservative treatment for women
}

\author{
with stress incontinence
}

\section{and bladder overactivity}

\author{
PROEFSCHRIFT
}

ter verkrijging van de graad van doctor

aan de Universiteit Maastricht

op gezag van de Rector Magnificus, Prof. dr. A.C. Nieuwenhuijzen Kruseman

volgens het besluit van het College van Decanen,

in het openbaar te verdedigen

op vrijdag 1 december 2000 om 12.00 uur

door

Lambertus Catharina Mathieu Berghmans 


\section{Promotores}

Prof. dr. Ph.E.V.A. van Kerrebroeck

Prof. dr. ir. P.A. van den Brandt

\section{Co-promotor}

Dr. R.A. de Bie

\section{Beoordelingscommissie}

Prof. dr. J.A. Knottnerus (voorzitter)

Prof. dr. C.G.M.I. Baeten

Prof. dr. H. Kuipers

Prof. dr. A.A.B. Lycklama à Nijeholt (Universiteit Leiden)

Prof. dr. R.A.B. Oostendorp (Katholieke Universiteit Nijmegen) 


\section{Contents}

page

Chapter 1 Introduction

Chapter 2 Conservative treatment of stress urinary incontinence in women: a systematic review of randomized clinical trials

Chapter 3 Efficacy of biofeedback, when included with pelvic floor muscle exercise treatment, for genuine stress incontinence:

a randomized clinical trial

Chapter 4 Guidelines for the physiotherapeutic management of genuine stress incontinence

Chapter 5 Conservative treatment of urge urinary incontinence in women: a systematic review of randomized clinical trials

Chapter 6 Efficacy of physical therapeutic modalities in women with proven bladder overactivity in extramural physical therapy:

a randomized clinical trial

Chapter 7 General discussion

Summary

Nederlandse samenvatting

Dankwoord

Authors

Curriculum Vitae 
Voor mijn ouders

Voor Caroline en Hetty 


\section{Chapter 1}

\section{Introduction}

\section{Conservative treatment for women with stress incontinence and bladder overactivity}

There is a growing need to justify the rationale for treatments, and to provide evidence that physiotherapy does have effect on the natural course of disease, and impact on the patient's condition. ${ }^{1,2}$ In many countries the physiotherapy profession is increasingly urged by society to justify its financial burden on public expenditure. This thesis focuses on the physiotherapeutic assessment and management of lower urinary tract disorders, resulting in stress urinary incontinence (SUI). Another subject of this thesis is conservative treatment for women with symptoms as urgency, frequency and/or (motor) urge urinary incontinence due to bladder overactivity or detrusor instability (DI).

The aim of this thesis is to make an inventarisation of the current state and the art of the conservative treatment. Next to this, we have tested the efficacy of conservative treatments for women with stress urinary incontinence or bladder overactivity.

It is important to inform health care providers, involved in any way in the diagnosis and treatment of urinary incontinence (UI), about the state of the art physiotherapy related to these health problems. Referring physicians need to keep abreast of the possibilities of physiotherapeutic diagnosis and intervention(s). Physiotherapists and other health care providers of conservative treatment for women with stress urinary incontinence and/or bladder overactivity, need to be informed about the current state of the art of these interventions. What evidence can be found in literature, supporting the rationale for the physiotherapeutic management of stress urinary incontinence and/or bladder overactivity? What is the effect of the different treatment modalities for women with stress urinary incontinence and/or bladder overactivity? Is there any surplus value for these treatment modalities?

The International Continence Society (ICS) defines urinary incontinence as the objectively demonstrable involuntary loss of urine, to such a degree of severity that it is a social or hygienic problem. ${ }^{3}$

Urinary incontinence affects millions of people worldwide. In the United States of America alone, more than 13 million Americans are affected. ${ }^{4}$ Loss of urinary control, for whatever reason, affects the social, psychological, domestic, occupational, physical and sexual lives of $15 \%$ to $30 \%$ of women of all ages..$^{5}$ In the United Kingdom, Thomas ${ }^{6}$ showed in research on the prevalence of urinary incontinence in women between $15-65$ years that $8.5 \%$ of women had urinary incontinence and that prevalence increased with age. In community dwelling women of 60 years and older, prevalence of urinary incontinence was $23.5 \% .^{7}$ In a series of randomly selected women (30-59 years old), $26 \%$ reported having experienced urinary incontinence at some time in adult life, and $14 \%$ had perceived urinary incontinence as a social or 
hygienic problem. ${ }^{8}$ In Norway $47 \%$ of younger women (mean 38.5 years) claimed to be incontinent for urine. ${ }^{9}$ In males prevalence is much lower. ${ }^{4}$ In men between 15-65 years, prevalence was $1.6 \%{ }^{6}$ In the category men above 65 years prevalence was $7 \%$. In Dutch general practice the incidence of urinary incontinence in men younger than 65 years is very low. ${ }^{10,11}$ In the Netherlands about $5 \%$ of the population above the age of 5 years (in general the age that continence for urine may be expected) has urinary incontinence. ${ }^{12}$ Because urinary incontinence affects women more often than men, this thesis will focus on women with urinary incontinence, more specific stress urinary incontinence and bladder overactivity in women.

In many studies the prevalence of urinary incontinence varies considerably. This could be due to different definitions of urinary incontinence. ${ }^{13,14} \mathrm{~A}$ review of the literature shows that proper classification and uniform terminology are very important with respect to the definition and registration of urinary incontinence in order to be able to quantify the health problem of urinary incontinence adequately. ${ }^{2,13,15}$

The prevalence of urinary incontinence is often underestimated, because most affected individuals do not seek help for urinary incontinence, primarily because of embarrassment or because they are not aware that help is available. ${ }^{6}$ The psychosocial impact of urinary incontinence imposes a burden on individuals, their families and health care providers. ${ }^{1}$ Many women report to be depressed and embarassed about their appearance and odor. ${ }^{5}$ Consequently, holidays or day trips, social and sexual activities may be restricted or avoided entirely due to incontinence. $^{5}$

When individuals do seek help, practitioners hesitate to discuss the problem or do little to assess or treat it properly. ${ }^{1}$

On the other hand, in the period between 1971 and 1993, more and more urinary incontinence problems are presented to the general practitioner. ${ }^{11}$ So, for the general practitioner it is important to learn more about these problems and to pay attention to the consequences of urinary incontinence in order to be able to give the necessary and relevant health care. ${ }^{16}$

There are various types of urinary incontinence. Stress urinary incontinence is the most common form of urinary incontinence in women, with an estimated prevalence of $8-33 \% .{ }^{17}$ Prevalence of stress urinary incontinence in women of 65 years and older varies between 22 and $38 \% .6,18$ Stress urinary incontinence is the involuntary loss of urine during physical exertion, e.g., coughing, sneezing, laughing, running, jumping and lifting. Next to stress incontinence, bladder overactivity or detrusor instability is the most frequently observed disorder of the reservoir function in women. ${ }^{19}$ Bladder overactivity is defined by the ICS as a disorder of filling/storage in which involuntary bladder contractions are demonstrated while the patient is attempting to inhibit. ${ }^{13}$ If the involuntary bladder contractions are secondary to a known neurologic disease, such as stroke, multiple sclerosis, etc., the condition is known as detrusor hyperreflexia. If the involuntary bladder contractions are not due to a known neurologic disease, then the condition is known as detrusor instability. The symptoms of detrusor instability consist of urgency and/or frequency and/or nocturia and/or urge incontinence. They may exist singly or in combination with one another. Urgency is defined as a strong desire to void. Urge incontinence is defined as involuntary loss of urine associated with urgency due to an overactive detrusor (motor urge incontinence). Prevalence of bladder overactivity in Dutch women of 18 years and older is $11 \%$, while bladder overactivity affects about $20 \%$ of women above 50 years. ${ }^{20}$ In the European Community prevalence of bladder overactivity in 
women of 40 years and older is between $12 \%$ (France, Italy) to $22 \%$ (Spain). ${ }^{20}$ Despite these high prevalence percentages, $64 \%$ of the affected individuals claimed that they never discussed their problem(s) with others! $!^{20}$

Urinary incontinence in women is caused by a variety of pathological conditions that interfere with the normal micturition reflexes. Specific differentiated therapy is essential in order to obtain a high therapeutic success rate.

Incontinence therapy has mainly been based on multiple surgical methods, a variety of pharmacological agents, and various behavioural methods. The variety of etiologies and treatment options for urinary incontinence necessitate specific and detailed monitoring of the physical and the functional conditions of the lower urinary tract in order to clarify the underlying cause(s). Only accurate diagnosis can be an appropriate basis for therapeutic success. Nowadays, ambulatory urodynamic tests and visual on-screen monitoring methods are available to do this. ${ }^{21}$ It is very important to use accurate, reliable and valid diagnostic methods and tools in order to select those patients who will benefit from conservative treatments. A multidisciplinairy approach, aiming at adequate diagnosis preceeding conservative treatment, is necessary. Close cooperation between referring urologist, gynaecologist or general practitioner and physiotherapist is mandatory.

The high prevalence of stress urinary incontinence and bladder overactivity and the understanding that surgery with its attendant risks, and drugs because of side-effects is not appropriate for all patients, has re-awakened interest in conservative treatments. Physiotherapists may play an important role in the conservative treatment and prevention of stress urinary incontinence and bladder overactivity. A term often used in relation with conservative treatment and urinary incontinence and related conditions is pelvic floor re-education. This term encompasses the various techniques to increase the functionality (and strenght) of the pelvic floor (muscles) and to improve control of the pelvic floor. ${ }^{22}$ So, the aim of pelvic floor re-education is to improve or restore lost or compromised control and functionality of the pelvic floor, using a systematic strategy and adequate tools. This can only be achieved if there is a close cooperation, between the highly motivated patient and physiotherapist. In this sense, mutual understanding and respect between the incontinent patient and the physiotherapist are mandatory. ${ }^{23}$ Success of pelvic floor re-education for female urinary incontinence is highly dependent upon the degree and duration of treatment and frequent supervision by the physiotherapist. ${ }^{24}$

So far, little attention has been paid in medical literature to pelvic floor re-education and conservative treatment. Physicians often preferred surgery as the treatment of first choice for pelvic floor disorders, because it was thought to be highly effective.22 However, Black and Downs ${ }^{25}$ assessed the effectiveness of surgery for stress urinary incontinence in women in a systematic review and found that the long term success rates may be as low as $33 \%$, despite surgeons often quote success rates of $90-95 \%$. Also, not well qualified and trained practitioners may have negatively influenced the results of conservative treatment. Many physicians did not believe that conservative treatment could be an effective treatment for lower urinary tract disorders. ${ }^{22}$ Health care providers, who are trained in conservative treatment, like physiotherapists, often depend on physicians for referral of patients. Thus, it is possible that only those patients might have been referred, who were no candidates for surgery, like very old or infirm patients. Moreover, few gynaecologists, urologists and general practitioners 
received formal training in the use of physiotherapeutic techniques. This reinforced the belief that this kind of therapy was inefficient. ${ }^{22}$ Because of these reasons, the group of patients, referred to the physiotherapist for conservative treatment, might have been (very) heterogeneous regarding the nature and the severity of their symptoms. So, based on proper diagnostics and patientselection, it is extremely important to prove the effectiveness of physiotherapeutic management of stress urinary incontinence and bladder overactivity and to justify the rationale for these treatments.

Whidespread application of conservative treatments should be preceeded by evidence of improvement in function attributable to their use. Randomized clinical trials (RCTs) can serve this vital purpose. Systematic reviews on the basis of methodological criteria put much emphasis on the quality of the randomized clinical trials involved and are very useful to support evidence for the effectiveness of therapy. ${ }^{26}$

Guidelines in physical therapy for diagnosis, treatment and prevention in patients with urinary incontinence improve the quality of conservative treatment for these disorders. ${ }^{27}$

Chapter 2 holds a systematic review of RCTs that have been reported in the literature discussing the conservative treatment of stress urinary incontinence. The literature search yielded 173 publications, of which 24 met all inclusion criteria and were included in the review.

Chapter 3 constitutes the role of biofeedback (BF) as an adjunct to pelvic floor muscle exercises (PFME). In a randomized clinical trial, biofeedback, as an application to a standardisized programme of pelvic floor muscle exercises, is compared with the same pelvic floor muscle exercises programme. The study objective was to investigate whether or not a physical therapeutical training programme (pelvic floor muscle training) combined with biofeedback is more effective than the same programme without biofeedback in patients with mild or moderate stress urinary incontinence.

In chapter 4 evidence-based and systematic guidelines for the physiotherapeutic management of stress urinary incontinence are described. Because there is still a lack of standardization in the terminology related to stress urinary incontinence and physiotherapy, in this chapter relevant nomenclature and classification systems related to stress urinary incontinence are discussed and compared.

Chapter 5 contains a systematic review of RCTs that have been reported in literature discussing the conservative treatment of bladder overactivity. Fifteen RCTs were included after a computer-aided and manual search.

In another RCT, chapter 6, the aim is to evaluate the effectiveness of different physiotherapeutical treatment modalities for the treatment of bladder overactivity. In this study, in women with bladder overactivity, the effect of electrical stimulation alone versus the effect of pelvic floor muscle exercises alone or in combination with electrical stimulation will be determined compared to a no-treatment group.

A general discussion and conclusions regarding conservative treatment for stress urinary incontinence and bladder overactivity are given in chapter 7 .

Next, an English and a Dutch summary can be found.

\section{References}

1. Fantl JA, Newman DK, Colling J, et al. Urinary incontinence in adults: Acute and chronic management. Rockville Md: US Dept of Health and Human Services, Public Health Service, 
Agency for Health Care Policy and Research; March 1996. AHCPR publication 96-0682 Clinical Practice Guideline No.2, 1996 Update.

2. Berghmans LCM, Bernards ATM, Hendriks HJM, Bø K, Grupping MHM. Guidelines for physiotherapeutic management for genuine stress incontinence. Phys Ther Rev 1998; 3: 133147.

3. Abrams P, Blaivas JG, Stanton SL, Andersen JT. The standardization of terminology of lower urinary tract function. Scand J Urol Nephrol 1988; 114: 5-19.

4. Newman DK. How much society pays for urinary incontinence. Ostomy Wound Manage 1997; 43: 18-25.

5. Jackson $\mathrm{S}$. The patient with an overactive bladder-symptoms and quality-of-life issues. Urology 1997; 50 (suppl 6a): 18-22.

6. Thomas TM, Plymat KR, Blannin J, Meade TW. Prevalence of urinary incontinence. BMJ 1980; 281: 1243-1245.

7. Kok ALM, Voorhorst FJ, Halff-Butter CMC, Janssens J, Kenemans P. De prevalentie van urineincontinentie bij oudere vrouwen. NTVG 1991; 135: 98-101.

8. Elving LB, Foldspang A, Lam GW, Mommsen S. Descriptive epidemiology of urinary incontinence in 3100 women age 30-59.Scan J Urol Nephrol 1989; 125: 37-43.

9. Nygaard I, DeLancey J, Amsdort L, Murphy E. Exercise and incontinence. Obstet Gynecol 1990; 75: 848-851.

10. Borghuis ME, Lemain TTJ, Schreuder JLM: Groepsgewijze behandeling van vrouwen met incontinentieklachten. Fysiopraxis 1993; 8: 4-6.

11. Lisdonk EH van de, Bosch WJHM van der, Huygen FJA, Lagro-Janssen ALM. Ziekten in de huisartspraktijk. Utrecht: Bunge 1990.

12. Rekers $H$, Drogendijk $A C$, Valkenburg $H$, Riphagen $F$. Urinary incontinence in women from 35 to 79 years of age: prevalence and consequences. Eur J Gynecol Reprod Biol 1992; 43: 229-234.

13. Hampel C, Wienhold D, Benken N, Eggersmann, Thòroff JW. Definition of overactive bladder and epidemiology of urinary incontinence. Urology 1997; 50 (suppl 6a): 4-14.

14. Bump RC. Discussion: Epidemiology of urinary incontinence. Urology 1997; 50 (suppl 6a): 15-16.

15. Lagro-Janssen TLM, Debruyne FMJ, Smits AJA, Van Weel C. Controlled trial of pelvic floor exercises in the treatment of urinary stress incontinence in general practice. $\mathrm{Br} J$ Gen Pract 1991; 41: 445-449.

16. Kerssens JJ, Curfs EC. Extramurale fysiotherapie. Thesis University of Utrecht, the Netherlands 1993.

17. Iosif MD, Batra $S, E f A$, Astedt $B$. Oestrogen receptors in the human female lower urinary tract. Am J Obstet Gynecol 1981; 141: 817-820.

18. Diokno AC, Brock BM, Brown MB, Herzog AR. Prevalence of urinary incontinence and other urological symptoms in the non-institutionalized elderly. J Urol 1986; 136: 1022-1025.

19. Resnick NM. Urinary incontinence. Lancet 1995; 346: 94-99.

20. Schothorst YC. De overactieve blaas. Edited by bureau Veldkamp, the Netherlands 1998.

21. Waalwijk van Doorn ESC van, Ambergen AW. Diagnostic assessment of the overactive bladder during the filling phase: the detrusor activity index. Br J Urol 1999; 83 (suppl 2): 16-21.

22. Schussler B. Introduction. In: Schussler B, Laycock J, Norton P, Stanton S (eds). Pelvic Floor ReEducation. London. Springer-Verlag 1994; 1 : 3.

23. Berghmans LCM, Frederiks CMA, Bie RA de, Weil EHJ, Smeets LWH, Waalwijk van Doorn ESC van, Janknegt RA: Efficacy of biofeedback, when included with pelvic floor muscle exercise treatment, for genuine stress incontinence. Neurourol Urodyn 1996; 15: 37-52.

24. Bø K, Hagen RH, Kvarstein B, Jorgensen J, Larsen S. Pelvic floor muscle exercise for the treatment of female stress urinary incontinence: III. Effects of two different degrees of pelvic floor muscle exercises. Neurourol Urodyn 1990; 9: 489-502.

25. Black NA, Downs SH. The effectiveness of surgery for stress incontinence in women: a systematic review. Br J Urol 1996; 78: 497-510.

26. Vet HCW de, Bie RA de, Heijden GJMG van der, Verhagen AP, Sijpkes $P$, Knipschild PG. Systematic reviews on the basis of methodological criteria. Physiotherapy 1997; 83: 284-289.

27. Urinary Incontinence Guidelines Panel: Urinary incontinence in adults: Clinical Practice Guideline. AHCPR Pub.No.92-0038. Agency for Health Care Policy and Research, Public Health Service, US Department of Health and Human Services, Rockville, MD, 1992. 



\section{Conservative treatment of stress urinary incontinence in women: a systematic review of randomized clinical trials*}

LCM Berghmans, MSc, RPt (1), HJM Hendriks, PhD, RPt (2), K Bø, PhD, RPt (3), EJ Hay-Smith, MSc, MNZSP (4), RA de Bie, PhD, MSc, RPt (5),

ESC van Waalwijk van Doorn, PhD, DSc (1)

1 Department of Urology, University Hospital Maastricht, Maastricht, the Netherlands

2 Dutch National Institute of Allied Health Professions, Amersfoort, the Netherlands

3 Norwegian Centre for Physiotherapy Research, Oslo, Norway

4 School of Physiotherapy, Division of Health Sciences, University of Otago, Dunedin, New Zealand

5 Department of Epidemiology, Maastricht University, Maastricht, the Netherlands 


\section{Abstract}

Objective To assess the efficacy of physical therapies for first-line use in the treatment and prevention of stress urinary incontinence (SUI) in women, using a systematic review of randomized clinical trials (RCTs).

Materials and methods A computer-aided and manual search for published RCTs investigating treatment and prevention of stress urinary incontinence using physical therapies, e.g. pelvic floor muscle exercises, with or without other treatment modalities, was carried out. The methodological quality of the included trials was assessed using criteria based on generally accepted principles of interventional research.

Results Twenty-four RCTs (22 treatment and two prevention) were identified; the methodological quality of the studies included was moderate and 11 RCTs were of sufficient quality to be included in further analysis. Based on levels-of-evidence criteria, there is strong evidence to suggest that pelvic floor muscle exercises are effective in reducing the symptoms of stress urinary incontinence. There is limited evidence for the efficacy of high-intensity vs a low-intensity regimen of pelvic floor muscle exercises. Despite significant effects of biofeedback after testing as an adjunct to pelvic floor muscle exercises, there is no evidence that pelvic floor muscle exercises with biofeedback are more effective than pelvic floor muscle exercises alone. There is little consistency (of stimulation types and parameters) in the studies of electrical stimulation, but when the results are combined there is strong evidence to suggest that electrical stimulation is superior to sham electrical stimulation, and limited evidence that there is no difference between electrical stimulation and other physical therapies. In the prevention of stress urinary incontinence the efficacy of pelvic floor muscle exercises, with or without other adjuncts, is uncertain.

Conclusions More research of high methodological quality is required to further evaluate the effects of physical therapies used to treat and prevent stress urinary incontinence.

Key words systematic review, stress urinary incontinence, conservative treatment, prevention, physical therapy, (pelvic floor muscle) exercises, biofeedback, electrical stimulation, vaginal cones. 


\section{Introduction}

The International Continence Society (ICS) defines urinary incontinence (UI) as the involuntary loss of urine, which is objectively demonstrable, with such a degree of severity that it is a social or hygienic problem. ${ }^{1}$ Such urinary incontinence is often a debilitating and demoralizing condition which affects approximately $15 \%$ of the ambulatory adult population, more than $35 \%$ of women over age 60 years living in the community in the USA $\mathrm{A}^{2.3}$ and at least half of the 1.5 million nursing-home residents in the USA; ${ }^{4}$ urinary incontinence and related health problems cause major social and economic problems world wide. It is estimated that the USA alone spend at least $\$ 10$ billion annually on therapeutic management, absenteeism and disability related to urinary incontinence..$^{5-7}$

Urinary incontinence is particularly a problem for women; the overall estimated prevalence of urinary incontinence in women is approximately $30 \%{ }^{2,8-11}$ In contrast, the estimated prevalence of urinary incontinence in men aged $15-65$ years is $1.5 \%$ to $5 \% .^{11}$

Stress urinary incontinence is the most common form of urinary incontinence in women, with an estimated prevalence of $8 \%-33 \% .{ }^{12}$ Stress urinary incontinence is the involuntary loss of urine during physical exertion, e.g. coughing, sneezing, laughing, running, jumping and lifting. Genuine stress incontinence (GSI) is defined as the involuntary loss of urine which occurs when, in the absence of a simultaneous detrusor contraction, the intravesical pressure exceeds the maximum urethral pressure; ${ }^{13,14}$ Genuine stress incontinence can be diagnosed using urodynamic assessment. ${ }^{15,16}$

A wide range of surgical procedures has been used in the management of stress urinary incontinence, including colposuspension, needle suspension, sling procedures and anterior colporhaphy. Reported cure rates of surgery are $23-96 \%{ }^{17}$. ${ }^{20}$ and although surgeons often quote success rates of $90-95 \%$ for primary antiincontinence procedures, recent publications with longer evaluation periods and more objective methodology suggest that the long-term cure rates may be as low as $33 \%{ }^{21}$ Black and Downs ${ }^{22}$ assessed the effectiveness of surgery for stress urinary incontinence in women in a systematic review. They concluded that evidence of the effectiveness of surgery for stress urinary incontinence is weak and that until large, rigorous, prospective studies evaluating surgery for stress urinary incontinence have been completed, recommendations for best clinical practice cannot be based on scientific evidence. With the high prevalence of stress urinary incontinence, the understanding that surgery with its attendant risks is not appropriate for all patients, ${ }^{17,18,21-24}$ and the possible overestimation of the 'cure' rates of surgery, interest in conservative treatments has been revived. ${ }^{19,21,23}$

Several conservative treatment options are available for the management of stress urinary incontinence, e.g. physical therapies, behavioural modifications, pharmaceutical interventions and hormone replacement therapy. As physical therapies, particularly pelvic floor muscle exercises, with or without other treatment adjuncts such as vaginal cones, bio- or myofeedback, and electrical stimulation, are the mainstay of conservative management for the treatment and prevention of stress urinary incontinence, this review will focus on the efficacy of these interventions. The theoretical basis of these physical therapies, for the treatment of pelvic floor muscle dysfunction associated with stress urinary incontinence, is that facilitation and strengthening of the pelvic floor muscle may improve efficiency of the sphincteric action around the urethra and support the pelvic organs. It has been suggested that 
a strong contraction of the pelvic floor muscle will 'clamp' the pressure rise in the urethra as it is pressed against the public symphysis. In addition, it seems that a pelvic floor muscle contraction in response to a rise in intra-abdominal pressure may prevent urethral descent. Pelvic floor muscle training may also result in hypertrophy of the muscles, increasing the external mechanical pressure on the urethra, and improving structural support for the pelvic organs. ${ }^{14}$ Wall and Davidson ${ }^{25}$ suggested that pelvic floor muscle exercises are useful in the prevention of (genuine) stress urinary incontinence, as during pregnancy they might reduce delivery trauma and accelerate postpartum recovery, with potential benefits for long-term pelvic floor function in women. However, this theory of prevention is unproven.

Evaluating the effectiveness of individual physical therapies is difficult as they are often applied in a variety of combinations. We chose to include both explanatory (placebo or no-treatment comparison) and pragmatic (experimental intervention compared with a standard/active intervention) trials to examine the efficacy of physical therapies in isolation and/or commonly used combinations.

Recent reviews of conservative management and prevention of stress urinary incontinence show very promising short-term and long-term results. ${ }^{14,15,25-32}$ Although, most of these reviews summarized the literature, none describe an explicit and systematic method of identifying relevant studies, assessing their methodological quality and synthesizing the findings based on the outcomes of randomized controlled trials (RCTs). Thus the purpose of this systematic review was to investigate the methodological quality of RCT evidence for, and efficacy of physical therapies in the treatment and prevention of stress urinary incontinence in women.

\section{Materials and methods}

\section{Literature search strategy}

A search of the following computerized bibliographic databases, from 1980-1998, was undertaken: Medline, Excerpta Medica, the database of the Dutch National Institute of Allied Health Professions, and the database of the Cochrane Field in Therapies and Rehabilitation at Maastricht University. Key words representing impairments and disabilities were incontinence, urinary incontinence, stress urinary incontinence and genuine stress incontinence. Key words representing the intervention were conservative management, surgical and non-surgical treatment, behavioural modification, physiotherapy, pelvic floor muscle exercises, and all specific modalities (biofeedback, myofeedback, electrical stimulation, vaginal cones) and prevention. Key words identifying the design were RCTs, controlled trials, evaluation, effectiveness, efficacy and outcome. Manual searches for manuscripts found in the references fo this literature and manual review of the proceedings of ICS meetings from 1980 to 1997 were undertaken. In addition, several relevant non-computerized databases (e.g. Physiotherapy Index) and physiotherapy joumals that are not covered by Medline were screened, and experts in this field were consulted for additional information.

\section{Selection criteria}

A study was included when it met all of the following criteria: (i) the design was either an explanatory (placebo or no-treatment comparison) or pragmatic RCT (experimental intervention compared with a standard/active intervention) RCT; (ii) the trial reported exclusively or separately, results on women with stress urinary incontinence; (iii) the study investigated conservative management for the treatment 
or prevention of stress urinary incontinence; (iv) the experimental intervention or reference group(s) included pelvic floor muscle exercises, and/or other physical therapy interventions; ( $v$ ) the outcome measures were clinically relevant and reliable for the problem under investigation; (vi) the trial report was published in English, German or Dutch. Abstracts and unpublished studies were excluded.

\section{Methodological quality of the studies}

All RCTs were assessed for inclusion and methodological quality by two independent reviewers (LCMB, HJMH) except the RCT by Berghmans et al. ${ }^{33}$ which was assessed by $\mathrm{HJMH}$ and $\mathrm{KB}$. Disagreements were resolved by consensus and when required other reviewers $(\mathrm{KB} / \mathrm{JHS} / \mathrm{RdB})$ made the final decision. In addition, other review publications ${ }^{14,15,25-32}$ were consulted to validate the list of studies included in the present systematic review.

To assess the quality of the studies, a list of predefined methodological criteria was used, ${ }^{34,35}$ based on generally accepted principles of interventional research. ${ }^{36-36}$ These criteria assessed internal and external validity and power, and are listed in Table 1. The level (at least 50 subjects per group) of criterion B was based on two main factors. Firstly, prognostic comparability at baseline is not guaranteed by randomization of small groups of subjects and prognostically relevant differences might occur by chance. ${ }^{33}$ Secondly, in RCTs with small groups, type II-error is more likely than in RCTs with larger groups. A score of one point $(+)$ was given to each criterion fulfilled and zero $(-)$ if not. Criteria were graded as 0.5 points $( \pm)$ if the description was unclear, or if criteria were incomplete for intervention, measurement of outcome, or data presentation, etc. (e.g. criterion G - blinding; an unclear description of blinding graded \pm ). A maximum methodological quality score (MQS) of 10 was possible. After assessment, a hierarchical list was generated where higher scores indicated studies of higher methodological quality.

Table 1. Criteria for assessing methods in randomized clinical trials of conservative treatment and prevention of stress urinary incontinence in women. Adapted from Kleijnen et al. ${ }^{34,35}$

Criterion

A: Well-described inclusion criteria (diagnostic criteria, duration and severity of disease, and previous treatment)

B: $\quad$ At least 50 patients per group

C: Prestratificaton (prognostic variables)

D: $\quad$ Random allocation procedure described

E: Presentation of relevant baseline characteristics

F: $\quad<10 \%$ withdrawals and dropouts described

G: Blinding (patients, therapist, observer)

$\mathrm{H}$ : Interventions well described (nature, number, duration of treatments)

I: Effect/outcome measurements relevant and well described

$\mathrm{J}$ : $\quad$ Analysis and presentation of the results so that the analysis can be assessed (intention to treat, depending on the outcome measurement: at least the mean and SD, SEM, or Cl per group, or, if rates or proportions are used, the number of patients with a certain outcome

\section{Levels of evidence}

Summary statements on the efficacy of the therapeutic or preventive interventions were based on the amount and quality of RCT evidence. A rating system was used that considered four levels of scientific evidence based on the quality and the 
outcome of the studies. ${ }^{39,40}$ For the purposes of the rating scale, RCTs were either classified as of 'sufficient' methodological quality (i.e. moderate to high quality trials scoring $\geq 6$ points) or 'low' quality. Levels of evidence were rated as follows: Level 1 , strong evidence, i.e. multiple relevant RCTs of sufficient methodological quality; Level 2, moderate evidence, i.e. one relevant RCT of sufficient methodological quality and multiple low quality RCTs; Level 3, limited evidence, one relevant RCT of sufficient methodological quality or multiple low quality RCTs; Level 4, no evidence, i.e. no relevant RCTs, or contradictory outcomes.

\section{Results}

\section{Included and excluded studies}

The literature search yielded 173 publications, of which 32 were abstracts; of the remaining 141 papers, 26 were considered for inclusion in the review. ${ }^{33,41-65}$

Table 2. The methodological scores assigned to the RCTs on the efficacy of conservative treatment ( $N=22)$ and prevention $(\mathrm{N}=2)$ of $\mathrm{SUI}$ in order of total methodological quality score.

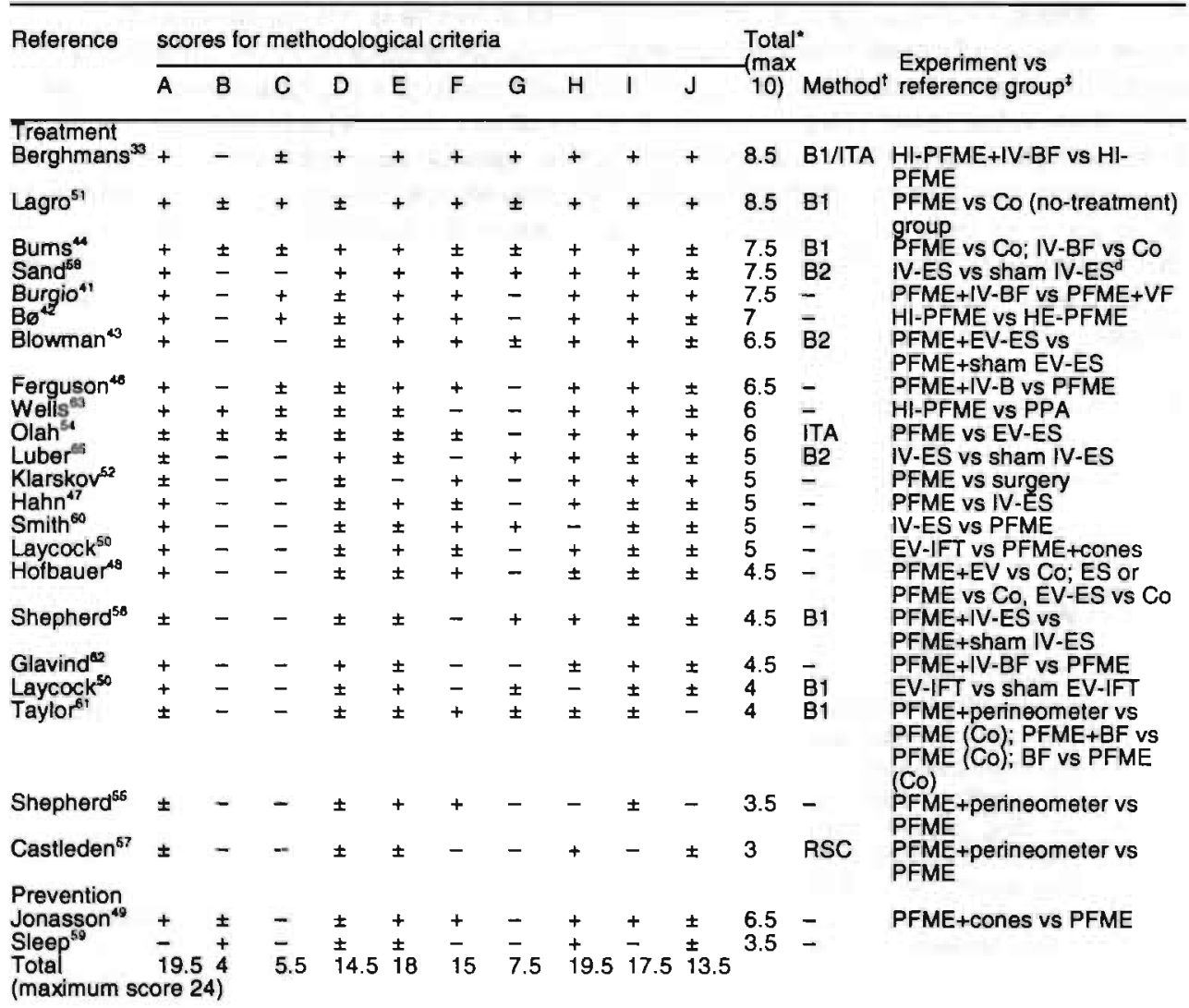

- item is score; +1 point; \pm partly scored, 0.5 point; - no points.

† $\mathrm{B}$, blinded, 1 single, 2 double; ITA, intention-to-treat analysis; RSC, random sequence crossover.

$\ddagger$ HI, high-intensity, PFME, pelvic floor muscle exercise; IV, intravaginal; EV, extravaginal; BF, bioleedback; ES, electrical stimulation; HE, home (PFM) exercises; VF, verbal feedback; $B$, balloon; IFT, interferential therapy; UI, urinary incontinence; Co, control(s). 
Of these 26 papers, three were excluded from further analysis. The excluded trials were: the study Wilson et al., ${ }^{62}$ because it was not a RCT, as participants were consecutively allocated to intervention groups; the study by O'Donnell et al., ${ }^{53}$ because it was not clear whether participants had stress urinary incontinence exclusively; and the preliminary report of a RCT by Burns et al., ${ }^{45}$ because a full report was published in $1993 .{ }^{44}$ One other paper was considered; in the study by Burns et al., ${ }^{44} 112$ of the 123 participants had stress urinary incontinence, and 11 had mixed incontinence with predominantly stress incontinence symptoms, thus it was decided to include this study in the review.

A total of 24 RCTs (from 23 papers) met the inclusion criteria; one paper reported two clinical trials. ${ }^{50}$ Twenty-two RCTs reported the outcomes of various conservative treatments and two reported the outcomes of conservative interventions for the prevention of stress urinary incontinence (Table 2). Seventeen of the 24 RCTs were 'pragmatic ${ }^{133,41,42,45-47,49,52-57,59-63}$ and seven were considered to be 'explanatory'. $43,44,48.50,51,58,65$

\section{Methodological quality and outcome of the studies}

In Table 2, all included RCTs are presented in a hierarchical order according to the MQS; the median (range) MQS was 5 (3-8.5) from the maximum 10 points. Of the 10 methodological quality criteria, four (B, C, G and J) were met by $<60 \%$ of the included studies. The main methodological shortcomings of the trials included were small sample sizes, lack of prestratification on prognostic determinants, (sub)optimal blinding and lack of proper (description of) analysis and presentation of results. Eleven of the 24 trials (46\%) scored $\geq 6$ points and were therefore classified as of 'sufficient' methodological quality. Of these 11 trials 10 were 'treatment' trials ${ }^{33,41,42-}$ 44,46,51,54,58,63 and one was a 'prevention' trial. ${ }^{49}$ Table 3 summarizes each of the included trials, giving a brief description of the participants, but the outcome, results and follow-up are complex and full details of these can be obtained from the authors on request.

\section{Efficacy of conservative interventions for the treatment of SUI}

There were two RCTs comparing pelvic floor muscle exercises with no treatment $t^{4,51}$ and both trials were of sufficient methodological quality ( 8.5 and 7.5 points, respectively; Table 2). With two such RCTs there is strong evidence in favour of pelvic floor muscle exercises vs no treatment (level 1).

There was one trial comparing an intensive pelvic floor muscle exercises programme with a home pelvic floor muscle exercises programme ${ }^{42}$ which was of sufficient methodological quality (7 points; Table 2). However, on the basis of only one relevant trial we conclude that there is limited evidence (level 3 ) for the efficacy of a high-intensity pelvic floor muscle exercise programme vs a low-intensity home-based programme.

Three RCTs were identified comparing pelvic floor muscle exercises with an intravaginal resistance device against pelvic floor muscle exercises alone, ${ }^{48,55,81}$ with MQS of 3.5-6.5 points (Table 2). One trial was of sufficient quality, ${ }^{48}$ while two trials were of low quality. ${ }^{55,61}$ Because data were reported poorly in the study by Taylor and Henderson, ${ }^{61}$ it is not possible to isolate the comparisons between the treatments. With only one RCT of sufficient methodological quality and one low-quality trial which reported relevant outcomes, ${ }^{55}$ evidence for the efficacy of pelvic floor muscle exercises with an intravaginal resistance device over pelvic floor muscle exercises alone is limited (level 3). 
Table 3. Brief details of the included randomized clinical trials (full details of treatments and outcome may be obtained from the authors on request).

\begin{tabular}{|c|c|c|c|c|}
\hline Reference & $\begin{array}{l}\text { Sample size } \\
\text { (age range or } \\
\text { mean age, } \\
\text { SD, years) }\end{array}$ & $\begin{array}{l}\text { Duration of complaint(s) (years) } \\
\text { TG1(/TG2...)/CG (\%)* }\end{array}$ & $\begin{array}{l}\text { Severity, grade } 1-4 \text { or } \\
\text { mild/moderate/severe (\%) }\end{array}$ & $\begin{array}{l}\text { Length of } \\
\text { treatment } \\
\text { (months) }\end{array}$ \\
\hline \multirow{3}{*}{$\begin{array}{l}\text { Treatment } \\
\text { Berghmans } \\
\text { Lagro }^{51} \\
\text { Bums }^{44}\end{array}$} & & & \multirow{3}{*}{$\begin{array}{l}\text { TG+CG } 1(55) ; 2(45) \\
\text { TG 12/52/36; CG 6/61/33 } \\
\text { TG1 33/47/20; TG2 23/42/35; } \\
\text { CG 37/37/26 }\end{array}$} & \\
\hline & $\begin{array}{r}40(18-70) \\
66(20-65) \\
135(>55)\end{array}$ & $\begin{array}{l}\mathrm{TG}+\mathrm{CG} 0.1-2(25) ;>(75) \\
<2(21) /(33) ; 2-5(24) /(33) ;>5(55) /(33) \\
\end{array}$ & & $\begin{array}{l}1 \\
3\end{array}$ \\
\hline & & & & 2 \\
\hline Sand ${ }^{50}$ & $52(53.2,11.4)$ & - & - & 3.8 \\
\hline Burgio"1 & $24(29-64)$ & 10.8 (SD 13)/9.6 (SD 5.8) & - & 2 \\
\hline$B \theta^{42}$ & $52(24-64)$ & $8.5 / 10.8$ & - & 6 \\
\hline $\begin{array}{l}\text { Blowman } \\
\text { Ferguson }\end{array}$ & $\begin{array}{l}14(33-68) \\
20(22-50)\end{array}$ & TG median 3; CG median 3.5 & $\bar{C}_{\text {Cystocele } 1(80), ~} 2(20) ;$ & 1.5 \\
\hline & & & rectocele $1(60), 2(40)$ & 1.5 \\
\hline Wells ${ }^{33}$ & $157(55-90)$ & $\mathrm{TG}+\mathrm{CG}>1(8) ; 1-5(38) ;>5(54)$ & $=$ & 6 \\
\hline $\mathrm{Olah}^{54}$ & $69(24-73)$ & $0.5-1(13) /(13) ; 1-5(46) / 50) ;>5(41) /(27)$ & TG1 54/21/25; TG2 40/37/23 & 1 \\
\hline Luberss & $54(53.9,10.3)$ & - & - & 3 \\
\hline Klarskov $^{52}$ & $50(31-66)$ & - & - & 1.3 \\
\hline $\begin{array}{l}\text { Hahn }^{47} \\
\text { Smith }\end{array}$ & $\begin{array}{l}20(34-64) \\
56 ;\end{array}$ & - & - & 6 \\
\hline & 18 SUI (26-72) & & $\mathrm{TG}+\mathrm{CG}$ grade 2 & 1.5 \\
\hline Laycock $^{50}$ & $46(28-59)$ & $7.9 / 6.8$ & 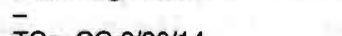 & 1.5 \\
\hline Hofbauer ${ }^{48}$ & $43(30-88)$ & - & TGs+CG 9/20/14 & 1.5 \\
\hline Shepherd ${ }^{56}$ & $107 i$ & & & \\
\hline & 42 SUI (26-72) & - & $\bar{z}$ & - \\
\hline Glavind ${ }^{20}$ & $34(40-48)$ & - & TG+CG 15/15/4 & 1 \\
\hline Laycock $k^{50}$ & $30(16-66)$ & $9.5 / 6.3$ & - & 2.5 \\
\hline Taylor $r^{81}$ & $12(55-79)$ & - & - & 2.3 \\
\hline Shepherd ${ }^{55}$ & $22(23-67)$ & $11 / 9$ & - & 1.5 \\
\hline $\begin{array}{l}\text { Castleden }{ }^{67} \\
\text { Prevention }\end{array}$ & $19(23-85)$ & 9 & - & 1.5 \\
\hline Jonasson $^{49}$ & $83(19-36)$ & - & - & 3 \\
\hline Sleep $p^{50}$ & 1800 & - & - & 1 \\
\hline
\end{tabular}

- TG, treatment group; CG, control group

Five RCTs were identified comparing pelvic floor muscle exercises with biofeedback (BF) against pelvic floor muscle exercises alone ${ }^{33,44,61,62}$ with MQS of 3-8.5 points (Table 2). Two trials ${ }^{33,44}$ were of sufficient quality and three were of low quality. ${ }^{57,61,62}$ Again, the analysis in the study by Taylor and Henderson ${ }^{61}$ cannot be assessed. All five studies appear to report improvement or significant effects after testing with biofeedback as an adjunct to pelvic floor muscle exercises, yet only the low-quality study of Glavind et al. ${ }^{62}$ showed significant results between groups. There is strong evidence that biofeedback as an adjunct to pelvic floor muscle exercises is no more effective than pelvic floor muscle exercises alone (level 1).

One trial, ${ }^{41}$ with a MQS of 7 points, compared pelvic floor muscle exercises with visual biofeedback against pelvic floor muscle exercises with verbal feedback given during vaginal palpation. There appears to be limited evidence for the effectiveness fo visual biofeedback vs verbal feedback (level 3).

Only one RCT of sufficient quality ${ }^{61}$ was identified, that compared pelvic floor muscle exercises and medication, with a MaS of 6 points. There is limited evidence of no difference in efficacy between medication and pelvic floor muscle exercises (level 3 ). One low quality $\mathrm{RCT}^{52}$ with a MQS of 5 points, compared surgery (Burch colposuspension) and pelvic floor muscle exercises. There was no evidence of any difference in the efficacy of surgery vs pelvic floor muscle exercises (level 4). 
Six trials were identified comparing electrical stimulation with sham electrical stimulation. ${ }^{43,48,50,56,58,65}$ The trials by Sand et al. ${ }^{58}$ and Blowman et al. ${ }^{43}$ were of sufficient methodological quality, with a MQS of 7.5 and 6.5 , respectively, and the remaining four trials were of low quality. Two of the trials ${ }^{43,56}$ included pelvic floor muscle exercises with both active and sham stimulation groups, so these trials were considered to be a comparison of active and sham stimulation. Of the six trials, all but Shepherd et al. ${ }^{56}$ and Luber et al. ${ }^{65}$ report electrical stimulation to be more effective than sham stimulation. Combined results imply strong evidence for the efficacy of electrical stimulation vs sham electrical stimulation (level 1). However, there was no consistency between the trials in the type of stimulation (e.g. extravaginal vs intravaginal, neurotrophic versus interferential) or the stimulation parameters used in these trials, and therefore these conclusions must be viewed with caution.

Five trials were identified that compared electrical stimulation with any other intervention; three compared electrical stimulation with pelvic floor muscle exercises, ${ }^{47,48,60}$ one with vaginal cones, ${ }^{54}$ and another with pelvic floor muscle exercises and vaginal cones. ${ }^{50}$ Of these five trials, only that by Olah et al. ${ }^{54}$ was of sufficient methodological quality ( 6 points) while the remaining four ${ }^{47,48,50,60}$ were of low quality. None of the trials showed electrical stimulation to be more effective than pelvic floor muscle exercises alone, vaginal cones, or pelvic floor muscle exercises with vaginal cones. There is limited evidence to suggest that there is no difference between stimulation and other physical therapies (level 3). However, there was no consistency between the trials (both in terms of their stimulation types and parameters, and with what the stimulation was compared).

There was one trial of low quality comparing electrical stimulation with pelvic floor muscle exercises vs any other intervention. ${ }^{48}$ There is no evidence that electrical stimulation with pelvic floor muscle exercises is any more effective than any other physical therapy intervention (level 4).

\section{Efficacy of prevention}

There was one pragmatic RCT comparing pelvic floor muscle exercises and vaginal cones vs pelvic floor muscle exercises alone, ${ }^{49}$ with a MQS of 6.5 points. Thus there is limited evidence that pelvic floor muscle exercises with vaginal cone treatment is superior to pelvic floor muscle exercises alone in improving pelvic floor muscle strength (level 3).

There was one low-quality pragmatic $\mathrm{RCT}^{59}$ comparing postpartum home programmes of high-intensity pelvic floor muscie exercises with 'standard' pelvic floor muscle exercises. There is no evidence of any difference in efficacy between highintensity and 'standard' pelvic floor muscle exercise postpartum home programmes for the prevention of incontinence (level 4). A summary of the levels of evidence for the efficacy of physical therapies for the treatment and prevention of stress urinary incontinence in women is presented in Table 4. 
Table 4. Levels of evidence of efficacy of different conservative treatment modalities and prevention.

Level Efficacy

Conservative treatment

1 - PFM exercises are effective

- Biofeedback adjunct to PFM exercises is no more effective than PFM exercises alone

- Electrical stimulation is more effective than sham electrical stimulation

3

- High-intensity PFM exercises are more effective than (low-intensity) home PFM exercises

- High-intensity PFM exercises are no more effective than medication (phenylpropanolamine)

- Visual biofeedback is more effective than verbal feedback

- PFM exercises with an intravaginal resistance device is no more effective than PFM exercises alone

- Electrical stimulation alone is no more effective than PFM exercises alone or PFM exercises and vaginal cones

4 - Surgery is more effective than PFM exercises

- Electrical stimulation with PFM exercises is no more effective than PFM exercises alone

Prevention

3

- PFM exercises with vaginal cones at home are more effective than PFM exercises at home

- High-intensity PFM exercises postpartum at home are more effective than normal PFM exercises postpartum at home

\section{Discussion}

To our knowledge, this is the first published systematic review of physical therapies for the treatment and prevention of stress urinary incontinence that has used a list of criteria to access the methodological quality of the studies included. When assessing methodological quality the primary goal is to assess the reported effects of interventions and the influence and direction of bias on the results of these treatments, as methodological quality plays an important role in weighing the conclusions of different trials. To explore the possibility that an increasing likelihood of bias was reflected in the results of the trials (through an increasing number of methodological shortcomings), a list of well-established methodological criteria was used in this systematic review. ${ }^{3-37}$

The methodological assessment criteria (Table 1) were chosen to measure the precision of studies (using sample size and variability), and internal validity (through measures such as randomization, blinding, loss to follow-up, the relevance of choices with respect to study population, interventions and outcome measures). The main methodological shortcomings in the studies are listed in Table 2. Although interventions are well described in most of the RCTs of sufficient quality, in many of the others there are flaws in the description of the content, the duration and the intensity of the interventions.

Does this indicate negligent reporting by the investigators, or does it imply a lack of consensus about the appropriate treatment of stress urinary incontinence, and suggest that some patients may be receiving inappropriate or suboptimal care? The use of weighing to discriminate between minor and major flaws in trial designs remains highly controversial. What errors in design and conduct are most crucial? There is still no consensus about a definitive methodological criteria list which, if 
satisfied by the study under review, can guarantee study validity and absence of bias. ${ }^{66}$ Decisions about thresholds between 'sufficient' and 'low' methodological quality are especially difficult and debatable. Usually, a trial is considered to be of sufficient quality if its design and conduct are likely to have prevented systematic errors or bias. ${ }^{67}$ If there is a relationship between methodological quality of studies, their variances and effect sizes, it make sense to allow the best quality studies to have the greatest influence on the findings of a review. Therefore, a rating system that considered four levels of scientific evidence was used, based on the methodological quality and outcomes of the selected RCTs. However, there was enormous variability in the quality of included studies, and the use of different measures of effect in most of the trials under review made comparisons between studies difficult; therefore, results should be interpreted with caution.

A systematic review is not a panacea for the problems associated with reviews of the literature. Because it is not experimental, it is prone to the flaws that apply to all such research. ${ }^{67}$ However, the explicit reporting of the search methods, criteria for inclusion and exclusion of studies, the quality assessment criteria, the tables of studies, and levels-of-evidence criteria, allow readers to judge for themselves the quality of the review and the reliability of its findings.

One criticism of the method used in the present review is that RCTs were not assessed while unaware of the authors, source and outcome of the studies, or the journals in which articles were published, because the reviewers were familiar with most of the studies before starting the review. Recent studies show conflicting results as to whether quality assessment under blinded conditions delivers more unbiased results than unblinded assessment. ${ }^{67,68}$

An important issue in reviews is publication bias; RCTs with positive results are more likely to be submitted and published than 'negative' trials, especially if the sample size is limited. ${ }^{69}$ This may lead to an overestimate of positive effects. It is difficult to estimate the magnitude of publication bias in any review and this review is no exception. Another potential source of bias in this review is selection bias, as only RCTs published in English, German or Dutch were included. It is possible that relevant $\mathrm{RCTs}$ published in other languages were omitted.

\section{PFM exercises for the treatment of SUI}

Generally, the conservative management of stress urinary incontinence focuses on pelvic floor muscle exercises with or without other adjuncts to treatment. Wilson et al. ${ }^{64}$ concluded that pelvic floor muscle exercises, properly taught, are still the mainstay of physical therapy. The results of this review suggest that pelvic floor muscle exercises alone may be an effective treatment for female stress urinary incontinence, and this finding is consistent with that of other reviews. ${ }^{19,25,26,29}$ Cure and satisfaction rates after pelvic floor muscle exercises (assessed by patients opinion and other reliable, sensitive and valid measures) may be as high as $60 \%-70 \%{ }^{64}$

Clearly, pelvic floor muscle exercises programmes should be designed to develop optimum muscle function ${ }^{32}$ but unfortunately there seems to be little agreement on the content of such programmes. ${ }^{30}$ Having found only one trial comparing two pelvic floor muscle exercise programmes, ${ }^{42}$ there is little evidence to suggest what type of pelvic floor muscle exercise programme might be most effective.

The extrapolation of exercise prescription guidelines suggest that pelvic floor muscle exercise programmes should include short and long duration exercises based on diagnostic findings as both type I and type II muscle fibres need to be exercised with 
overload strategies. Increased frequency or duration of activity, or the addition of resistance, produces overload. Daily or twice-daily regimens of increasing repetitions to the point of fatigue seem to be recommended (5-30 repetitions). ${ }^{32}$ It may also be important to select relevant starting positions and incorporate functional activities into the exercise programme. ${ }^{32}$ If pelvic floor muscle exercise programmes in general seem to be an effective treatment for stress urinary incontinence, then further investigation is required to determine the most effective regimen. Whilst the purpose of this review was to investigate the efficacy of physical therapies for female stress urinary incontinence, it is important to recognize that effective treatment with pelvic floor muscle exercises may also be influenced by a range of factors that are not discussed her, e.g. the identification of relevant characteristics in patients who respond to treatment, ${ }^{27,70-72}$ the assessment of correct pelvic floor muscle contraction, ${ }^{24}$ thorough instruction and measurement to improve motivation and adherence to training, ${ }^{25,26,31}$ and willingness to continue with home exercises. ${ }^{19}$

\section{PFM exercises with intravaginal resistance devices}

Despite the possibility that the addition of resistance to pelvic floor muscle exercises might improve muscle strength, the findings of the present review suggest that there is little evidence to support the use of intravaginal resistance devices in pelvic floor muscle exercise programmes.

\section{PFM exercises with biofeedback}

The effect of adding biofeedback to pelvic floor muscle exercises is controversial; ${ }^{26}$ the present finding was that pelvic floor muscle exercises with biofeedback were no more effective than pelvic floor muscle exercises alone. This result contrasts with that in the review of De Kruif and Van Wegen ${ }^{28}$ who found, in a review of RCTs, a trend for increased pelvic floor muscle exercises with biofeedback over pelvic floor muscle exercises alone. There seems to be limited evidence to suggest one type of biofeedback may be superior to another, as only one trial comparing two different types of biofeedback was found ${ }^{41}$ in the present review, but this may be worth further investigation.

Although comparisons between pelvic floor muscle exercises with biofeedback and pelvic floor muscle exercises alone often showed no significance, this may have been because samples were not specific to those who might benefit most by receiving biofeedback. It is possible that biofeedback as an adjunct to pelvic floor muscle exercises is more effective than pelvic floor muscle exercises alone in patients with insufficient or no awareness how to contract the pelvic floor muscle correctly. ${ }^{25,33}$ If patients with these problems could be selected by appropriate diagnostics, it could be possible to identify if and to what extent biofeedback is beneficial as an adjunct to pelvic floor muscle exercises in treating stress urinary incontinence. Another problem with existing trials may be that effect sizes appear to be small and therefore many subjects per treatment group would be necessary to have adequate power to detect significance at the $5 \%$ level. ${ }^{33,44}$ Further work is also needed to investigate the positive trend in speed of improvement with the addition of biofeedback to a pelvic floor muscle exercise programme. ${ }^{33}$

\section{Electrlcal stimulation for the treatment of SUI}

The most noticeable factor about the trials of electrical stimulation included in this review was the considerable variation in the types of stimulation used. Trials investigated intravaginal and extravaginal stimulation, interferential and neurotrophic 
stimulation, maximal and long term stimulation; no trial replicated the intervention of another. Electrical stimulation uses excitation of the pudendal nerves to create a pelvic floor muscle contraction, ${ }^{73}$ so any method of stimulation that produces a pelvic floor muscle contraction may be effective in rehabilitation.

Because there was no consistency between stimulation types and parameters, the results should be interpreted with caution. Trends in the evidence suggest that active stimulation is more effective than sham stimulation, but electrical stimulation may be no more effective than pelvic floor muscle exercises alone or other physical therapies. Wilson ${ }^{31}$ concluded that the addition of electrotherapy offers no significant advantages. It seems that further investigation of electrical stimulation is required to establish its efficacy for stress urinary incontinence, a view also supported by others. ${ }^{26,29,32}$ Electrical stimulation is not widely used as a first-line management and is used predominantly in patients when other methods have failed. It may be that electrical stimulation is particularly appropriate for patients who are initially unable to contract their pelvic floor muscle, but once active contraction is possible, pelvic floor muscle exercises may be more effective. ${ }^{26}$

\section{Vaginal cones for the treatment of SUI}

There was only one trial of vaginal cones combined with pelvic floor muscle exercises compared with electrical stimulation and pelvic floor muscle exercises. ${ }^{53}$ Results from vaginal cones alone in the treatment of stress urinary incontinence have not yet been reported. $\mathrm{B} \varnothing^{70}$ questioned the theoretical basis for cone therapy. Further work is needed to evaluate the role of vaginal cones in treating stress urinary incontinence. ${ }^{26,31}$

\section{Conservative management for the prevention of SUI}

Only two trials ${ }^{49.59}$ investigating the effects of conservative management strategies for the prevention of stress urinary incontinence were found in this review, so there is little evidence available of the efficacy of physical therapies for preventing stress urinary incontinence. To date, studies in prevention have been minimal and of marginal quality. Trials to detect the effects of prevention strategies are difficult to undertake because many subjects are needed, considerable organization is required and the costs are high. In view of the scarcity of this sort of trial, it would be inappropriate to make recommendations about the efficacy of therapies for preventing stress urinary incontinence and more research should be initiated in evaluating pelvic floor muscle exercises and other conservative therapies for preventing stress urinary incontinence. Wall and Davidson ${ }^{25}$ suggested that pelvic floor muscle exercises during pregnancy might reduce delivery trauma and accelerate postpartum recovery, with potential benefits for long-term pelvic floor function in women.

In summary, appropriate treatment should be based on the present body of knowledge, which can be obtained from scientific research leading to clinical practice guidelines for health care professionals. ${ }^{39,40.74}$ As conservative therapy seems to have no side-effects it should be considered the first choice of treatment for stress urinary incontinence. This opinion has been expressed by others ${ }^{19,31}$ because there is a significant improvement in symptoms after conservative treatment. If the outcome of conservative management is unsatisfactory, the patient can be referred for further evaluation and possible surgical intervention. It seems that the primary focus of treatment should be pelvic floor muscle exercises, although in some circumstances other adjuncts may be deemed appropriate. 
In conclusion, the methodological quality of the studies included in the present review was moderate. It seems that pelvic floor muscle exercises alone are an effective treatment for stress urinary incontinence, but there is uncertainty about the most effective pelvic floor muscle exercise programme. Biofeedback as an adjunct to pelvic floor muscle exercises does not seem to be more effective than pelvic floor muscle exercises alone, although this strategy might be more effective than pelvic floor muscle exercises alone in the first period of treatment. More research is needed to evaluate this positive trend in larger studies. Further RCTs are necessary to evaluate the effect of electrical stimulation and the use of vaginal cones in the treatment of stress urinary incontinence, and the effects fo conservative therapies in the prevention of stress urinary incontinence. All future research investigating conservative treatment and prevention of stress urinary incontinence should be of optimal methodological quality. To optimize this factor, future researchers are recommended to use a well-established methodological criteria list when designing and constructing trials.

\section{References}

1. Abrams P, Blaivas JG, Stanton SL, Andersen JT, The standardization of terminology of lower urinary tract function. Scand J Urol Nephrol 1988; 114: 5.

2. Fantl JA, Wyman JF, McClish DK, Harkins SW, Eiswick RK, Taylor JR, Hadley EC. Efficacy of bladder training in older women with urinary incontinence. JAMA 1991; 265: 609.

3. Cutner A, Cardozo L. Urinary incontinence: clinical features. Practitioner 1990; 234: 1018.

4. Urinary Incontinence Guidelines Panel: Urinary incontinence in adults: Clinical Practice Guideline. AHCPR Pub. No. 92-0038. Agency for Health Care Policy and Research, Public Health Service, US Department of Health and Human Services, Rockville, MD, 1992.

5. Hu TW. The economic impact of urinary incontinence Clin Geriatr Med 1986; 2: 673.

6. National Institute of Health. Urinary incontinence in adults. Washington DC: Medical applications of research. National Institute of Health 1988; $7: 1$.

7. Consensus Development Panel (Rowe JW, Besdine RW, Ford AB, et al.). Urinary incontinence in adults: National Institutes of Health Consensus Development Conference. JAMA 1989; 261: 2685.

8. Jolleys JV. Reported prevalence of urinary incontinence in women in a general practice. BMJ 1988; 296: 1300.

9. Holst K, Wilson PD. The prevalence of female urinary incontinence and reasons for not seeking treatment. N Z Med J 1988; 101: 756.

10. Mohide EA. The prevalence and scope of urinary incontinence. Clin Geriatr Med 1986; 2: 639.

11. Thomas TM, Plymat KR, Blannin J, Meade TW. Prevalence of urinary incontinence. BMJ 1980; 281: 1243.

12. losif MD, Batra $S$, Ef $A, A s t e d t ~ B$. Oestrogen receptors in the human female lower urinary tract. Am J Obstet Gynecol 1981; 141: 817.

13. Bø K. Stress urinary incontinence, physical activity and pelvic floor muscle strength training. Scand J Med Sci Sports 1992; 2; 197.

14. Enhorning G. Simultaneous recording of intravesical and intra-urethral pressure: A study on urethral closure in normal and stress incontinent women. Acta Chir Scand 1961; 276: 1.

15. Bo K. Pelvic floor muscle exercise for the treatment of stress urinary incontinence: an exercise physiology perspective. Int Urogynecol J 1995; 6: 282.

16. Waalwijk van Doom ESC van. Ambulatory Urodynamics. Thesis Maastricht University, the Netherlands 1993.

17. Leach GE, Trockman BA, Sakamoto M, Santiago L, Zimmern PE. Modified Peyrera bladder neck suspension: Minimum 5-year follow-up in 101 patients. J Urol 1995; 153: 813.

18. Knispel HH, Klän $R$, Siegmann K, Miller K. Results with the Stamey procedure in 251 consecutive patients with genuine stress urinary incontinence. J Urol 1995; 153: 812.

19. Rush CB, Entman SS. Pelvic organ prolapse and stress urinary incontinence. Med Clin North Am 1995; 79: 1473.

20. Pow-Sang JM, Lockart JL, Suarez A, Lansman H, Politano VA. Female urinary incontinence: preoperative selection, surgical complications and results. J Urol 1986; 136: 831. 
21. Schussler B. Introduction. In: Schussler B, Laycock L, Norton $P$, Stanton $S$ (eds). Pelvic Floor Re-Education. Schussler B, Laycock J, Norton P, Stanton S (Eds). London. Springer-Verlag 1994; $1: 3$.

22. Black NA, Downs SH. The effectiveness of surgery for stress incontinence in women: a systematic review. Br J Urol 1996; 78: 497-510.

23. McGuire EJ. Stress incontinence: New alternatives. Int J Fert 1996; 41: 142.

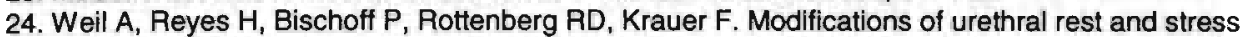
profiles after different types of surgery for urinary stress incontinence. $\mathrm{Br} J$ Obstet Gynaecol 1984; $91: 46$.

25. Wall L, Davidson TG. The role of muscular re-education by physical therapy in the treatment of genuine stress urinary incontinence. Obstet Gynecol Surv 1992; 47: 322-331.

26. Bø K. Physiotherapy to treat genuine stress incontinence. Int Cont Surv 1996; 6: 2.

27. Bourcier AP, Juras JC. Nonsurgical therapy for stress incontinence. Urol Clin North Am 1995; 22 : 613.

28. Kruif YP de, Wegen EEH van. Pelvic floor muscle exercise therapy with myofeedback for women with stress urinary incontinence: a meta-analysis. Physiotherapy 1996; 82: 107.

29. Fedorkow DM. Nonsurgical management of stress urinary incontinence. J SOGC 1993; 15: 695.

30. Wells TJ. Pelvic (floor) muscle exercise. JAGS 1990; 38: 333.

31. Wilson PD. Conservative management of urethral sphincter incompetence. Clin Obstet Gynecol 1990; 33: 330.

32. Wallace K. Female pelvic floor functions, dysfunctions, and behavioral approaches to treatment. Clin Sports Med 1994; 13: 459.

33. Berghmans LCM, Frederiks CMA, Bie RA de, Weil EHJ, Smeets LWH, Waalwijk van Doorn ESC van, Janknegt RA. Efficacy of biofeedback, when included with pelvic floor muscle exercise treatment, for genuine stress incontinence. Neurourol and Urodyn 1996; 15: 37.

34. Kleijnen J, Knipschild P. Niacin and vitamin B6 in mental functioning: a review of controlled trials in humans. Biol Psychlatry 1991; 29: 931.

35. Kleijnen J, Craen AJM de, Everdingen J van, Krol L. Placebo effect in double-blind clinical trials with medications. Lancet 1994; 344: 1347.

36. Pocock SJ. Clinical trials: a practical approach. Chisester: Wiley, 1983.

37. Meinert CL. Clinical trials: design, conduct and analysis. New York: Oxford University Press, 1986.

38. Chalmers TC, Smith H, Blackburn B, Silverman B, Schroeder B, Reitman D, Ambroz A. A method for assessing the quality of a randomized control trial. Control Clin Trials 1980;2: 31.

39. Bigos S, Bowyer O, Braen G, et al. Acute low back problems in adults. Clinical practice guideline no. 14. AHCPR Publication no. 95-0642. Rockville, MD: Agency for Health Care Policy and Research, Public Health Services, U.S. Department of health and Human Services. December, 1995.

40. Tulder MW van. Diagnostics and treatment of chronic low back pain in primary care (Thesis VU Amsterdam). Amsterdam, Thesis Publishers, 1996.

41. Burgio KL, Courtland JC, Engel BT. The role of biofeedback in Kegel exercise training for stress urinary incontinence. Am J Obstet Gynecol 1986; 154: 58.

42. Bø K, Hagen RH, Kvarstein B, Jorgensen J, Larsen S. Pelvic floor muscle exercise for the treatment of female stress urinary incontinence: III. Effects of two different degrees of pelvic floor muscle exercises. Neurourol Urodyn 1990; 9: 489.

43. Blowman C, Pickles C, Emery S, Creates V, Towell L, Blackbum N, Doyle N, Walkoen B. Prospective double blind controlled trial of intensive physiotherapy with and without stimulation of the pelvic floor in treatment of genuine stress incontinence. Physiotherapy 1991; 10: 661.

44. Burns PA, Pranikoff K, Nochajski TH, Hadley EC, Levy KJ, Ory MG. A comparison of effectiveness of biofeedback and pelvic muscle exercise treatment of stress incontinence in older community-dwelling women. J Gerontol 1993; 48: M167.

45. Bums PA, Pranikoff K, Nochajski TH, Desotelle P, Harwood MK. Treatment of stress incontinence with pelvic floor exercises and biofeedback. JAGS 1990; 38: 341.

46. Ferguson KL, McKey PL, Bishop KR, Kloen P, Verheul JB, Dougherty MC. Stress urinary incontinence: effect of pelvic muscle exercise. Obstet Gynecol 1990; 75: 671.

47. Hahn I, Sommar S, Fall M. A comparative study of pelvic floor training and electrical stimulation for the treatment of genuine female stress urinary incontinence. Neurourol Urodyn 1991; 10: 545.

48. Hofbauer J von, Preisinger F, Nurnberger N. Der stellenwert der physikotherapie bei der weiblichen genuinen stressinkontinenz. Z Urol Nephrol 1990; 83: 249. 
49. Jonasson A, Larsson B, Pschera H. Testing and training of the pelvic floor muscles after childbirth. Acta Obstet Gynecol Scand 1989; 68: 301.

50. Laycock J, Jerwood D. Does pre-modulated interferential therapy cure genuine stress incontinence? Physiotherapy 1993; $79: 553$.

51. Lagro-Janssen TLM, Debruyne FMJ, Smits AJA, Weel C van. Controlled trial of pelvic floor exercises in the treatment of urinary stress incontinence in general practice. Br J Gen Pract 1991; 41: 445.

52. Klarskov P. Belving D, Bischoff N, Dorph S, Gerstenberg T, Akholm B, Pedersen PH, Tikjob G, Wormslev $\mathrm{M}$, Hald T. Pelvic floor exercise versus surgery for female urinary stress incontinence. Urol Int 1986; 41: 129.

53. O'Donnell PD, Doyle R. Biofeedback therapy technique for treatment of urinary incontinence. Urology 1991; 5: 432.

54. Olah KS, Bridges N, Denning J, Farrar DJ. The conservative management of patients with symptoms of stress incontinence: a randomized prospective study comparing weighted vaginal cones and interferential therapy. Am J Obstet Gynecol 1990; 1:87.

55. Shepherd AM, Montgomery E. Treatment of genuine stress incontinence with a new perineometer. Physiotherapy 1983; 69: 113.

56. Shepherd AM, Tribe E, Bainton D. Maximum perineal stimulation. A controlled study. Br J Urol 1984; 56: 644 .

57. Castleden CM, Duffin HM, Mitchell EP. The effect of physiotherapy on stress incontinence. Age and Ageing 1984; 13: 235.

58. Sand PK, Richardson DA, Staskin DR, Swift SE, Appell RA, Whitmore KE, Ostergard DR. Pelvic floor electrical stimulation in the treatment of genuine stress incontinence: a multicenter placebo controlled trial. Am J Obstet Gynecol 1995; 173: 72.

59. Sleep J, Grant A. Pelvic floor exercises in postnatal care. Midwifery 1987; 3: 158.

60. Smith JJ. Intravaginal stimulation randomized trial. J Urol 1996; 155: 127.

61. Taylor $\mathrm{K}$, Henderson J. Effects of biofeedback and urinary stress incontinence in older women. J Gerontol Nurs 1986; 12: 25.

62. Glavind K, Nohr B, Walter S. Biofeedback and physiotherapy versus physiotherapy alone in the treatment of genuine stress urinary incontinence. Int Urogynecol J 1996; 7: 339-343.

63. Wells TJ, Brink CA, Diokno AC, Wolfe R, Gillis G L. Pelvic muscle exercise for stress urinary incontinence in elderly women. JAGS 1991; 39: 785.

64. Wilson PD, Samarrai TA, Deakin M, Kolbe E, Brown ADG. An objective assessment of physiotherapy for female genuine stress incontinence. Br J Obstet Gynecol 1987; 94: 575.

65. Luber KM, Tsadik GW. Efficacy of functional electrical stimulation in treating genuine stress incontinence: a randomized clinical trial. Neurourol Urodyn 1997; 16: 543-551.

66. Bie RA de. Methodology of systematic reviews: an introduction. Phys Ther Rev 1996; 1: 47.

67. Jadad AR, Moore RA, Carroll D, Jenkinson C, Reynolds DJM, Gavaghan DJ, McQuay HJ. Assessing the quality of reports of randomized clinical trials; is blinding necessary? Control Clin Trials 1996; 17: 1.

68. Verhagen AP, Vet HCW de, Bie RA de, Kessels AGH, Boers M, Knipschild P G. Balneotherapy and quality assessment: The interobserver reliability of the Maastricht criteria list and blinding the articles for systematic reviews. 1998; In press.

69. Dickersin K, Chan S, Chalmers TC, Sacks HS, Smith H. Publication bias and clinical trials. Control Clin Trials 1987; 8: 343.

70. Eriksen $8 C$. Electrostimulation of the pelvic floor in female urinary incontinence. Thesis University of Trondheim, Norway 1989.

71. Bø K. Vaginal welght cones. Theoretical framework, effect on pelvic floor muscle strength and female stress urinary incontinence. Acta Obstet Gynecol Scand 1995; 74: 87.

72. Mantle J, Versi E. Physiotherapy for stress urinary incontinence: a national survey. BMJ 1991; 302: 753.

73. Bourcier AP. Physical therapy for female pelvic floor disorders. Curr Opin Obstet Gynecol 1994; 6: 331.

74. Hendriks $\mathrm{H}$, Ettekoven van $\mathrm{H}$, Reitsma $\mathrm{H}$. Improving the quality of physical therapy by central guidelines (PL-SI-1156-T). In: Proceedings of the 12th International Congress of the World Confederation for Physical Therapy. Washington DC, June 25-30, 1995. 
Chapter 3

\section{Efficacy of biofeedback, when included with pelvic floor muscle exercise treatment, for genuine stress incontinence*}

LCM Berghmans, MSc, RPt (1), CMA Frederiks, PhD (2), RA de Bie, PhD, MSc, RPt (2), EHJ Weil, PhD, MD (1), LWH Smeets, RPt (1), ESC van Waalwijk van Doorn, $\mathrm{PhD}, \mathrm{DSc}(1), \mathrm{RA}$ Janknegt, $\mathrm{PhD}, \mathrm{MD}$ (1)

1 Department of Urology, University Hospital Maastricht, Maastricht, the Netherlands

2 Department of Epidemiology, Maastricht University, the Netherlands 


\section{Abstract}

We performed a randomized clinical trial on the efficacy of physical therapy on genuine stress incontinence. Study objective: 'Is a physical therapeutical training programme (pelvic floor muscle training) combined with biofeedback, more effective than the same programme without biofeedback in women with mild or moderate stress incontinence?'

Forty-four patients were referred by a general practitioner or a urologist. After informed consent, 40 patients were randomized in an exercises and biofeedback group (BF), or treated with exercises exclusively (pelvic floor muscle training=PFMT). After a diagnostic phase of 1 week every patient received twelve treatment sessions, three times weekly.

The primary measure of effect, the quantity of involuntary urine loss, was measured with the 48 hours PAD test (Inco-test Mölnlycke). Before every treatment session the Symptoms questionnaire was filled out by the patient and the Patient diary was controlled.

The data of the trial were analysed according to the principal of intention to treat. During the trial there was $100 \%$ compliance. There were no drop-outs. Both treatment modalities appeared to be effective. After twelve treatment sessions there was a mean improvement of $\pm 55 \%(p=0.00)$ in both treatment groups, measured by the primary measure of effect. In the group with biofeedback this improvement was already realized after six treatment sessions $(p=0.01)$. Yet, the difference between biofeedback and pelvic floor muscle training faded to reach significance at six treatment sessions $(p=0.08)$.

Although differences in treatment effects between both groups were not significant, our findings suggest that adding biofeedback to pelvic floor muscle exercises might be more effective than pelvic floor muscle exercises alone after six treatments.

Key words biofeedback, stress incontinence, physical therapy, physiotherapy, pelvic muscle, exercise 


\section{Introduction}

The International Continence Society (ICS) defines urinary incontinence as involuntary urine loss that is a social or hygienic problem and which is objectively demonstrable. ${ }^{1}$ The most prevalent form of urinary incontinence among women is stress urinary incontinence. ${ }^{2-3}$

Pelvic floor muscle training and pelvic floor muscle training with biofeedback seem to be promising interventions. ${ }^{48}$ The pelvic floor muscle training programme in this study is a special physical therapeutical programme, consisting of information, pelvic floor re-education, homework exercises, and toilet regime. ${ }^{9}$ Pelvic floor re-education may act in three ways: to increase the reflex action of the pelvic floor muscles through fast-twitch recruitment, to increase the awareness of these muscles, or to increase muscular strength and endurance. ${ }^{10}$

Biofeedback is the technique whereby information regarding 'hidden' physiological processes is displayed in a form understandable to the patient, to permit selfregulation of these events. ${ }^{11}$ An incontinence patient can be taught, with the aid of biofeedback, to be selective in the use of the pelvic floor muscles.

Biofeedback is based on the principle of operant conditioning. Bø et al. ${ }^{12}$ and Bump et al. ${ }^{13}$ have found that approximately $30 \%$ of women are unable to perform an isolated pelvic floor contraction following written or verbal instruction. Once pelvic floor muscle contractions can be isolated, the patient gains improved awareness of this muscle action. ${ }^{14}$ It is hypothesised that in pelvic floor re-education, biofeedback will enhance the effect of the exercise programme and improve motor unit recruitment ${ }^{15}$ and functional activity. ${ }^{14}$ At the beginning of the therapy the support of biofeedback is of vital importance. ${ }^{16}$

Excerpts show that much research has been done on the efficacy of physical therapy with and without biofeedback. ${ }^{17-18}$ But only few randomized clinical trials have been conducted to prove the efficacy of exercise combined with biofeedback as opposed to exercise alone.$^{14} \mathrm{~B} \varnothing^{19}$ reviewed 5 studies ${ }^{16,20-23}$ which compared the effect of additional biofeedback with pelvic floor muscle exercises to regular exercise. According to $\mathrm{B} \emptyset$, the sample sizes in these studies are small and the reliability and validity of the methods applied to measure outcome can be questioned. Burns ${ }^{24}$ reviewed studies, using various combinations of biofeedback and pelvic muscle exercise, with symptom reduction rates of 78 to $90 \%$, but these studies lacked the rigor of a 'phase three' or randomized clinical trial. In 1992 the US government created a special panel of experts on incontinence who recommended guidelines for clinical practice in urinary incontinence. These experts recognized that the literature on management of pelvic floor disorders includes many small studies lacking objective outcome criteria and correct methodology. ${ }^{18}$ In many reports on clinical efficacy, the studies are uncontrolled and involve small numbers of patients. There are problems defining the most important parameter to be measured. Is it to be maximum strength, duration of contraction or speed of recruitment?

Standardization of these measurements is another problem. Many studies report only on subjective outcome. What is the best method of teaching pelvic floor reeducation? Which patients are most likely to benefit from pelvic floor re-education? ${ }^{18}$ This article describes the results of a randomized clinical trial, in which the research question is whether pelvic floor muscle training and biofeedback is more effective than pelvic floor muscle training alone in patients with mild or moderate genuine stress incontinence. 


\section{Material and methods}

\section{Introduction}

With the aid of a single blind, randomized clinical trial tests were performed to check the efficacy of biofeedback as an addition to a pelvic floor muscle training programme for women with mild or moderate* stress incontinence. The study took place in an extramural practice for physiotherapy in coordination with the Department of Urology of the University Hospital Maastricht (UHM), the Netherlands, and the Department of Epidemiology of Maastricht University, the Netherlands.

\section{Patient recruitment}

Forty-four patients were referred by an urologist or a general practitioner. The diagnosis genuine stress incontinence by the urologist was based on history taking, cystometry, uroflowmetry, urethral profilometry with determination of urethral closure pressure during rest and stress (cough), pad test with standardized bladder volume, and ambulatory urodynamics. The diagnosis genuine stress incontinence by the general practitioner was based on history taking and physical examination, according to the guidelines applied by Lagro-Janssen..$^{25}$ All patients received from their doctor a patient information form. Approval to participate in the programme was obtained through inclusion and exclusion criteria and history taking. During history taking these criteria were checked by the observer, to insure the homogenity of the research population in relation to the prognosis and the presumed sensitivity for the intervention. ${ }^{26}$ In Table 1 the inclusion and exclusion criteria are presented. Only patients with mild or moderate levels of stress incontinence were allowed to participate in the experiment because more severe cases of stress incontinence are treated primarily surgically. ${ }^{27}$ When proven suitable the patient was extensively briefed about the intent and manoeuvre of the trial. After the informed consent form was obtained, the patient entered the trial.

Table 1. Inclusion and exclusion criteria

\footnotetext{
Inclusion Criteria

Sex: Female

Age: $18-70$ years

Mild or moderate form of stress incontinence: grade 1 and 2

Able to fill out forms

Willingness to participate

Exclusion Criterla

Positive sediment of urine culture

Non-compliance in the diagnostic phase lesion, etc.

Surgery of urological and/or gynecological nature

Period of six weeks after a delivery

Other forms of treatment to cure stress incontinence

Stress incontinence grade 3 or 4

Psychological disorders

Irritable vagina

Pacemaker, hip prothesis

Not able to speak Dutch
}

Use of medicine to counteract functional disabilities of the lower urinary tract

Pronounced lesions of the pudendus nerve during clinical neurophysiological examination

Neurogenic bladder function disability caused by pathology such as spina bifida, spinal cord

\footnotetext{
mild=grade 1: $<20$ gr/48 hours; moderate=grade 2: $20-100$ gr/48 hours. Source: Mulder $^{34}$
} 


\section{Diagnostic phase}

A diagnostic phase of 1 week preceeded treatment. During the diagnostic phase the patient was required to fill out a symptoms questionnaire three times with an interval of 2 days. The patient also kept a patient's diary. The results of the PAD test (Incotest) classified the patient on the seriousness of the incontinence. These effect measurements formed the baseline values.

\section{Stratification and randomization}

Stratification was done by seriousness of incontinence (grade 1 and 2) and by referral (general practitioner or urologist) because of differences in diagnostic possibilities and therefore prognostic incomparability. Next, randomization was done in blocks of four within the strata, using sealed envelopes, containing a note with pelvic floor muscle training or biofeedback. The observer was blinded for allocation of treatment. Physiotherapist and patient were not blinded for the treatment. Forty patients were randomized in a pelvic floor muscle training or a biofeedback group (Table 2 ), after giving informed consent.

Table 2. Stratification sketch

$\mathrm{N}=40$

$\operatorname{PFMT}(\mathrm{N}=20)$

$\mathrm{BF}(\mathrm{N}=20)$

Stratum 1 (general practitioner, grade 1)

Stratum 2 (general practitioner, grade 2)

Stratum 3 (urologist, grade 1)

Stratum 4 (urologist, grade 2)

$\begin{array}{rr}10 & 9 \\ 5 & 6 \\ 1 & 2 \\ 4 & 3\end{array}$

\section{Interventions}

After the diagnostic phase, each patient received twelve treatments, three times a week. Approximately 25-35 minutes per visit were spent. A choice was made for a frequent and intensive programme. Bø et al. ${ }^{28-29}$ showed that intensive and enthusiastic management strongly influences the progress in the positive direction of patients who participate in pelvic exercises. The physiotherapist gave the treatments in such a way that no difference was noticable in the approach of the two interventions. Each patient received an explanation about the pelvic anatomy, the function of the pelvic floor and the bladder and the use of pelvic exercises. Every week during the treatment period, vaginal palpation was performed with the patients in the supine position with the legs straight and slightly abducted. The physiotherapist used the 'PERFECT' Assessment Scheme ${ }^{30}$ for evaluation of the pelvic floor: power $(P)$, endurance $(E)$, number of repetitions $(R)$, and number of fast (F) contractions; furthermore, every (E) contraction (C) is timed (T). This mnemonic provided a simple reminder of pelvic floor muscle assessment and also provided data regarding the fast- and slow-twitch muscle fibres, which provided information for the planning of the exercise programme. ${ }^{31}$ All patients received an identical homework exercise programme and were instructed to practice 3 times every day.

\section{Description of PFMT}

The exercise programme started with exercises in the supine position, followed by exercises in the side position, standing position and crawling position. In these positions the duration of contractions of the pelvic floor muscles varied from 3 to 30 
seconds. The frequency of contractions varied from 10 to 30 times. All patients began with 4 sets of 10 (5 quick and 5 sustained) and increased by 10 per set until 30 times per set were realized. A more functional training (pelvic floor exercise combined with coughing, climbing stairs, lifting, and jumping) completed the exercise programme.

\section{Description of BF}

Biofeedback treatment was accomplished through the use of a vaginal probe (Verimed Inc., Coral Springs, FL, USA) attached to a portable electromyograph (Myaction 12 of Uniphy BV, Son, the Netherlands). The EMG activity was sampled 10 times per second. The rectified averaged EMG was displayed as a line graph both on the EMG unit as on a computer screen, for which software was specifically designed (Uniphy BV). A contract/relax session type was used for which the contract/relax period (seconds), and number of exercise cycles and treatment time (minutes: seconds) varied for the treatments 1-12. The sensitivity $(\mu \mathrm{V})$ and threshold $(\mu \mathrm{V})$ were set dependent on the muscle activity of the patient. All patients received visual and acoustical signals and were stimulated to exceed the threshold during contraction. The Myaction 12 scores very well on reproducibility and validity. ${ }^{32}$

\section{Parameters used}

The PAD test objectively measures the quantity of involuntary urine loss. Evaluation has been performed on reliability and applicability. ${ }^{33-34}$ This test is also advantageous because urine incontinence is measured by the patient during normal daily activities. ${ }^{35-36}$ Patients were instructed to wear a standard-weighed pad ( $25 \mathrm{gr}$ ) day and night during a 48-hour period and to change pads when required. The pads were weighed by the patients on a standardized balance after use; the weights were noted in a log-book. The patients were instructed to store the pads in airtight plastic bags and hand them in for weight control. The pads are weighed again by the observer within 24 hours. In the present study a good correlation existed between the weights measured by the patients as well as the observer (Pearson's $r=0.97$ ). The Inco-test is measured before the start of therapy, after six treatments and at the end of therapy. Before each treatment the Symptoms questionnaire is filled out by the patient and the Patient s diary is controlled by the therapist.

The Symptoms questionnaire, a modification of the standardized PRAFAB-score, ${ }^{34}$ is a questionnaire that bundles a number of important objective and subjective elements of the experienced seriousness of involuntary urine loss. The list consists of five elements:

1 at what level of bladder pressure starts involuntary loss of urine starts

2 degree of wet caused by involuntary loss of urine

3 frequency of involuntary loss of urine

4 level of limitation of social activities because of incontinence

5 emotional state related to involuntary loss of urine

The score is expressed at a 10-point interval scale, adding up to a minimum of 5 and a maximum of 50 points. The higher the score, the more serious is the problem.

The Patient's diary logs quantity, frequency and time of drinking, number of times and exact time of involuntary urine loss, activity level by involuntary urine loss, frequency of urinating and pad changes. 
The three parameters together reflect a total change of improvement. Therefore a combined measure of effect is created. Every parameter has been assigned an equal weight. The results were expressed in percentages of improvement after six and after twelve treatments.

\section{Data analysis}

Analysis of the research data took place according to the intention to treat principle. The primary measure of effect, the PAD test, and the secondary measures of effect, the Symptoms questionnaire, the Patient's dairy and the combined measure of effect, were measured on percentage changes in parametric Student t-tests and paired t-tests. The combined measure of effect is analysed by way of linear regression.

\section{Results}

Compliance was $100 \%$. There were no drop-outs. The comparison between the research groups was based on the information gathered during the diagnostic phase. Comparing both groups on anamnestical data and baseline characteristics, no significant differences $(p<0.05)$ were found, except for mean quantity of liquid intake $(p=0.02)$ (Table 3a) and mean drink of the Patient's diary $(p=0.01)$ (Table 3b).

Figure 1 shows the mean amount of urine loss per stratum. The mean (sd) urine loss in stratum 2 and stratum 4 was respectively $32.5 \mathrm{gr} \mathrm{(22.8)}$ and $70.9 \mathrm{gr}(31.2)$ per 48 hours. The difference amounted to 38.4 gr per 48 hours. Grade 2 patients, who were referred by the urologist appeared to be in a more serious category than the grade 2 patients referred by the general practitioner.

A treatment effect between patients with grade 1 and grade 2 was measured with the PAD test. For grade 1 patients the mean of involuntary urine loss was at the start of the therapy $10.7 \mathrm{gr} / 48$ hours, after six treatments 10.2 , and after twelve treatments 8.7. For grade 2 patients these numbers were, respectively, $51.7,22.0$ and 20.1 gr/48 hours.

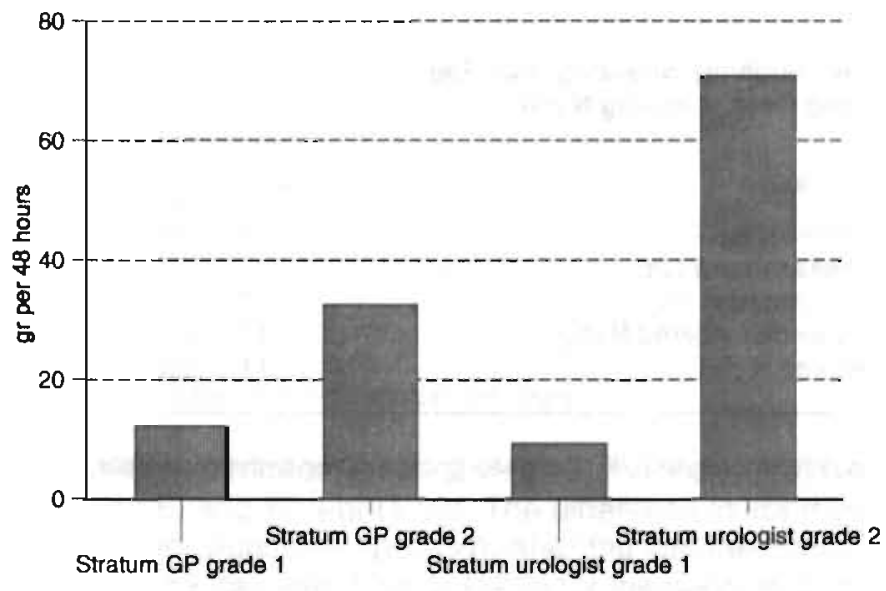

Figure 1. Mean amount of involuntary urine loss per stratum. 
Table 3a. Group Companison Through Anamnestical Data*

Pelvic floor muscle

training Biofeedback

$(\mathrm{N}=20)(100 \%) \quad(\mathrm{N}=20)(100 \%)$

Mean age (sd)

Grades:

Grade $1 \mathrm{~N}(\%)$

Grade $2 N(\%)$

Referred by

General Pract. N (\%)

Urologist N (\%)

Prevlous Treatment for Stress Incontinence

Medication and Physical Therapy N (\%)

Physical Therapy N (\%)

Duration Since Onset of Urine Loss

$1-12$ Months $N(\%)$

12-24 Months $N(\%)$

$>24$ Months $\mathrm{N}(\%)$

Urine Loss Started After

Delivery N (\%)

Menopauze N (\%)

Mean Number of Pads or other Recepticles per day (sd)

Mean Number of Wet Days per Week (sd)

Mean Number of Urination Perlods per Night (sd)

Mean Number of Urination Perlods in Daytime (sd)

Mean Quantlty of Llquild Intake (ml)** (sd)

Urine Loss whlle Walking $\mathbf{N}(\%)$

Not

Seldom

Often

Urine Loss while Shlfting Body Position, Dancing,

Sports, Climbling Stalrs N (\%)

Not

Seldom

Often

Urine Loss while Coughing, Sneezing, Pushing,

Lifting, Bending Over, Jumping $N(\%)$

Not

Seldom

Otten

Dolng Team Sports N (\%)

Incontinence - Assessment List

Daily Activities: Altered N (\%)

Social Consequences: Altered $\mathrm{N}(\%)$

Self Worth: Altered N (\%)

$50.35(10,50)$

$46.40(12,12)$

$11(55 \%)$

$9(45 \%)$

$15(75 \%)$

$5(25 \%)$

$0 \quad(0 \%)$

$0 \quad(0 \%)$

$3(15 \%)$

$2 \quad(10 \%)$

$15(75 \%)$

$7 \quad(35 \%)$

$14 \quad(70 \%)$

$2.74(1.92)$

$4.85(2,38)$

$1.6 \quad(1.53)$

7.65 (2.82)

$2180 \quad(648)$

$9 \quad(45 \%)$

$7 \quad(35 \%)$

$4 \quad(20 \%)$

$11 \quad(55 \%)$

$9 \quad(45 \%)$

$15 \quad(75 \%)$

$5 \quad(25 \%)$

$3 \quad(15 \%)$

$1 \quad(5 \%)$

$3 \quad(15 \%)$

$2 \quad(10 \%)$

$15 \quad(75 \%)$

$5 \quad(25 \%)$

$11 \quad(55 \%)$

$1.93(2.16)$

$4.50(2.42)$

$1.2(1.16)$

6.15 (3.06)

$1690 \quad$ (662)

$11 \quad(55 \%)$

$5 \quad(25 \%)$

$4 \quad(20 \%)$

$\begin{array}{rrrr}5 & (25 \%) & 6 & (30 \%) \\ 2 & (10 \%) & 2 & (10 \%) \\ 13 & (65 \%) & 12 & (60 \%)\end{array}$

$\begin{aligned} 1 & (5 \%) & 1 & (5 \%) \\ 0 & (0 \%) & 2 & (10 \%) \\ 19 & (95 \%) & 17 & (85 \%) \\ 9 & (45 \%) & 8 & (40 \%) \\ 12 & (60 \%) & 12 & (60 \%) \\ 11 & (55 \%) & 9 & (45 \%) \\ 11 & (55 \%) & 14 & (70 \%)\end{aligned}$

No significant differences $(p<0.05)$ between groups on anamnestical data.

** $p=0.02$ 
Table 3b. Comparison of Baseline Characteristics $(T=0) *$

Pelvic floor muscle training

$(\mathrm{N}=20)$

Biofeedback

$(\mathrm{N}=20)$

\section{PAD test (Inco-test)}

Quantity of urine loss during 48 hours in ml., mean (sd)

Symptom scores

Number of points (5-50), mean (sd)

Patient's dlary

Drink Mean (sd) ${ }^{\star \star}$

Daily urination frequency, mean (sd)

Number of daily pad changes, mean (sd)

Number of involuntary daily urine losses, mean (sd)

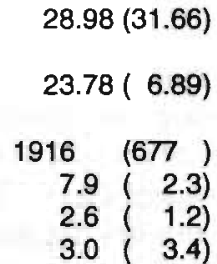

$26.63(24.47)$

22.12 ( 4.64$)$

$1462(466)$

$7.2(2.7)$

$2.4(1.8)$

$2.0(2.1)$

* $(T=0)=$ exact time of first treatment; $s d=$ standard deviation; $m \mathrm{l}=$ millilitres; $a=0.05$. No significant differences between groups on baseline characteristics

** $p=0.01$

\section{Quantity of involuntary urine loss per $\mathbf{4 8}$ hours}

Before the first treatment (Week 0 ) the mean (sd) quantity of involuntary urine loss in grams per 48 hours was 29.0 (31.7) for the pelvic floor muscle training group, 26.6 (24.5) for the biofeedback group (see Figure 2).

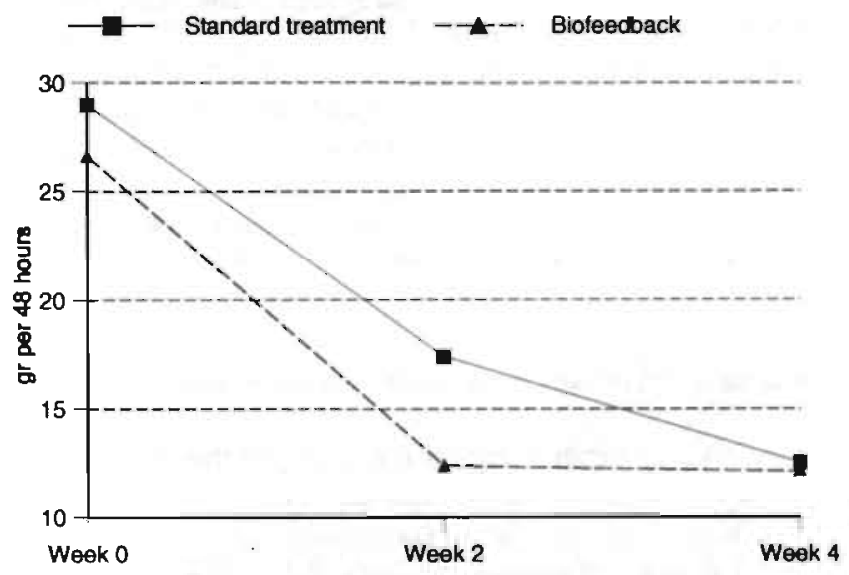

Figure 2. Mean involuntary urine loss in grams per 48 hours.

At the onset of the seventh treatment (start of week 3) the mean (sd) were respectively $17.4 \mathrm{gr},(17.6)$ and $12.4 \mathrm{gr}$ (10.0). The difference in improvement between both groups is not significant $(p=0.36)$. After the last treatment, the mean quantity of involuntary urine loss was $12.5 \mathrm{gr}(12.0)$ for the pelvic floor muscle training and $12.2 \mathrm{gr}$ (15.4) for the biofeedback. The difference in improvement between the groups is not significant $(p=0.40)$. The results of the PAD test for both the pelvic floor muscle training and biofeedback showed a significant $55 \%(p=0.00)$ 
improvement after twelve treatments, however for biofeedback alone, the same results already reached significance after six treatments $(p=0.005)$. Pelvic floor muscle training showed no significant improvement after six treatments $(p=0.06)$. After twelve treatment sessions in the pelvic floor muscle training group 3 patients were cured, 14 patients improved, and 3 patients were worse. In the biofeedback group 5 patients were cured, 14 improved, and only 1 patient was worse. After six treatment sessions 16 patients improved, 2 patients were unchanged, and 2 were worse.

\section{Symptoms questionnaire and Patient's dairy}

Figure 3 shows a weekly overview of the mean (sd) symptoms score for both research groups. The difference in improvement between both groups in W2 and W4 compared to $W 0$ is not significant (WO-W2: $p=0.48 ; W O-W 4: p=0.45$ ). On the Symptoms questionnaire the biggest improvement in the biofeedback versus the pelvic floor muscle training was realized in the first six treatments; this corresponds with the findings of the PAD test.

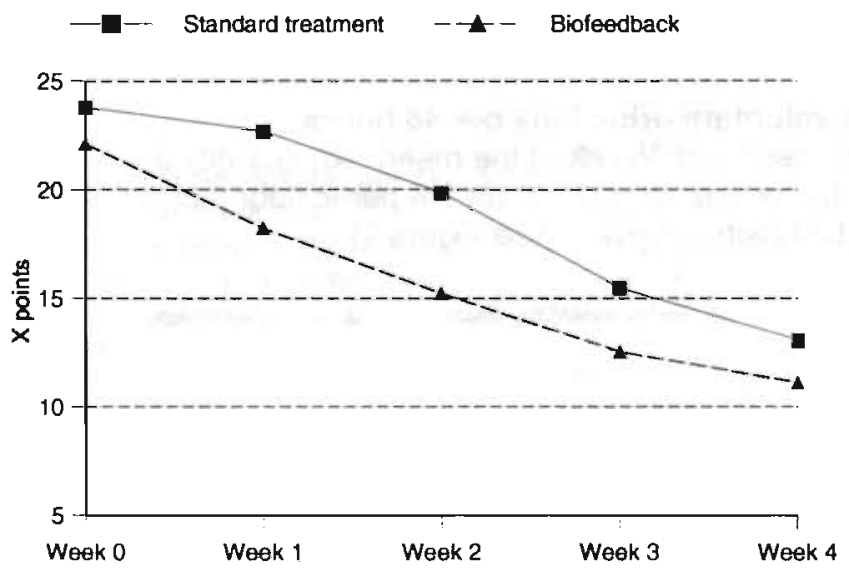

Figure 3. Mean total score of the Symptoms questionnaire per week.

In the Patient's diary among other things the pattern of the daily occurrence of involuntary urine loss (IU) was noted. In Figure 4 the mean numbers of IU per week are recorded. The difference in decrease between both groups between W0 and W2 and between $W_{0}$ and $W_{4}$ is not significant (WO-W2: $p=0.40 ; W_{0}-W_{4}: p=0.18$ ).

Table 4. Mean Daily Liquid Intake*

\begin{tabular}{lccccc}
\hline & W0 & W1 & W2 & W3 & W4 \\
\hline PFMT & 1915 & 1804 & 1858 & 1874 & 1928 \\
BF & 1461 & 1488 & 1563 & 1524 & 1561 \\
\hline
\end{tabular}

- $\quad P F M T=$ pelvic floor muscle training; BF = biofeedback; $m l$ = millilitres; WO = diagnostic phase; W1-W4 = treatment week 1-4 
Analysis in level of activity showed no difference. In Table 4 the mean daily liquid intake is shown. Between WO and W4, the biofeedback group increased with a mean daily liquid intake of $100 \mathrm{ml}$, and the pelvic floor muscle training group with $13 \mathrm{ml}$.

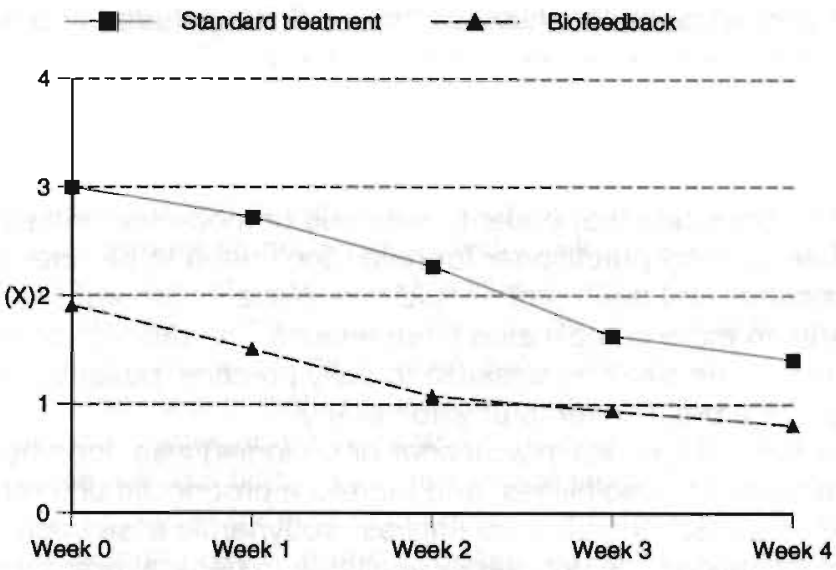

Figure 4. Mean involuntary urine loss per week.

\section{Combined measure of effect}

The mean (sd) percentage improvement after six treatment sessions is for pelvic floor muscle training $15.1 \%$ (55.4) and for biofeedback $34.7 \%$ (23.8) (see Figure 5). After twelve treatment sessions the mean are $51.8 \%$ (34.6) for pelvic floor muscle training and $46.2 \%$ (26.2) for biofeedback. The difference in improvement between both research groups after six treatments was $19.6 \%$ in favour of biofeedback.

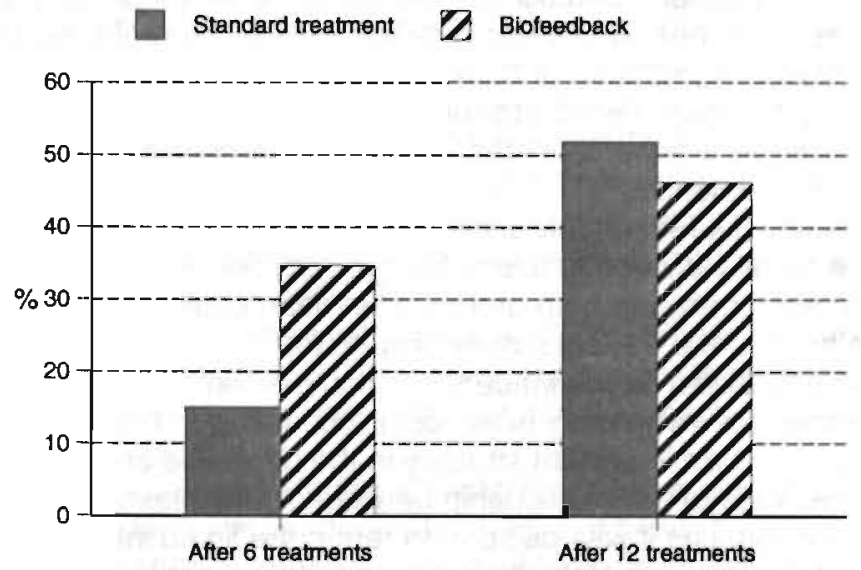

Figure 5. Mean percentages of improvement measured by the combined measure of effect.

The difference is not significant $(p=0.08)$. Table 4 shows that there is a difference in the mean intake of daily liquid between both groups. This difference cannot be based 
on the difference in body weight. The mean body weight in the biofeedback group is $76.2 \mathrm{~kg}$, in the pelvic floor muscle training group $77.6 \mathrm{~kg}$. After correction for liquid intake and body weight by means of linear regression, a significant improvement for biofeedback compared to pelvic floor muscle training after six treatments was shown $(p=0.04)$. After twelve treatments however, these findings faded to reach significance $(p=0.43)$.

\section{Discussion}

Lagro-Janssen ${ }^{37}$ concluded that patients with mild or moderate urinary incontinence, who apply to their general practitioner for help, don't need to be referred to the urologist. Diagnostics and treatment should take place in general practice, before exposing patients to more complicated interventions. ${ }^{37}$ In order to conduct a study under circumstances as close as possible to daily practice, patients could directly be referred by a general practitioner to physiotherapy.

Stratification by referral (general practitioner or urologist) was done because of differences in diagnostic possibilities, and therefore prognostic differences. The diagnosis genuine stress incontinence implies urodynamic assessment. ${ }^{19}$ However, urodynamic investigations are not readily available to general practitioners and often not effective in the setting of general practice. ${ }^{25}$ Lagro-Janssen assessed the diagnostic value of the patient's medical history in distinguishing between genuine stress incontinence, detrusor instability, and mixed incontinence. A total of 103 women with urinary incontinence presented to their general practitioner and underwent a standard history taking, physical examination and urodynamic testing. The urodynamic diagnoses were analysed against symptoms and symptom complexes. Symptoms of stress incontinence in the absence of symptoms of urge incontinence had a sensitivity of $78 \%$, a specificity of $84 \%$, and a predictive value of $87 \%$. Symptoms of urge incontinence in the absence of symptoms of stress incontinence excluded genuine stress incontinence. It was concluded that a standard history is valuable in general practice to distinguish between genuine stress and other types of incontinence. Urodynamic evaluation can be restricted to patients whose history reveals symptoms of both stress and urge incontinence. ${ }^{25}$ Because the guidelines of Lagro-Janssen were applied in the present study, it is possible that 1 in 5 patients, referred by a general practitioner, was inappropriately diagnosed having genuine stress incontinence.

The randomization was reasonably successful. The relevant prognostic variables appeared to be equally divided between the groups (Table $3 a$ and $3 b$ ). The only significant difference between both groups was mean quantity of liquid intake (Table 3a) and mean drink of the Patient's diary (Table 3b).

No known research exists on the influence of liquid intake versus the results of the treatment (decrease of involuntary urine loss). According to Brink, ${ }^{38}$ influencing the liquid intake pattem is an important strategy in the decrease and elimination of incontinence, because of the relationship between liquid intake and urination. Because of these reasons it was decided to report the liquid intake pattern and thus possible differences in liquid intake became part of the analysis. However, the biological plausibility and the (causal) link between liquid intake and the measure and frequency of involuntary urine loss need to be further researched and proven.

A possible explanation for the high compliance is the very high motivation among the patients and a very enthousiastic supervision during the treatments. ${ }^{3,28,39}$ Protocol 
deviation was almost non existent. No harmful effects were reported neither by patients, nor by therapists.

Blinding was not possible at all levels. Biofeedback was given as a support to exercise therapy. Because of an intravaginal electrode during biofeedback no blinding of patient and therapist was possible. Double blind research is often unrealistic in physiotherapy. ${ }^{40}$ However, effect measurements and data analysis were blinded.

This study was based on three effect measurements to measure subjectively and objectively the involuntary urine loss. Pad tests are a relatively crude way to estimate urine loss, they are limited and are problematic in reproducibility and interrater reliability. ${ }^{41}$ Pad tests without standardized bladder volume are known to be less reproducible than those with standardized bladder volume. As found by Victor et al. ${ }^{36}$ and Jacobsen et al., ${ }^{42}$ a 48-hour test, performed by the patient at home while performing ordinary daily activities, has shown good reproducibility and patient compliance. ${ }^{41,43}$ The Inco-test is tested on reliability and acceptability. ${ }^{33-34}$ The coefficient of correlation between patient's and examiner's measurement was $0.98 .^{34}$ This is in accordance with the findings in the present study. The Inco-test can be easily handled and is suitable for evaluation purposes. ${ }^{37}$ However, lack of standardization restricts the use of home pad tests for scientific purposes. ${ }^{42}$ It is preferable to use standardized, reliable, and valid tests. It is not known wether any pad test for objective urine-loss measurement will ever have these qualities. ${ }^{41}$ The patient's diary is an important test instrument. ${ }^{44}$ It shows a daily pattern of, among other things, the frequency of the numbers of involuntary urine loss. A disadvantage is that patients might get sloppy during routine reporting. During the diagnostic phase emphasis was put on the exact and accurate record keeping, and during the treatment phase, compliance was checked by the therapist.

The results of the PAD test showed that in chronic complaint pattern such as stress incontinence the treatment realized an improvement of $\pm 55 \%(p=0.001)$ in both groups. The biofeedback group realized this big progress after only six treatments $(p=0.005)$. Remarkably, the biofeedback group showed only little improvement between six and twelve treatments. It is possible that the optimal physiological improvement, as a result of the treatment, was already realized in the first 2 weeks. In the first weeks of training, success of pelvic re-education, with and without the aid of biofeedback, can be explained as due to an increased reflex action of the pelvic floor through fast-twitch recruitment, to an increased awareness of these muscles, ${ }^{10}$ and to strength development caused by a more effective recruitment of motor units and increased frequency of excitation. Further increase in strength because of hypertrophy is a much slower process. ${ }^{45}$

The support of the exercise therapy with the aid of biofeedback could increase the coordination in muscle strength and better control of the pelvic muscles versus exercise therapy by itself. ${ }^{8}$ Burgio ${ }^{16}$ concluded that biofeedback is of vital importance at the beginning of the therapy.

The American College of Sports Medicine ${ }^{46}$ recommended a duration of treatment of at least 5 months in order to reveal the real potential of pelvic floor muscle strength training. In the present study a short treatment period was chosen in order to reveal the short-term effects of exercises and biofeedback vs. exercises alone after 2 and 4 weeks. Benvenuti et al. ${ }^{47}$ found in a study of 26 women undergoing supervised pelvic floor exercises and behavioural modification, that most of the improvement was seen within 2 weeks of initiating therapy. Examining study patients for improvement after 2 weeks of treatment might demonstrate wether the benefit is simply an increased 
awareness of the pelvic floor muscles, but most studies do not measure improvement until after a treatment period of 4-6 weeks. ${ }^{10}$

Because of the choice for a short treatment period, the real potential of pelvic floor muscle strength could not be revealed in this study. Therefore, no emphasis was put on pelvic muscle strength as a measure of effect.

In 5 studies biofeedback (vaginal devices demonstrating the results while exercising) was compared to pelvic floor muscle training. In the studies of Burgio et al. ${ }^{16}$ and Shepherd et al. ${ }^{20}$ adding biofeedback improved the results compared to exercises without such systems. In contrast to these studies, Castieden, ${ }^{21}$ Dougherty, ${ }^{22}$ and Ferguson ${ }^{23}$ could not demonstrate such improved effect. The effect of adding biofeedback is controversional. ${ }^{19}$ Extrapolation of the results of the present study to other research is not easy due to the use of other research populations, interventions, equipment, and effect measures.

It is necessary to perform follow-up tests, including measurements of pelvic floor muscle strength, in view of the effects during a longer period of time $e^{15,24,48}$ The long term effects are currently being researched.

\section{Conclusions}

Pelvic floor muscle training with biofeedback and pelvic floor muscle training alone are effective treatment modalities for involuntary urine loss in patients with mild or moderate stress incontinence. It is clear from the analysis that biofeedback as a support to therapy is most important in the first 2 weeks, during the first six treatments. Although differences in treatment effects between both groups were not significant, our findings suggest that adding biofeedback to pelvic floor muscle exercises might be more effective than pelvic floor muscle exercises alone after six treatments.

Research of these results during a longer period of time is momentarily in progress.

\section{Acknowledgments}

We express our sincere gratitude to Loe MA van Veggel, MSc, and Alfons GH Kessels, MSc, for their assistance with the production of this article.

\section{References}

1. Abrams P. Blaivas JG, Stanton SLR, et al. Standardization of terminology of lower urinary tract function. Neurourol Urodynam 1988; 7: 403.

2. Lagro-Janssen ALM, Debruyne FMJ, Smits AJA, Weel C van. Controlled trial of pelvic floor exercises in the treatment of urinary stress incontinence in general practice. Brit J Gen Prac 1991; 41: 445-449.

3. Wall LL, Davidson GD. The role of muscular re-education by physical therapy in the treatment of genuine stress urinary incontinence. Obstet and Gynecol Surv 1992; 47: 326-327.

4. Kegel AH. Physiologic therapy for urinary stress incontinence. J Am Med Ass 1951; 14: 915-917.

5. Chiarelli PE, O'Keefe DR.. Physiotherapy for the pelvic floor. Australian Joumal of Physiotherapy 1981; 27: 103-108.

6. Harrison SM. Stress incontinence and the physiotherapist. Physiotherapy 1983; 69: 144-147.

7. Laycock J. Graded exercises for the pelvic floor muscles in the treatment of urinary incontinence. Physiotherapy 1983; 73: 371-373.

8. Burns PA, Pranikoff K, Nochajski TH, Desotelle P, Harwood MK. Treatment of stress incontinence with pelvic floor exercises and biofeedback. JAGS 1990; 38: 341-344.

9. Bruin AJJ de, Haage-de Bruin MJJC. Hulpverlening en speciële fysiotherapie. In Bruin AJJ de (ed). Incontinentie en hulpverlening. Houten/Antwerpen. Bohn Stafleu Van Loghum 1990. 
10. Norton P. Treatment of stress urinary incontinence. In Schussler B, Laycock J, Norton P, Stanton $S$ (eds). Pelvic floor re-education. London. Springer-Verlag 1994.

11. Krebs DE. Biofeedback in therapeutic exercise. Basmajian JV, Wolf SL (eds). Therapeutic Exercise. Baltimore. Williams and Wilkins 1990.

12. Bø K, Larsen S, Oseid S, Kvarstein B, Hagen A, Jorgensen J. Knowledge about the ability to perform correct pelvic muscle exercises in women with urinary stress incontinence. Neurol Urodynam 1988; 7: 261-262.

13. Bump RC, Glenn Hurt W, Fantl JA, Wymann JF. Assessment of Kegel pelvic muscle exercise performance after brief verbal instruction. Am J Obstet Gynecol 1991; 165; 2: 322-329.

14. Knight $S J$, Laycock $J$. The role of biofeedback in pelvic floor re-education. Physiotherapy 1994; 80: 145-148.

15. Bø K. Isolated muscle exercises. In Schussler B, Laycock J, Norton P, Stanton S (eds). Pelvic floor re-education. London. Springer-Verlag 1994.

16. Burgio KL, Robinson JC, Engel BT. The role of biofeedback in Kegel exercise training for stress urinary incontinence. Am J Obstet Gynecol 1986; 154: 58-64.

17. Berghmans LCM. Stress-incontinentie en fysiotherapie, een literatuuroverzicht (Jaarwerkstuk). Maastricht: Rijksuniversiteit Limburg 1993.

18. Schussler B, Laycock J, Norton P, Stanton S (eds). Pelvic floor re-education. London. SpringerVerlag 1994.

19. Bø K. Stress urinary incontinence, physical activity and pelvic floor muscle strength training. Scand J Med Sci Sports 1992; 2: 197-206.

20. Shepherd A, Montgomery I, Anderson RS. A pilot study of a pelvic exercise in women with stress urinary incontinence. J Obstet Gynecol 1983; 3: 201-202.

21. Castleden CM, Duffin HM, Mitchell EP. The effect of physiotherapy on stress incontinence. Age Ageing 1984; 13: 235-237.

22. Dougherty MC, Abrams RM, Battisch CD, Bishop KR, Gimptty P. Effect of exercise on the circumvaginal muscles (CVM). Neurourol Urodynam 1987; 6: 189-190.

23. Ferguson KL, McKey PL, Bishop KR, Kloen P, Verheul JB, Dougherty MC. Stress urinary incontinence: effect of pelvic muscle exercise. Obstet Gynecol 1990; 75: 671-675.

24. Burns PA, Pranikotf K, Nochajski TH, Hadley EL, Levy KJ, Ory MG. A comparison of effectiveness of biofeedback and pelvic muscle exercise treatment of stress incontinence in older community-dwelling women. J Gerontol Medical Sciences 1993; 48: 167-174.

25. Lagro-Janssen ALM, Debruyne FMJ, Weel $C$ van. Value of the patient's case history in diagnosing urinary incontinence in general practice. Brit J Urol 1991; 67: 569-572.

26. Tijssen JPG, Lubsen J, Roelandt JRTC. Grondslagen van interventie-onderzoek. NTVG 1988; 132: 2006-2010.

27. Maksimovic $\mathrm{P}$, Schröder FH, Kurth $\mathrm{KH}$. Stress-incontinentie bij de vrouw; resultaten van de operatieve behandeling volgens Stamey Pereyra. NTVG 1985; 129: 951-954.

28. Bø K, Hagen RR, Kvarstein B, et al. Pelvic floor muscle exercise for the treatment of female stress urinary incontinence. Validity of vaginal pressure measurements of pelvic floor muscle strength and the necessity of supplementary methods for control of correct contraction. Neurol Urodynam 1990; 9: 479.

29. Bø K, Hagen RR, Kvarstein B, et al. Pelvic floor muscle exercise for the treatment of female stress urinary incontinence: 111 . Effects of two different degrees of pelvic floor muscle exercises. Neurourol Urodynam 1990; 9: 489.

30. Laycock J. Assessment and treatment of pelvic floor dysfunction. PhD thesis, University of Bradford 1992.

31. Laycock J. Clinical evaluation of the pelvic floor. In: Schussler B, Laycock J, Norton P, Stanton S (eds). Pelvic floor re-education. London. Springer-Verlag 1994.

32. Smidt N, Giffel MAB te. Valideringsonderzoek Myaction-12. Onderzoek naar de validiteit, reproduceerbaarheid en hanteerbaarheid van de Myaction-12 (Jaarwerkstuk). Maastricht: Rijksuniversiteit Limburg 1994.

33. Mulder AFP, Vierhout ME. The Incotest: A 48-hour home pad weighing test for objective quantification of urinary incontinence. Papers to be read by title. 19th annual meeting ICS, Ljubljana, Yugoslavia: 1989; 109-110.

34. Mulder AFP, Vierhout ME. De Inco-test. Medicus 1990; 264.

35. Hellström AL, Andersson R, Hjälmäs K, Jodal K. Padtests in children with incontinence. Scand J Urol Nephrol 1986; 20: 47-50.

36. Victor A, Larsson G, Asbrink AS. A simple patient administered test for objective quantification of the symptom of urinary incontinence. Scand J Urol Nephrol 1984; 21: 277-279. 
37. Lagro-Janssen ALM. Urine-incontinentie bij vrouwen in de huisartspraktijk (dissertatie). Lelystact: Meditekst 1991.

38. Brink CA. Absorbent pads, garments, and management strategies. JAGS 1990; 38: 368-373.

39. Susset JG, Galea G, Read L. Biofeedback therapy for female incontinence due to low urethral resistance. J Urol 1990; 143: 1205-1208.

40. Deyo RA, Walsh NE, Schoenfeld LS, et al. Can trials of physical therapy be blinded? The exampel of transcutaneous electrical nerve stimulation for chronic pain. Am J Phys Med Rehabi) 1990; 69: 6-10.

41. Kromann-Andersen $B$, Jacobsen $H$, Anderson JT. Pad weighing tests: A literature survey on test accuracy and reproducibility. Neurol Urodynam 1989; 8: 237-242.

42. Jacobsen $H$, Vedel $P$, Andersen JT. Objective assessment of urinary incontinence: An evaluation of three different pad-weighing tests. Neurourol Urodynam 1987; 6: 325-330.

43. Mouritsen L, Berild G, Hertz J. Comparision of different methods for quantification of urinary leakage in incontinent women. Neuourol Urodynam 1989; 8: 579-587.

44. Bates CP, Loose H, Stanton SLF. The objective study of incontinence after repair operations. Surg Gynecol Obstet 1973; 136: 17.

45. DiNubile NA. Strength training. Clin Sports Med 1991; 10: 33-62.

46. American College of Sports Medicine (ACSM). The recommended quantity and quality of exercise for developing and maintaining cardiorespiratory and muscular fitness in healthy adults. Med Sci Sports Ex 1990; 22: 265-274.

47. Benvenuti F, Caputo GM, Bandinelli S, Mayer F, Biagini C, Sommavilla A. Re-educative treatment of female genuine stress incontinence. Am J Med 1987; 66: 155-168.

48. Elia G, Bergman A. Pelvic muscle exercises: When do they work. Obstet Gynecol 1993; 81: 283. 286. 


\section{Chapter 4}

\section{Guidelines for the physiotherapeutic management of genuine stress incontinence*}

LCM Berghmans, MSc, RPt (1), ATM Bernards, MD (2), HJM Hendriks, PhD, RPt (2), K Bø, PhD, RPt, PE (3), MHM Grupping, RPt (2)

1 Department of Urology, University Hospital Maastricht, Maastricht, the Netherlands

2 Dutch National Institute of Allied Health Profession, Amersfoort, the Netherlands

3 Norwegian University of Sport \& Physical Education, Oslo, Norway 


\section{Abstract \\ This article describes an evidence-based and systematic approach to the physiotherapeutic management of genuine stress incontinence. Genuine stress incontinence is the result of a dysfunction of the urethral closing mechanism. Today there is still a lack of standardization in the terminology related to genuine stress incontinence and physiotherapy. This article discusses and compares relevant nomenclature and classification systems related to genuine stress incontinence. Based on the medical diagnosis and the diagnosis of the physiotherapist, a treatment plan will be made, taking into account explicit formulation of the objective of therapeutic training and management. Whether, and to what extent, these objectives can be achieved, depends on the severity and the nature of the pathology, whether there are local or general complicating factors for recovery and improvement, and to what extent these factors can be influenced by physiotherapy. The process of diagnosis, the process of therapy, and patient education in physiotherapy practice are described. Finally, relevant treatment modalities are discussed, and suggestions for further research noted.}

Key words dysfunction, genuine stress incontinence, guideline, patient education, pelvic floor, physiotherapy, stress urinary incontinence. 


\section{Introduction}

In 1992 a panel of experts developed the US Clinical Practice Guideline 'Urinary incontinence in adults'; 'this guideline outlines a multidisciplinary approach to the diagnosis and treatment of urinary incontinence in adults. In the Netherlands (as elsewhere) the physiotherapy profession is increasingly urged by society to justify its continued resources from public expenditure in these times of financial pressure. There is consequently a growing need to justify the rationale for treatments, and to deliver proof that physiotherapy does have clinically relevant effects on the natural course of disease, and impact on the patient's condition. To assess the effectiveness of physiotherapeutic management and to justify patient treatment for genuine stress incontinence (GSI), a systematic approach to the process of physiotherapy diagnostic and treatment must be established. A systematic approach is a prerequisite for making explicit choices and decisions during physiotherapeutic management. The current article describes physiotherapeutic management for genuine stress incontinence and is based on the National Practice Guideline 'Stress urinary incontinence (SUI) in adults' for physiotherapy practice; this guideline has been developed by a panel of experts appointed by the Royal Dutch Association for Physiotherapy (KNGF). ${ }^{2}$ The National Practice Guideline was developed on the basis that physiotherapy practice must be evidence-based, and based upon a systematic, methodical process; ${ }^{3}$ this process in physiotherapy can be considered as being divided into different phases (see Table 1). Development of the NPG 'Stress urinary incontinence in adults' was informed by a recognition of these different phases of this process. Within these different phases of the physical therapy process several variables are important, as is the need for appropriate means of classification to categorize and order these variables.

Table.1. The physical therapy process.

Referral

History taking

Physical examination

Analysis

Formulation of treatment plan

Treatment

Evaluation

\author{
Referral data \\ Personal data \\ Patient's complaint \\ Use of technical aids \\ Psychosocial data \\ Medical data \\ Interview technique \\ Diagnostic procedures \\ Examination findings \\ Physical therapist's diagnosis \\ Treatable components \\ Treatment goals \\ Freq/lenghtamount of sessions \\ Procedures used \\ Time/lenght/place of sessions \\ Treatment results
}




\section{Classification and diagnosis}

The World Health Organization (WHO) has developed several classification systems for the medical profession. ${ }^{4-5}$ In view of the different nature of the health care which physiotherapists provide, there is also a specific need for a classification system that meets the particular requirements of physiotherapists ${ }^{6}$ This notwithstanding, there is still a lack of a standardized terminology related to physiotherapy, and to lower urinary tract disorders in particular.

For effective management of a health problem like genuine stress incontinence, it is fundamentally important to be able to distinguish between the nature and the severity of genuine stress incontinence. In medical terms, the diagnosis genuine stress incontinence can be classified by the International Classification of Diseases (ICD-10); ${ }^{4}$ however, this system does not provide any insight into the underlying pathology that will result in genuine stress incontinence. Genuine stress incontinence can be due to a dysfunction of the intrinsic urethral closing mechanism, or of the extrinsic supporting mechanism, or, indeed, a combination of both factors. This distinction between intrinsic and extrinsic factors is important because it determines whether (and to what extent) genuine stress incontinence and the resulting health problem can be influenced by physiotherapy. For the physiotherapist, the conceptual framework provided by the International Classification of Impairments, Disabilities and Handicaps (ICIDH) ${ }^{5}$ is fundamental in the articulation and categorization of health problems as impairments, disabilities and handicaps (Table 2). ${ }^{7}$ The ICIDH enables description of the severity of genuine stress incontinence not only as the objective extent of involuntary loss of urine, but also in terms of the as the patient's resultant functional health status on three distinct levels (impairment, disability and handicap). Providing that the potential impact of the physiotherapeutic intervention upon the underlying pathology is known, the indication for physiotherapy and the prognosis of the outcome of physiotherapy can be determined, and goals for physiotherapy specified in terms of the ICIDH.

The International Continence Society (ICS) established a committee for the standardization of terminology of lower urinary tract function; the standards proposed by the committee are recommended to facilitate comparison of results by investigators using urodynamic methods. ${ }^{8}$ The ICS defines urinary incontinence on three levels: as a symptom, a sign or a condition. Stress urinary incontinence is regarded a symptom when the patient tells (the physician) that there is involuntary loss of urine during exertion. Stress urinary incontinence is regarded a sign when it is observed that there is involuntary loss of urine from the urethra synchronous with physical exertion. Stress urinary incontinence is viewed as a condition when, during urodynamic examination, stress urinary incontinence is confirmed by observing involuntary loss of urine as a result of an increase in abdomal pressure in the absence of a detrusor contraction or an overdistended bladder. ${ }^{8-9}$ The diagnosis genuine stress incontinence in terms of the ICD-10 corresponds with stress urinary incontinence as a condition in terms of the ICS. ${ }^{9}$

Comparison of the ICIDH and the ICS terms of the health problem and medical diagnosis genuine stress incontinence leads to the following conclusions: the complaint 'involuntary urine loss during physical exertion' is in terms of the ICIDH a disability (in the ability to urinate at the correct time and place); in terms of the ICS this is classified as a symptom.

The determination of urine loss synchronous with exertion as a sign, and the loss of urine during increase of intra-abdominal pressure in the absence of a detrusor contraction as a condition, are in terms of the ICIDH determination of impairments in 
the storage and voiding of urine. A major advantage of the ICIDH-terminology is the possibility to describe the health status related to genuine stress incontinence on participation (handicap level).

Efforts should be made to achieve standardization of terminology, based on the specific requirements of physiotherapists. This terminology has to be clear and understandable for all other involved health care providers.

Table 2. Definitions of the ICIDH-terms impairment, disability and handicaps

Impairment Loss or abnormality of psychological, physiological, or anatomical structure or function at organ level. With respect to the "Classification of disorders in the storage and voiding of urine and faeces', this means the impairment 'stress incontinence'

Disability Restriction or loss of ability of a person to perform functions/activities in a normal manner. With respect to the 'Classification of disabilities of voiding and stool' this means the disability 'involuntary loss of urine'

Handicap Disadvantage due to impairment or disability that limits or prevents fulfillment of a normal role (depends on age, sex, sociocultural factors) for the person

Modified from Heerkens et al. ${ }^{6}$

\section{GSI and dysfunction of the urethral closing mechanism}

Genuine stress incontinence is the result of a dysfunction of the urethral closing mechanism; the concurrent involuntary loss of urine (disability) influences to a certain extent the psychosocial function of the involved person (handicap). As stated before, genuine stress incontinence can be due to a dysfunction of the intrinsic urethral closing mechanism, or of the extrinsic supporting mechanism or a combination of both factors. Dysfunction of the intrinsic urethral closing mechanism can be due to atrophy of the tunica mucosa and spongiosa (e.g. postmenopausal) or a functional disorder of the tunica muscularis (e.g. after prostatectomy) ${ }^{1,10}$ Dysfunction of the extrinsic supporting mechanism can be caused by weakness of the pelvic floor muscles (because of inactivity or disuse and/or damage of local nerve fibres), or rupture of muscle fibers and connective tissue of the pelvic floor and/or damage of the endopelvic fascia (e.g., during a traumatic delivery). ${ }^{11-12}$ Because of a dysfunction of the pelvic floor, an insufficient active support of the urethral closing mechanism, an abnormal descent of the pelvic floor, and hypermobility of the urethra and bladder neck can arise during exertion. This may occur in conjunction with an effacement of the urethrovesical corner, causing an obstruction of the transmission of the intraabdominal pressure on the urethra. ${ }^{13}$

\section{Referral for physiotherapy intervention}

Within the Dutch health care system physiotherapy is only accessable after referral by a physician. Patients with genuine stress incontinence are in most cases referred by a general practitioner or alternatively by a urologist or gynaecologist. While the specialist has the possibility of diagnosing genuine stress incontinence based on urodynamic research, in general, referral by the general practitioner is based on history taking and physical examination. Lagro-Janssen ${ }^{14}$ reviewed case histories of patients with diagnosis urinary incontinence in general practice, and found that symptoms of stress incontinence in the absence of symptoms of urge incontinence had a sensitivity of $78 \%$, a specificity of $84 \%$ and predictive value of $87 \%$ compared to urodynamic diagnoses. Because the general practitioner normally has no 
possibility of urodynamic assessment, misclassification of the diagnosis genuine stress incontinence is more likely with such referrals.

When referring a patient with genuine stress incontinence for treatment, it is important that the referring physician's report contains the reason for referral and medical findings/information as well as the recommendations for (the goals of) physiotherapy intervention. According to the 'Fysiotherapeutenbesluit' (the Dutch Physiotherapy Act), the referral should contain at least the medical diagnosis, the referral diagnosis and the referral data. The referral diagnosis is not necessarily identical with the medical diagnosis genuine stress incontinence; while the latter is worded in medical terminology according to the ICD-10, the referral diagnosis is stated in terms which indicate the direction of the health problem. Referral data provide the context of the health problem as a result of genuine stress incontinence, with respect to previous disease/disorders, earlier interventions, the duration of symptoms and the patient's psycho/social functioning. In order to classify referral data, the conceptual framework, 'A Classification of Medical Terms', can be used.

\section{Process of diagnosis and therapy for genuine stress incontinence}

Based on the medical diagnosis, the referral diagnosis, and the referral data, the objective of the physiotherapist's diagnosis is to assess the severity and the nature of the condition of genuine stress incontinence, and to what extent this condition can be influenced by physiotherapeutic intervention.

The objectives of physiotherapy are formulated in terms of the reduction of impairments, disabilities and handicaps. Whether and to what extent these objectives can be achieved depends on the nature of the pathology, whether there are local or general obstructing factors for recovery and improvement, and to what extent these factors can be influenced by physiotherapy. Based on the diagnosis, a treatment plan will be devised, taking into account explicit formulation of the objectives of therapeutic intervention and management. In the following sections of this review, the process of physiotherapy practice comprising the processes of diagnosis, therapy and patient education (as well as evaluation of physiotherapy practice) are described. In Table 3 a flowchart for the referral and process of diagnosis for genuine stress incontinence is given; Table 4 provides an algorithm of the process of therapy. Physical therapies for the treatment of genuine stress incontinence are then discussed, followed by conclusions.

\section{Dlagnostic process of the physiotherapist}

Defining genuine stress incontinence with the use of ICIDH-terminology makes it possible to indicate changes in the results of genuine stress incontinence, and therefore provides an instrument to evaluate the effects of physiotherapeutic intervention. If the nature and the severity of genuine stress incontinence are defined using the ICIDH, the prognosis and objective of physiotherapeutic intervention for the individual patient can be stated in terms of total recovery, or reducing impairments, disabilities and handicaps. However, these terms provide no information about the nature and the severity of the pathology causing genuine stress incontinence; the diagnosic process must also determine whether or not this underlying pathology can be influenced by physiotherapy. Based upon the results of the diagnostic process, therapeutic management can be formulated in clear terms. Systematic history taking and relevant physical examination are essential for the diagnosis to guide treatment. ${ }^{6}$ 
Table 3. Flowchart of referral and process of diagnosis

Specialist:

Medical diagnosis GSI (urodynamics)

Referral diagnosis

Referral data
Referral for physiotherapy intervention

General practitioner:

Medical diagnosis GSI (?) (NO urodynamics)

Referral diagnosis

I

1

Referral data

Physiotherapy
Patient education \& Information on
Anatomy, physiology:
pelvic floor, bladder
toiletbehavior/-regimen

\section{Process of diagnosis}

History taking

Physical examination:

general examination

local examination

Relevant data from:

Subjective self-report:

questionnaires (e.g., PRAFAB)

diaries (e.g., voiding diary)

Functional testst (e.g., padtest)

Observation

Palpation:

vaginal/anal

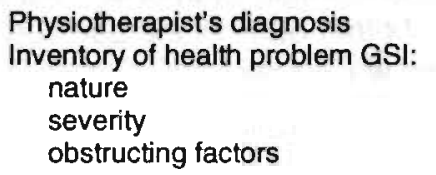

Conclusion: indication for physiotherapy $\rightarrow$ continue with treatment plan

No indication for physiotherapy $\rightarrow$ back to referring physician

\section{Formulation of treatment plan}

treatment objectives

treatment strategy

treatment procedures

expected outcome

prognosis of treatment duration

In terms of total time and number of treatment sessions

Moreover, history taking is the beginning of a relationship based on trust between the patient and the physiotherapist. History taking aims to establish and record:

- the severity of the health problem of genuine stress incontinence by noting impairment(s) (e.g., urine loss while coughing), disability(ies) (e.g., sanitation) and handicap(s) (e.g., social isolation);

- the likely nature of the underlying pathology by noting causal factors (e.g., trauma during vaginal delivery(ies)); 
- local factors, which may prevent the recovery and improvement (e.g. prolaps uteri);

- general or systematic factors, which may prevent recovery and improvement (e.g. diabetes mellitus);

- personal factors (e.g. what efforts does the patient make to alleviate genuine stress incontinence).

A physical examination of the patient is important in order to verify and support the patient-profile gained from the patient's history. To conduct the physical examination, a number of diagnostic tests are available to the physiotherapist. The severity of the genuine stress incontinence depends not only on the condition of the pelvic floor, but also on the posture, respiration, movement, as well as the general physical and psychological condition. ${ }^{15-16}$ Information on the severity of genuine stress incontinence can also be obtained by studying voiding diaries with relevant data about incontinence. These diaries give information on drinking and voiding behaviour, number of used pads, frequency of voiding and amount of involuntary urine loss. Also, subjective self-report, quality-of-life questionnaires and/or symptom questionnaires, such as the PRAFAB-score (which combines the most important objective and subjective elements of the degree of urinary incontinence) can be helpful; ${ }^{17}$ protection (use of pads), amount of urine loss, frequency of the complaint, adjustment in behaviour due to the complaint and body image as result of the urine loss are the five elements of the PRAFAB-score. With this questionnaire it is possible to illustrate the degree of incontinence in a reproducible manner. ${ }^{17} \mathrm{~A}$ padtest can be useful to test the extent and severity of the involuntary loss of urine. ${ }^{18}$

The objective of physical examination is to understand: the functionality of the pelvic floor in rest and during activities in terms of coordination, endurance and strenght; the possibility and degree of contraction (with or without awareness) of the pelvic floor muscles; the influence of other parts of the body on the function of the pelvic floor, by inspection at rest and while moving.

\section{Physlotherapy Dlagnosis}

Analysis of the results of diagnosis and relevant medical data will complete this process. The diagnosis can be stated and the indication for physiotherapy ascertained. Therefore, answering the following questions is necessary:

- Is referral diagnosis genuine stress incontinence likely?

- Are there any genuine stress incontinence related health problems?

- What is the nature of genuine stress incontinence?

- What is the severity and the extent of genuine stress incontinence?

- Is there a dysfunction of the pelvic floor?

- What caused this dysfunction?

- Are there any local factors which may prevent recovery or improvement and can physiotherapeutic intervention have an influence on these factors?

- Are there any general factors which may prevent recovery or improvement?

- Is physiotherapy indicated?

A given severity of genuine stress incontinence at referral has impact on the prognosis and the evaluation of the likely effect of the physiotherapeutic intervention, but provides no implicit data to inform the choice of physiotherapeutic management.

The question of the nature of the underlying pathology still remains unanswered.

Therefore, the question of whether or not, and to what extent, physiotherapeutic intervention can be of any help in the management of genuine stress incontinence 
cannot always be answered or fully understood. One of the reasons is that tools and instruments available to the physiotherapist during the process of diagnosis are limited. In these cases physiotherapeutic treatment can be considered as a 'pilottreatment'.

Problem areas, in which physiotherapeutic treatment may be regarded (and provided) as a pilot treatment can be identified as follows:

- genuine stress incontinence and dysfunction of the pelvic floor;

a. without awareness of the pelvic floor muscles;

b. with awareness of the pelvic floor muscles;

c. and the function of the pelvic floor is compromised by disorders in the tractus respiratorius and other parts of the tractus motorius.

- genuine stress incontinence but without dysfunction of the pelvic floor.

- genuine stress incontinence (with and without dysfunction of the pelvic floor) together with general factors which may prevent or delay recovery or improvement.

In considering treatment in these problem areas, it is also important to take into account prognostic and patient variables, which will have their impact on the process of therapy.

\section{GSI and dysfunction of the pelvic floor}

In patients with genuine stress incontinence and dysfunction of the pelvic floor, there is a failure in the extrinsic supporting mechanism. In these patients, the objective of pelvic floor muscle exercises (PFME) is improvement in the function of the pelvic floor as an extrinsic supporting mechanism. It should be recognised in these cases that physiotherapeutic diagnosis cannot exclude a concurrent dysfunction of the intrinsic urethral closing mechanism. However, pelvic floor muscle exercises may also benefit such cases. In a study based on 6 young healthy nulliparous continent women, $\mathrm{B} \varnothing$ and colleagues have shown with concentric needle EMG that voluntary pelvic floor muscle contraction always gives synergistic contraction of the urethral wall striated muscle. She concluded that correctly performed pelvic floor muscle exercises also induces strength training of the striated muscle of the urethral wall. ${ }^{18}$ Thus, besides the possibility of compensation of a concurrent dysfunction of the intrinsic urethral closing mechanism with pelvic floor muscle exercises, this could mean that improving the function of the pelvic floor also could have a positive influence on this mechanism, provided there is no damage of the neuromuscular tissue. However, the results in the study of $\mathrm{B} ø$ et al. were obtained in a relatively small group of young healthy nulliparous females; it is possible that the conclusions of this group are only valid in persons with an undamaged internal sphincter. ${ }^{19}$ If there really is a dysfunction of the intrinsic urethral closing mechanism, it is therefore important to evaluate the nature of this. Is there an atrophied tunica mucosa or a damaged tunica muscularis or both? Is there a problem in the smooth or striated muscles of the internal sphincter? Contraction of the striated muscles of the internal sphincter may also be possible because of an increase of the intra-abdominal pressure. Further research on this topic is necessary in a matched group of females with genuine stress incontinence. ${ }^{19}$

The effect of pelvic floor muscle exercises largely depends on an intact neuromuscular apparatus; the structural integrity of the connective elements of the pelvic floor may not be disturbed (too much). ${ }^{20}$ 
With physiotherapeutic diagnosis, it is impossible to trace endopelvic fascia lesions; these lesions, depending on severity and extent, can prevent restoration of the normal function of the pelvic floor. ${ }^{12}$

\section{GSI and dysfunction of the pelvic floor without awareness of the pelvic floor muscles}

In patients with genuine stress incontinence and dysfunction of the pelvic floor without awareness of the pelvic floor muscles (i.e. the patient has no ability/feeling to contract or relax the pelvic floor muscles), there is an indication for digital assessment by transvaginal palpation (in women) by the patient and/or the physiotherapist, electrical stimulation and/or biofeedback. After successful restoration of awareness with these interventions, further management with pelvic floor muscle exercises is possible. First, by isolated contractions of the pelvic floor muscles, then during activity of daily living (ADL-) tasks, initially with awareness, from single to multiple complex tasks, in order to achieve an automatic functional use (i.e. automatic control) of the pelvic floor during ADL and sport.

If awareness cannot be achieved, the patient has to be sent back for further evaluation by a specialist. An insufficient restoration of awareness can be the consequence of undiagnosed neurologic disorders, sometimes concurrent with endopelvic fascia lesion(s) (e.g., after a traumatic delivery). ${ }^{11}$

\section{GSI and dysfunction of the pelvic floor with awareness of the pelvic floor muscles}

In patients with genuine stress incontinence and dysfunction of the pelvic floor but with awareness of the pelvic floor, there is an indication for pelvic floor muscle exercises, with the objective being to achieve automatic control during ADL and sport. If results of treatment are limited, concurrent dysfunction(s) of the intrinsic urethral closing mechanism or endopelvic fascia lesion(s) can be the cause. In the first case, oestrogen therapy can be helpful (e.g., in postmenopausal women), ${ }^{21}$ in the latter further evaluation by a specialist is necessary (e.g., after a traumatic delivery).

\section{GSI and dysfunction of the pelvic floor and function of the pelvic floor is mal- Influenced}

In patients with genuine stress incontinence and dysfunction of the pelvic floor and the function of the pelvic floor is adversely affected by disorders in the tractus respiratorius or other parts of the tractus motorius, ${ }^{22}$ physiotherapeutic intervention besides pelvic floor muscle exercises - also has to focus, as efficiently as possible, upon the improvement of impairment(s) responsible for these disorders.

\section{GSI without dysfunction of the pelvic floor}

In patients with genuine stress incontinence but without dysfunction of the pelvic floor, dysfunction of the intrinsic urethral closing mechanism is (obviously) the cause. This dysfunction can be caused by catheterization, by prostatectomy in men or by atrophy of the internal sphincter ${ }^{1,23}$ the latter occurs especially in postmenopausal women. ${ }^{23}$ It is unlikely that physiotherapeutic intervention has influence on the dysfunction of the intrinsic urethral closing mechanism itself; ${ }^{12}$ therefore, the object of pelvic floor muscle exercises in this case is compensation of the dysfunction of the intrinsic urethral closing mechanism as far as possible by improving the functionality of the pelvic floor as an extrinsic supporting mechanism. However, as indicated 
above, Bø et al. showed a synergistic contraction of the urethral wall striated muscle during voluntary pelvic floor muscle contractions; thus, besides the possibility of compensation of a concurrent dysfunction of the intrinsic urethral closing mechanism with pelvic floor muscle exercises, such intervention could also have improve the function of the intrinsic urethral closing mechanism itself. ${ }^{19}$ Whether, and to what extent, physiotherapeutic intervention has influence on the improvement of the intrinsic urethral closing mechanism is yet to be definitively determined and therefore requires more research.

\section{GSI (with or without dysfunction of the pelvic floor) and general obstructing factors}

In patients with genuine stress incontinence in the presence of other general factors which may obstruct or delay recovery and improvement, it is important to recognise that a number of these factors, such as hormonal changes, cannot be influenced by physiotherapy. These factors therefore have prognostic importance, because they can reduce or limit the potential for recovery and/or improvement. Physiotherapy has little effect on the reduction of nerve- and muscle tissue and other age-related changes in the condition of the connective tissue; this will therefore adversely affect the potential outcome or benefit of physiotherapeutic interventions. In contrast, physiotherapy in the sense of providing relevant information, education and care by the physiotherapist, probably can affect other factors, such as misunderstanding or ignorance, sense of shame or guilt, avoidance behaviour, and limitation in social participation.

\section{Prognostic factors}

Understanding prognostic factors is important in order to estimate the potential extent and rate of recovery; however, in the literature it is difficult to identify which clinical prognostic factors predict a positive response to physiotherapeutic intervention. ${ }^{16,24-26}$ Some authors suggest that successful re-education of the pelvic floor depends on the grade of severity of genuine stress incontinence, ${ }^{27}$ the duration of the complaint, ${ }^{28-29}$ whether the patient is postpartum, ${ }^{14}$ pre- or postmenopausal, ${ }^{27}$ has had former surgery ${ }^{24,30}$ and the general condition of the patient. ${ }^{29}$ In other studies it has been suggested that successful re-education depends on the intensity of the physiotherapeutic intervention, care by and enthusiasm of the physiotherapist, and motivation of the physiotherapist and the patient. ${ }^{18,25.31}$

Efforts to identify urodynamic predictive factors for successful re-education of the pelvic floor has resulted in similar confusion. ${ }^{26}$ Reviewing relevant studies, Hilton concluded - with extreme caution - that maximal urethral closing pressure during exertion, functional urethral length during exertion and perineometry tend to be positive predictive factors in the selection of patients who will benefit from reeducation of the pelvic floor. ${ }^{26}$

\section{Process of therapy}

As a general rule, the least invasive and the least troublesome treatment procedures should be considered as a first choice. Low-risk interventions involve educating the patient and providing positive reinforcement for effort and progress. ${ }^{1}$ Whithin this framework physiotherapy techniques include education and information, pelvic floor muscle exercises, biofeedback, vaginal cone retention and electrical stimulation. Comprehensive physiotherapy starts with patient education embracing all relevant concepts (e.g. What is the function of the bladder) and information for the patient. 
Comprehension on the part of the patient will promote the motivation to start on other stages of treatment. The objectives of physiotherapy and management are formulated, based on the process of diagnosis by the physiotherapist, together with the evaluation of the general practitioner and/or the urologist and/or gynaecologist. The interplay between patient and physiotherapist, each with their own interests, wishes and expectations, is very important in this process. Before starting the specific training of the pelvic floor, it is important to know and appreciate the position and the function of the pelvic floor and how to contract and relax the pelvic floor muscles. To achieve satisfactory results from intervention (in the long term), information and supervision by the physiotherapist throughout the process of therapy are essential, especially concerning the adequate use of the pelvic floor muscles and behaviour of micturition.

Table 4. Algorithm of process of therapy.

\section{Process of therapy}

Therapeutic training/management for distinguished problem areas

GSI + dysfunction pelvic floor + NO awareness of pelvic floor: digital palpation by patient and/or physiotherapist electrical stimulation (intravaginal/extravaginal) + PFME biofeedback + PFME

Objective: restoration of awareness of the pelvic floor if awareness restored: see following paragraph unsatisfactory results $\rightarrow$ back to referring physician

GSI + dysfunction pelvic floor + awareness of the pelvic floor:

PFME +home exercises; isolated contractions of the pelvic floor $\rightarrow$ with awareness of pelvic floor, single tasks $\rightarrow$ double tasks $\rightarrow$ multiple tasks $\rightarrow$ automatic controlled tasks; optional: vaginal cones

Objective: total recovery (of the functionality of the pelvic floor) unsatisfactory results $\rightarrow$ back to referring physician

GSI + dysfunction pelvic floor + function pelvic floor mal-influenced by disorders tractus

respiratorius, other parts tractus motorius, toilet regimen, toilet behaviour

PFME + home exercises

exercises to achieve adequate respiration, postural exercises relaxation exercises, lift-instruction

Objective: reduction or elimination mal-influence disorders, improvement functionality pelvic floor unsatisfactory results $\rightarrow$ back to referring physician

GSI + NO dysfunction of the pelvic floor PFME + home exercises; optional: vaginal cones

Objective: compensation. Expectation: total recovery is not likely unsatisfactory results $\rightarrow$ back to referring physician

GSI + general obstructing factors

Objective: maximal possible reduction of these negative factors unsatisfactory results $\rightarrow$ back to referring physician

Evaluation

Treatment results, (changes in) patient's health status, course of action physiotherapist

Concluding treatment period and reporting to referring physician 
As already indicated, there are a number of problem areas, in which physiotherapeutic intervention has to be postulated as a pilot-treatment. Whether or not the therapeutic objectives are achieved, this process provides important diagnostic information. In this way, it is possible to identify underlying pathology which cannot be influenced by physiotherapy, and to determine the necessity for further evaluation of this pathology.

\section{Objectives of therapy and management in problem areas}

\section{GSI and dysfunction of the pelvic floor without awareness of the pelvic floor Objective: restoration of awareness of the pelvic floor}

Therapy: digital assessment by transvaginal palpation by the patient and/or the physiotherapist (in women), electrical stimulation and/or biofeedback. After achieving awareness of the pelvic floor, physiotherapy continues with pelvic floor muscle exercises, with the patient encouraged to do exercises at home. The strategy of the physiotherapist is focused on the realisation of awareness of the pelvic floor by digital palpation by the patient (after being instructed by the physiotherapist) and/or the physiotherapist, by electrical stimulation, separately or as an application to pelvic floor muscle exercises, and/or by biofeedback. If the result is not satisfactory, that is the patient is not able to realise awareness of the pelvic floor, the patient should be sent back to the referring physician. Possible explanations are that there is a (central or peripheral) neurological problem not traceable by physiotherapy,or that, using electrical stimulation, an adequate contraction is not possible because of (lack of optimal) location of the electrode and/or intensity.

\section{GSI and dysfunction of the pelvic floor with awareness of the pelvic floor}

Objective: total recovery (of the functionality of the pelvic floor). Therapy: pelvic floor muscle exercises and exercises at home. Optional in women: pelvic floor muscle exercises and vaginal cones. At the start of the training the patient tries to produce isolated contractions of the pelvic floor. If the patient is able to do so, then, with awareness of the pelvic floor, she tries to realise single tasks, then double and multiple tasks and finally automatic controlled tasks. This can be more difficult in the elderly, for example because of difficulty in concentrating.

If the results of the pilot-treatment are unsatisfactory, a concurrent dysfunction of the intrinsic urethral closing mechanism or an endopelvic fascia lesion can exist. In postmenopausal women such a concurrent dysfunction can be caused by hormonal changes. ${ }^{32}$ The physiotherapy intervention in such cases improves genuine stress incontinence by compensating the dysfunction of the intrinsic urethral closing mechanism through improvement of the functionality of the pelvic floor; however, physiotherapy cannot lead to full recovery. In postmenopausal women combined pharmaceutical therapy (e.g. oestrogens) is possible; ${ }^{15,32-33}$ if the results are unsatisfactory, the patient has to be sent back to the referring physician.

\section{GSI and dysfunction of the pelvic floor and the function of the pelvic floor is} adversely influenced by disorders in the tractus resplratorius, in other parts of the tractus motorius, In toilet regime and in tollet behaviour Objective: reduction or elimination of the adverse influence of these disorders. Improvement of the functionality of the pelvic floor. Therapy: relevant exercises, for example exercises to achieve adequate respiration, relaxation exercises, postural exercises, lift-instruction, etc.; pelvic floor muscle exercises and exercises at home to 
improve the functionality of the pelvic floor. If the results are unsatisfactory, the patient has to be sent back to the referring physician.

\section{GSI but without dysfunctlon of the pelvic floor}

Objective: compensation. Therapy: pelvic floor muscle exercises and exercises at home. Optional in women: vaginal cones. Because there is no dysfunction of the pelvic floor, a dysfunction of the intrinsic closing mechanism (internal sphincter) is likely. In such cases physiotherapy focuses on reducing the impairments and disabilities as a result of genuine stress incontinence. Total recovery is unlikely. In postmenopausal women, combined pharmaceutical therapy (e.g.

phenylpronolamine) is possible. ${ }^{15,33}$ If the results are unsatisfactory, the patient has to be sent back to the referring physician.

\section{GSI in the presence of other general or systematic factors, which may prevent recovery or improvement}

Objective: maximal possible reduction of these negative factors.

\section{Discussion}

Widespread application of physical therapies should be preceded by evidence of improvements in function attributable to their use. How strong is the evidence that physical therapies for treatment of stress urinary incontinence in women are effective? What methodology is used in relevant studies. To assess the efficacy of physical therapies for treatment of stress urinary incontinence in women, a systematic review of randomised clinical trials (RCTs) has previously been undertaken. ${ }^{34}$ A computer aided search for published RCTs investigating treatment of stress urinary incontinence by physical therapies, i.e. pelvic floor muscle exercises, biofeedback, vaginal cones and electrical stimulation, was completed. Methodological quality of included triais was assessed by using criteria, based on generally accepted principles of intervention research. ${ }^{34}$

Twenty-two RCTs were identified; however, the methodological quality of these was found to be moderate. Summary statements on the efficacy of the therapeutic interventions were based on the amount and quality of RCT evidence; to assess this, a rating system that considered four levels of scientific evidence, based on the quality and the outcome of the studies ${ }^{35-36}$ was used. For the purposes of the rating scale, RCTs were either classified as of 'sufficient' methodological quality or 'low' quality. Levels of evidence were rated as follows:

Level 1: Strong evidence - multiple relevant RCTs of sufficient methodological quality;

Level 2: Moderate evidence - one relevant RCT of sufficient methodological quality and multiple low quality RCTs;

Level 3: Limited evidence - one relevant RCT of sufficient methodological quality or multiple low quality RCTs;

Level 4: No evidence - no relevant RCTs or contradictory outcomes.

Based upon this scale, Table 5 gives the relevant levels of evidence for the efficacy of the different treatment modalities used in genuine stress incontinence.

\section{Pelvic floor muscle exercises}

Pelvic floor muscle exercises are low-risk interventions, applied by physiotherapists with special training in the underlying problem, with the objective to reduce 
involuntary loss of urine. The major advantage of (adequate) pelvic floor muscle exercises is the fact that there are no side effects and future (other) treatment modalities (e.g. operation) will be possible, if necessary. The most important object of pelvic floor muscle exercises is (as adequate as possible) restoration of functionality of the pelvic floor. Some patients will become dry quickly and simply, while in other patients this cannot be realised fully.

Table 5. Levels of evidence of efficacy of different treatment modalities in GSI.

Level 1 PFME exercises are effective

Biofeedback adjunct to PFME is no more effective than PFME alone

Electrical stimulation is more effective than sham electrical stimulation

Level 2 Not found

Level 3 High-intensity PFME are more effective than (low-intensity) home PFME High-intensity PFME are no more effective than medication (phenylpropanolamine) Visual biofeedback is more effective than verbal feedback

PFME with an intravaginal resistance device is no more effective than PFME alone Electrical stimulation alone is no more effective than PFME alone or PFME and vaginal cones

Level 4 Surgery is more effective than PFME

Electrical stimulation with PFME is no more effective than PFME alone

Source: Berghmans et al., ${ }^{34}$

Pelvic floor muscle exercises are effective in the reduction of involuntary loss of urine in patients with stress urinary incontinence, ${ }^{34,37}$ Wilson ${ }^{38}$ concluded that pelvic floor muscle exercises, properly taught, are still the mainstay of physiotherapy. Cure and satisfaction rates after pelvic floor muscle exercises (assessed by patient's opinion and other reliable, sensitive and valid measures) may be as high as $60 \%-70 \% .{ }^{38}$ Pelvic floor muscle exercises improve the extrinsic supporting mechanism and have a positive effect on the urethral closing mechanism. ${ }^{39}$ Pelvic floor muscle exercises increase the strength of the voluntary peri-urethral and the pelvic floor muscles. Contraction of the pelvic floor supports the intestines in the pelvis and narrows the urethra, which can hinder involuntary urine loss during fulminant increased intraabdominal pressure. ${ }^{40}$

If pelvic floor muscle exercises programmes in general seem to be an effective treatment for genuine stress incontinence, then further investigation is required to determine the most effective programme. Even in healthy people, during vaginal/anal palpation, the variation in power and endurance of the levator ani muscle is high. For this reason, standardization of physiotherapeutic training, focused on the realisation of optimal power, velocity and endurance of the pelvic floor muscles, is difficult. Therefore, within the available literature many different concepts, norms and ideas can be identified ${ }^{37}$ At present there is little trial evidence to suggest which level of intensity of pelvic floor muscle exercises programme might be most effective. Only $\mathrm{B} ø$ et al. ${ }^{25}$ have compared intensive pelvic floor muscle exercises with low-intensity home-based pelvic floor muscle exercises. After one month, both groups had improved but after 6 months the high-intensity group reported significantly better results. 
Appropriate treatment with pelvic floor muscle exercises should always include an assessment of pelvic floor muscle contraction, because the effect of pelvic floor muscle exercises is dependent on whether the contractions are performed correctly. ${ }^{37}$ Thorough instruction and measurement of improvement seem to be key factors in motivation and adherence to training ${ }^{9.31,37}$ Unfortunately there seems to be little agreement on the content of pelvic floor muscle exercises. ${ }^{1.41}$ Clearly pelvic floor muscle exercises should be designed to develop optimum muscle function. ${ }^{20}$

Repeated correct contractions of the pelvic floor, strengthening the pelvic floor muscles in a regular, intensive and long-lasting training programme, are essential for an effective improvement through pelvic floor muscle exercises. ${ }^{25,37,42}$

Extrapolation of exercise prescription guidelines suggests that pelvic floor muscle exercises should include short and long duration exercises, based on diagnostic findings, as both type I and type II muscle fibers types need to be exercised with overload strategies. The frequency and the number of repetitions of exercises should be selected following assessment of the pelvic floor muscles. Daily regimes of increasing repetitions to the point of fatigue seem to be recommended (8-12 maximal pelvic floor muscle contractions, 3 times a day for 6 months) ${ }^{25}$ It is important to select relevant starting positions while training and functional activities must be incorporated into the exercise programme. ${ }^{20}$

Improvement of absolute power and endurance of the pelvic floor does not guarantee a correct function of the continence mechanism. A process of patient awareness of isolated contractions to fully automatic controlled function of the pelvic floor during multiple complex tasks is required. ${ }^{22}$ Exercises at home, after instruction, are essential; motivation of patient and physiotherapist are essential conditions for successful pelvic floor muscle exercises. ${ }^{18.37}$

\section{Indivldual physiotherapeutic training versus training in groups}

Pelvic floor muscle exercises can be applied individually or in groups. Bø compared, after 6 months, the effects of special pelvic floor muscle training programmes in groups of women using a home exercise regimen on two similar groups of women with genuine stress incontinence. In one group, patients followed a special pelvic floor muscle exercise course, training with instructor in groups 45 minutes once a week for 6 months and these patients were asked to perform 8-12 strong pelvic floor muscle contractions three times a day for 6 months ('intensive exercise'). Another similar group of women did the same exercise regimen without the group training (' home exercise only'). The results after the intensive regimen were significantly better than after the home exercise regimen. ${ }^{25}$

Borghuis ${ }^{43}$ stated that if pelvic floor muscle exercises is indicated and the patient or physiotherapist has no preference for individual therapy, physiotherapeutic training in groups can be the choice. In her training programme, Borghuis offers over a 6 months-period, 9 sessions of two hours each, giving patients sufficient opportunity to learn the exercises. ${ }^{43} \mathrm{~A}$ physiotherapist supervises the group; however, other care providers, like the general practitioner, the sex therapist or the psychotherapist are involved in the training programme. Advantages of pelvic floor training in groups are the long periods of each session, which give patients more opportunity to ask questions, the contact between patients with the same problem, the demolishing of taboos ('we didn't know that we had the same problems'), mutual motivation and support. ${ }^{43}$ In a pilot-study, the conclusion was that individual pelvic floor muscle exercises and in groups are equally effective in the treatment of genuine stress incontinence and that for selected patients such group physiotherapy is of high 
value; however, these results need a more solid scientific base. ${ }^{43}$ Research on the effects of the physiotherapy programme of Borghuis is in progress at this moment. ${ }^{44}$

\section{Biofeedback}

Biofeedback is based on the principle of operant conditioning. ${ }^{18}$ After positive confirmation, behaviour will be encouraged; after negative confirmation, behaviour will be discouraged. Biofeedback involves the use of several audiovisual techniques, which inform the patient about the activity of striated muscles while trying to control the function of these muscles. Biofeedback can support a selective contraction of the pelvic floor muscles. A vaginal or anal electrode records and displays a visual or acoustic reading of the vaginal or anal pressure, or of the sphincter ani-EMG. It is important torecognise that biofeedback is an addition to other treatment modalities; it is no therapy in itselt. Reviewing different forms of biofeedback, a range of $54 \%-95 \%$ improvement of genuine stress incontinence is reported; ${ }^{46}$ however, the effect of adding biofeedback to pelvic floor muscle exercises is still controversial. ${ }^{45}$ Berghmans et al. ${ }^{18}$ concluded after direct comparison that pelvic floor muscle exercises with biofeedback is no more effective than pelvic floor muscle exercises alone. Although progress was quicker in the initial phase of the physiotherapy intervention when pelvic floor muscle exercises was combined with biofeedback, at the end of therapy there were no differences between both groups. This result is in contrast to the findings of a review by De Kruif and Van Wegen; ${ }^{46}$ although only few RCTs were identified and no conclusive evidence was presented, they reported a trend for pelvic floor muscle exercises with biofeedback being more effective than pelvic floor muscle exercises alone for women with genuine stress incontinence. Burgio et al. ${ }^{47}$ compared two different types of biofeedback, i.e. pelvic floor muscle exercises with visual biofeedback versus pelvic floor muscle exercises with verbal feedback during vaginal palpation; both groups in this study showed a significant reduction in the frequency of incontinence episodes per week, with the reduction being significantly greater in the visual biofeedback group (visual biofeedback group $76 \%$ reduction vs $51 \%$ in the verbal feedback group). Burgio et al. also noted that the visual biofeedback group improved in strength and selective control of pelvic floor muscles, whilst the verbal feedback group did not. In contrast, Berghmans ${ }^{34}$ concluded that there is limited evidence that visual biofeedback is superior to verbal feedback, but this may be worthy of further investigation (see Table 5). The reason that comparisons between pelvic floor muscle exercises with biofeedback and pelvic floor muscle exercises alone have often showed no significance, may be because of small sample sizes and possible type II-errors in relevant studies, and/or the lack of specificity in the identification of patients who might benefit most by receiving biofeedback. It is possible that biofeedback as an adjunct to pelvic floor muscle exercises is more effective than pelvic floor muscle exercises alone in patients with insufficient or no awareness how to contract the pelvic floor muscles correctly. ${ }^{9,18}$ In larger studies and/or if patients with these problems could be selected by appropriate diagnostic procedures, it could be possible to identify whether (and to what extent) biofeedback is beneficial as an adjunct to pelvic floor muscle exercises in treating genuine stress incontinence.

\section{Vaginal cones}

In women vaginal cones can be used as an addition to pelvic floor muscle exercises, providing proprioceptive feedback. The patient uses a set of cones of equal proportions, but of successively greater weight. In a standard procedure, the woman 
applies, twice daily, the selected cone into the vagina, as a part of the training programme. Next, she tries to hold the cone for 15 minutes by contracting the pelvic floor muscles. Once successful on two consecutive occasions, she proceeds to the next heaviest weight. ${ }^{31}$ Peattie et al. ${ }^{48}$ reported significant improvement in strength of the pelvic floor muscles of premenopausal women (as determined by cone retention) as well as high correlations between decreased urine loss and increase in retaining cone weights.

In several studies the success rate for vaginal cones in women with genuine stress incontinence varied between $68 \%-79 \%$ after four weeks..$^{24,40-49}$ Mostly these results concerned premenopausal women, so extrapolation to older women is not possible. ${ }^{1}$ In the review of Berghmans et al. ${ }^{34}$ only one randomised clinical trial (RCT) of vaginal cones was identified, but cones were combined with pelvic floor muscle exercises and compared with a group receiving electrical stimulation with pelvic floor muscle exercises. ${ }^{49}$ Results of the effects of cone therapy alone have not yet been reported in any $\mathrm{RCT}$. $\mathrm{B} \emptyset^{50}$ has questioned the theoretical basis for cone therapy; further work needs to be done to evaluate the role of vaginal cones in treating genuine stress incontinence. ${ }^{31,37}$

\section{Electrlcal stimulation}

Electrical stimulation focuses on the restoration of reflex activity by excitation of the pudendal nerves in order to create a pelvic floor muscle contraction. ${ }^{51}$ If the pudendal nerve is intact, electrical stimulation may induce a motor-response in patients where voluntary contraction of the pelvic floor muscles is problematic and may be useful in the re-education of insufficient pelvic floor muscles. ${ }^{51}$ According to this concept, adequate electrical stimulation provides reflex contraction of striated para-and periurethral muscles based on afferent excitation of the pelvic floor. Also, direct excitation of efferent fibres of the pudendal nerve can lead to contraction of the levator ani muscle and of the external urethral sphincter. In addition, this may affect the urethral closing mechanism, ${ }^{51-52}$ together with excitation of hypogastric fibres, which activate periurethral smooth muscles. ${ }^{53}$ Excitation of efferent fibres of the pelvic nerve seems to increase the intraluminal urethral pressure. ${ }^{51.53-54}$

Electrostimulation may also support the transformation from fatigable fibres to fatigue- resistent fibres. ${ }^{55}$ The physiological mechanism of electrical stimulation still remains unclear. Electrostimulation may have a role in creating a better awareness of a correct contraction of the pelvic floor. Therefore, selection and appropriate combination of the many available parameters is important, offering an adequate response in the pelvic floor muscles. Electrostimulation may provide a (cognitive) important first step to a functional physiotherapy programme, focused on the restoration of the load-bearing capacity of the pelvic floor. ${ }^{34,37}$ In those patients with genuine stress incontinence and dysfunction of the pelvic floor without awareness of the pelvic floor electrical stimulation is the therapy of first choice. ${ }^{37.56}$ It may also be that electrical stimulation is particularly appropriate for patients who are initially unable to contract their pelvic floor muscles, but once active contraction is possible with stimulation, pelvic floor muscle exercises may be more effective..$^{37}$ In physiotherapy, different categories of electrical stimulation are distinguished, i.e. short-term maximal electrical stimulation and low-intensity long term electrical stimulation, often applied at home by the patient him- or herself. Electrostimulation has a few side effects, such as pain and damage of tissue ${ }^{51}$ a pacemaker and pregnancy are also contra-indications. ${ }^{54}$ In the literature, successful electrical stimulation in patients with genuine stress incontinence has been reported in $37 \%$ - 
$92 \%$ of cases. ${ }^{34}$ However, most of these results are based on studies without controls and with poor methodological quality. The most noticeable factor about trials of electrical stimulation is the considerable variation in types of electrical stimulation used. Trials investigated intravaginal or extravaginal stimulation, interferential or neurotrophic stimulation, maximal or low-intensity long term stimulation; no trial has replicated the intervention of another. ${ }^{34}$ In view of this variability, results should be interpreted with caution. Trends in the evidence suggest that active stimulation is more effective than sham stimulation, but electrical stimulation may be no more effective than pelvic floor muscle exercises alone or other physiotherapies (see Table 5). ${ }^{2}$ Wilson ${ }^{31}$ concluded that the addition of electrotherapy does not offer any significant advantages. It seems that further investigation of electrical stimulation is required in order to establish its efficacy for genuine stress incontinence, a view also supported by other authors. ${ }^{20,33,37}$

\section{Patient education in physiotherapy practice}

In order to achieve a permanent positive result from physiotherapy, patients have to incorporate the newly acquired abilities into daily life. The physiotherapist is the most important mentor in this behavioural modification. Patient education is a very important aspect of this kind of care and a professional attitude towards providing patient education is required. Van der Burgt and Verhulst ${ }^{57}$ developed a model for allied health professions as an instrumental tool for patient education. This model is a combination of the ASE-model and the so-called Steps-model of Hoenen et al., developed for individual patient education. ${ }^{57}$ In the ASE-model the premise is that the interplay between attitude, social influence and own efficacy determines the willingness to modify behavior (see Table 6).

Table 6. Parallels between the ASE-model and the Steps-model.

be open $\rightarrow$ understand $\rightarrow$ intention $\longrightarrow$ maintenance of behaviour

Adapted from Van der Burgt ${ }^{57}$

In the model of Van der Burgt and Verhulst, a number of stages are distinguished, such as 'thinking', 'feeling', and 'doing'. In patients with genuine stress incontinence this model can be transformed into an exchange of information and explanation ('thinking'), in awareness and feeling of the pelvic floor, posture and movement ('feeling') and in training of the pelvic floor and promotion of short and long term compliance ('doing'). The standardized patient education model of van der Burgt and Verhulst can be seen as an example of how to facilitate 'best practice' and thus can provide physiotherapists with a framework upon which to base patient education in genuine stress incontinence.

\section{Conclusion}

In the Netherlands physiotherapy practice for genuine stress incontinence is based upon the National Practice Guideline 'Stress urinary incontinence in adults'. 
Development of guidelines is important, not only to ensure the quality of physiotherapy practice, but also because uniformity of evidence-based diagnosis and treatment will be stimulated. Additionally, other health care providers will gain more insight into physiotherapy.

In the Dutch health care system, referral by a physician to a physiotherapist is always necessary. Professional cooperation between referring physicians and physiotherapists is required in order to determine the indication for physiotherapy. Based on the diagnostic process, determining the nature of the underlying pathology causing genuine stress incontinence, still remains more or less unclear. Therefore, the question whether or not, and to what extent, physiotherapy can be helpful in the management of genuine stress incontinence cannot always be answered definitively. In these cases, physiotherapy is given as a 'pilot-treatment'. pelvic floor muscle exercises are effective in the reduction of involuntary urine loss in patients with genuine stress incontinence. Despite this, more randomised, controlled studies with optimal exercise protocols are needed to evaluate the effects of physiotherapy on genuine stress incontinence. Further research of high methodological quality on the efficacy of (other) physiotherapy modalities (biofeedback, vaginal cones, electrical stimulation) is also necessary. These National Physical Therapy Practice Guidelines reflect the current state of knowledge, at the time of the publication, on effective and appropriate care for patients with genuine stress incontinence. They are subject to a continuous process of integration of new views, based on inevitable changes in the state of scientific information and technology.

\section{References}

1. Urinary Incontinence Guidelines Panel. Urinary incontinence in adults. Clinical Practice Guideline. AHCPR Pub. No.92-0038. Agency for Health Care Policy and Research, Public Health Service, US Department of Health and Human Services, Rockville, MD, 1992.

2. Guideline Panel. National Physical Therapy Practice Guidelines for stress urinary incontinence in adults. Royal Dutch Association for Physiotherapy, 1998.

3. Hendriks HJM, Ettekoven $H$ van, Wees Ph van der, Reitsma E. Centrale Richtlijnen voor het fysiotherapeutisch handelen. Eindverslag. KNGF. Amersfoort, the Netherlands, 1997.

4. WHO. International Classification of Diseases, 10th revision. Eastern-Jouva, 1992.

5. WHO. International Classification of Impairments, Activities and Participation. a manual of dimensions of disablement and functioning. Geneva, 1997.

6. Heerkens YF, Brandsma JW, Lakerveld-Heyl K, Ravensberg CD van. Impairments and disablities - The difference. Proposal for adjustment of the International Classification of Impairments, Disabilities, an Handicaps. Physical. Therapy 1994; 74: 430-41

7. Hendriks HJM., Brandsma JW, Heerkens YF, Oostendorp RAB, Nelson RM. Intra-observer and inter-observer reliability of assessment of impairments and disabilities. Physical Therapy 1997; 77: $1097-106$

8. International Continence Society Committee for the Standardization of Terminology of the Lower Urinary Tract Function. Br. J. Obstet Gynaecol 1990; suppl 6

9. Wall LL, Davidson TG. The role of muscular re-education by physical therapy in the treatment of GSI. Obstet Gynecol Surv 1992; $47: 322-31$

10. De Bruin AJJ. In Incontinentie en hulpverlening. Houten/Antwerpen. Bohn Stafleu Van Loghum, 1990.

11. Smith ARB, Hosker GL, Warell DW. The role of pudendal nerve damage in the aetiology of GSI in women. Br. J. Obstet Gynaecol 1989; 96: 29-32

12. DeLancey JOL. Stress urinary incontinence. Where are we now, where should we go? Am J Obstet Gynecol 1996; 175: 311-19

13. Debruyne FMJ, Kerrebroeck PhEVA van. Practical aspects of urinary incontinence. Martinus Nijhoff, 1986.

14. Lagro-Janssen ALM. Urine-incontinentie bij vrouwen in de huisartspraktijk. Thesis Katholieke Universiteit Nijmegen, the Netherlands 1989. 
15. Wells TJ, Brink CA, Diokno AC, Wolfe R, Gillis GL. Pelvic muscle exercise for stress urinary incontinence in elderly women. JAGS 1991; 39: 785-91

16. Tapp AJS, Hills B, Cardozo LD. Randomized study comparing pelvic floor physiotherapy with the Burch colposuspension. Neurourol Urodyn 1989; 8: 356-57

17. Mulder AFP, Vierhout ME. De Inco-test. Medicus 1990: 264

18. Berghmans LCM, Frederiks CM.A, Bie RA de, Weil EHJ, Smeets LWH, Waalwijk van Doom ESC van, Janknegt RA. Efficacy of biofeedback, when included with pelvic floor muscle exercise treatment, for genuine stress incontinence. Neurourol Urodynam 1996; 15: 37-52

19. Bø K, Stien R. Needle EMG registration of striated urethral wall and pelvic floor muscle activity patterns during cough, Vasalva, abdominal hip adductor, and gluteal muscle contractions in nulliparous healthy females. Neurourol Urodyn 1994; 13: 35-41

20. Wallace K. Female pelvic floor functions, dysfunctions, and behavioral approaches to treatment. Clin Sports Med 1994; 13: 459-81

21. Walter $S$, Kjaergaard B, Lose G. Stress urinary incontinence in postmenopausal women treated with oral estrogen (estriol) and an alpha adrenoreceptor stimulating agent

(phenylpropanolamine). A randomized double blind placebo controlled study. Int Urol Gynecol J 1990; 1: 74-75

22. Versprille ES. Begeleiding van patiënten met bekkenbodemdysfunctie. Edited by Versprille ES Utrecht. De Tijdstroom, 1995.

23. McGuire EJ. Stress incontinence. New altematives. Int J Fert 1996; 41: $142-47$

24. Wilson PD, Samarrai TA, Deakin M, Kolbe E, Brown ADG. An objective assessment of physiotherapy for female genuine stress incontinence. Br J Obstet Gynaecol 1987; 94: 575-82

25. Bø K, Hagen RH, Kvarstein B, Jorgensen J, Larsen S. Pelvic floor muscle exercise for the treatment of female stress urinary incontinence. III. Effects of two different degrees of pelvic floor muscle exercises. Neurourol Urodyn 1990; 9: 489-502

26. Hilton $P$. The role of urodynamics in pelvic floor re-education. In: Schussler $B$, Laycock $L$, Norton P, Stanton S (eds). Pelvic Floor Re-Education. London. Springer-Verlag 1994; 1: 57.

27. Tapp AJS, Cardozo L Hills B, Bamick C. Who benefits from physiotherapy? Neurourol Urodyn 1988; 7: 259-61

28. Henalla SM, Kirwan P, Castleden CM, Hutchins CJ, Breeson AJ. The effect of pelvic floor exercises in the treatment of genuine stress incontinence in women at two hospitals. Br J Obstet Gynaecol 1988; 95: 602-06

29. Berglund $\mathrm{AL}$, Eisemann M, Lalos O. Personality characteristics of stress incontinent women; $a$ pilot study. J Psychosom Obstet Gynecol 1994; 15: 165-70

30. Norton P. Aims of pelvic floor re-education. In Pelvic Floor Re-Education. Edited by Schūssler B, Laycock J, Norton P and Stanton S. London. Springer-Verlag, 1994.

31. Wilson PD. Conservative management of urethral sphincter incompetence. Clin Obstet Gynecol 1990; 33: 330-45

32. Rush CB, Entman SS. Pelvic organ prolapse and stress urinary incontinence. Med Clin North Am 1995; 79: $1473-79$

33. Fedorkow DM. Nonsurgical management of stress urinary incontinence. J SOGC 1993; 17: 695605

34. Berghmans LCM, Hendriks HJM, Bø K, Hay-Smith EJ, Bie RA de, Waalwijk van Doom ESC van. Conservative treatment of stress urinary incontinence. A systematic review of randomized clinical trials. Br J Urol 1998; 82: 181-191.

35. Bigos S, Bowyer O, Braen G. Acute low back problems in adults. Clinical practice guideline no. 14. AHCPR Publication no. 95-0642. Rockville, MD. Agency for Health Care Policy and Research, Public Health Services, U.S. Department of health and Human Services. December, 1995.

36. Tulder MW van. Diagnostics and treatment of chronic low back pain in primary care (Thesis VU Amsterdam). Amsterdam. Thesis Publishers, 1996

37. Bø K. Physiotherapy to treat genuine stress incontinence. Int Cont Surv 1996; 6: 2-8

38. Wilson D, Herbison P. Conservative management of incontinence. Curr Opin Obstet Gynecol 1995; 7: 386-92

39. DeLancey JOL. Anatomy and mechanics of structures around the vesical neck; how vesical neck position might affect its closure. Neurourol Urodyn 1988a; 7: 161-62.

40. DeLancey J. Structural aspects of urethrovesical function in the female. Neurourol Urodyn 1988b; 7: 509-19

41. Wells TJ. Pelvic (floor) muscle exercise. JAGS 1990; 38: 333-37

42. DiNubile NA. Strength training. Clin Sports Med 1991; 10: 33-62 
43. Borghuis ME, Lemain TTJ, Schreuder JLM. Groepsgewijze behandeling van vrouwen met incontinentieklachten. Fysiopraxis 1993; 8, 4-6

44. Miltenburg ThEM, Janssen T. Urine-incontinentie bij vrouwen en oefentherapie. Een vergelijkende studie naar de effecten van groepsgerichte en individuele oefentherapie. Onderzoeksvoorstel, 1994.

45. Bø K. Stress urinary incontinence, physical activity and pelvic floor muscle strength training. Scand J Med Sci Sports 1992; 2; 197-206

46. Kruif YP de, Wegen EEH van. Pelvic floor muscle exercise therapy with myofeedback for women with stress urinary incontinence; a meta-analysis. Physiotherapy 1996; 82: 107-13

47. Burgio KL, Courtland JC, Engel BT. The role of biofeedback in Kegel exercise training for SUI. Am J Obstet Gynecol 1986; 154: 58-64

48. Peattie AB, Plevnic S, Stanton SL. Vaginal cones; a conservative method of treating genuine stress incontinence. Br J Obstet Gynaecol 1989; 95: 1049-53

49. Olah KS, Bridges N, Denning J, Farrar DJ. The conservative management of patients with symptoms of stress incontinence; a randomized prospective study comparing weighted vaginal cones and interferential therapy. Am J Obstet Gynecol 1990; 162: 87-92

50. Bø K. Vaginal weight cones. Theoretical framework, effect on pelvic floor muscle strength and female SUI. Acta Obstet Gynecol Scand 1995; 74: 87-92

51. Eriksen BC. Electrostimulation of the pelvic floor in female urinary incontinence. Thesis University of Trondheim, Norway 1989.

52. Erlandson BE, Fall M, Carlsson CA, Linder LE. Mechanisms for closure of the human urethra during intravaginal electrical stimulation. Scand J Urol Nephrol 1978; 44 suppl: $49-54$

53. Fall $\mathrm{M}$, Erlandson $\mathrm{BE}$, Carlsson $\mathrm{CA}$, Lindström $\mathrm{S}$. The effect of intravaginal electrical stimulation of the feline urethra and urinary bladder. Neuronal mechanisms. Scand J Urol Nephrol 1977; 44 suppl: $19-30$

54. Fall $\mathrm{M}$, Lindström $\mathrm{S}$. Electrical stimulation; a physiologic approach to the treatment of urinary incontinence. Urol Clin North Am 1991; 18: 393-407

55. Pette D, Vrbova G. Invited review. Neural control of phenotypic expression in mammalian muscle fibres. Muscle Nerve 1985; 8: 676-89

56. Bourcier AP, Juras JC. Nonsurgical therapy for stress incontinence. Urol Clin North Am 1995; 22: 613-27

57. Burgt $M$ van der, Verhulst $F$. Gedragsmodellen. In: Burgt $M$ van der, Verhulst $F$ (eds). Doen en blijven doen. Houten. Bohn Stafleu Van Loghum, 1996; 31. 


\section{Conservative treatment of urge urinary incontinence in women: a systematic review of randomized clinical trials*}

LCM Berghmans, MSc, RPt (1), HJM Hendriks, PhD, RPt (2),

RA de Bie, PhD, MSc, RPt (3), ESC van Waalwijk van Doom, PhD, DSc (1),

$\mathrm{K}$ Bø PhD, RPt, EXSCIENT (4), PhEVA van Kerrebroeck, PhD, MD (1)

1 Department of Urology, University Hospital Maastricht, Maastricht, the Netherlands

2 Dutch National Institute of Allied Health Professions Amersfoort, the Netherlands

3 Department of Epidemiology, Maastricht University, Maastricht, the Netherlands

4 Norwegian University of Sport \& Physical Education, Oslo, Norway 


\section{Abstract}

Objective To assess the efficacy of physical therapies for first-line use in the treatment of urge urinary incontinence (UUI) in women, using a systematic review of randomized clinical trials (RCTs).

Materials and methods A computer-aided and manual search was carried out for RCTs, published between 1980 and 1999 investigating treatment of urge urinary incontinence defined by the key words 'physical therapies', e.g. bladder (re)training (including "behavioural" treatment), pelvic floor muscle (PFM) exercises, with or without biofeedback and/or electrical stimulation, was carried out. The methodological quality of the included trials was assessed using methodological criteria, based on generally accepted principles of interventional research.

Results Fifteen RCTs were identified; the methodological quality of the studies was moderate, with a median (range) score of 6 (3-8.5) (maximum possible 10). Eight RCTs were considered of sufficient quality, i.e. an internal validity score of $\geq 5.5$ on a scale of 0-10 points, and were included in a further analysis. Based on levels-ofevidence criteria, there is weak evidence to suggest that bladder (re)training is more effective than no treatment (controls), and there is weak evidence that bladder (re)training is better than drug therapy. Stimulation types and parameters in the studies of electrical stimulation are heterogeneous. There is insufficient evidence that electrical stimulation is more effective than sham electrical stimulation. To date there are too few studies to evaluate effects of exercise with or without biofeedback and of toilet training for women with urge urinary incontinence.

Conclusion Although almost all studies included reported positive results in favour of physical therapies for the treatment of urge urinary incontinence, more research of high methodological high quality is required to evaluate the effects of each method in the range of physical therapies.

Key words Lower urinary tract, systematic review, urinary urge incontinence, physical therapy, overactive bladder, biofeedback, electrical stimulation. 


\section{Introduction}

Urinary incontinence (UI) is defined as the involuntary loss of urine, which is objectively demonstrable, with such a degree of severity that it is a social or hygienic problem. ${ }^{1}$ Urinary incontinence is a highly prevalent disorder that affects millions of people worldwide. Urinary incontinence affects about $15 \%$ of the ambulatory adult population and is frequently accompanied by depression, stigmatization and a significantly worse perceived quality of life than in healthy individuals. ${ }^{2}$ However, a large proportion of individuals do not report this health problem to their physicians, perhaps because of embarrassment or because of the mistaken notion that no effective treatment is available. ${ }^{3}$

Even though urinary incontinence is a common condition and the object of intensive research, there is still considerable lack of consistency among epidemiologists about the prevalence, risk factors and natural history of this condition. ${ }^{4}$ There are different types of urinary incontinence. The most common type in women is stress urinary incontinence (SUI), with an estimated prevalence of $8-33 \% .^{4-6}$ According to the ICS terminology, stress urinary incontinence is the involuntary urethral loss of urine when the intravesical pressure exceeds the maximum urethral pressure but in the absence of detrusor activity'. ${ }^{1}$ Reviewing the literature, Hampel et al. ${ }^{4}$ stated that nearly half of the women with urinary incontinence suffered from symptoms of stress urinary incontinence (49\%). The second most common type of symptoms related to urinary incontinence, i.e. urge urinary incontinence, accounted for $22 \%$ of urinary incontinence in women and is symptomatically described as the involuntary loss of urine associated with a strong desire to void (urgency). ${ }^{4,7}$ Urgency as a symptom of strong desire to void may be associated with two possible dysfunctions; either related to bladder overactivity (motor urgency) or hypersensitivity (sensory urge). ${ }^{1,4}$ From urodynamic studies including urethral pressure measurement there is a strong indication that sensory urgency is strongly related to urethral relaxations. ${ }^{8}$ The moments of occurrence are mostly unpredictable, in contrast to stress urinary incontinence, causing a greater effect on quality of life. ${ }^{9}$

Clinical experience has shown that an overactive bladder function with associated urge urinary incontinence is not amenable to surgical correction. ${ }^{10-11}$ Therefore it is important to find another satisfactory treatment modality for patients with this problem. Pharmaceutical agents in general lead to disappointing results, with success rates of only $30-45 \%$ for any single agent. Although combination therapy is claimed to be more successful, the use of drugs produces many side-effects, inevitably compromising compliance and causing the recurrence of incontinence. ${ }^{10,12}$ In the USA, the Clinical Guideline Panel ${ }^{13}$ stated that in general the least invasive and least dangerous procedure that is appropriate for diagnosis and treatment of a patient with urinary incontinence should be the first option. Conservative treatments, as physical therapy, report limited side-effects and do not exclude future options. These techniques can improve and eventually restore pelvic floor function and bladder function control. ${ }^{13}$ Additionally, physical therapy can increase the patient' understanding of lower urinary tract (dys)function.

The theoretical basis of how physical therapy for the treatment of urge urinary incontinence works remains unclear. Is it the change in pelvic floor muscle activity during exercises that automatically inhibits or better prevents detrusor overactivity? Is it a learning that makes the patient aware of contracting the pelvic floor muscle during urge to inhibit involuntary detrusor contraction (reciprocal inhibition)? Will an increase in strenght of the pelvic floor muscle provide more inhibition of the 
overactivity of the bladder? ${ }^{14}$ The different physiotherapeutic treatment modalities are therefore still based on hypotheses for the underlying pathologies causing bladder overactivity. However, clinical experience has shown that different physical therapy treatment modalities generally will provide some progress in most individuals with bladder overactivity. Bladder control can be improved even in the cognitively impaired individual. ${ }^{15-18}$

The different physical therapy modalities for the treatment of bladder overactivity consist of toilet training, bladder (re)training, pelvic floor muscle exercises with or without treatment adjuncts such as biofeedback or electrical stimulation (ES) and electrical stimulation alone. Toilet training is most feasable in an institutionalized population with lower urinary tract dysfunctions. In that environment, not only will a reduction in the loss of urine per individual be important, but so will the lower cost absorption materials and of incontinence-related care by health care providers. Bladder training generally consists of a 'behavioural' intervention, a programme of patient education addressing lower urinary tract function and a schedule of voluntary micturition. The educational programme emphasizes the neurological (cerebral) control of lower urinary tract function. The voiding schedule involves training to inhibit the sensation of urgency and postpone voiding, and to urinate according to a timetable. The goal is to attain a longer interval between two consecutive voids with larger voided volumes. It is essential that the therapist encourages the patient to succeed. ${ }^{13,19}$ The training of selective contraction of the pelvic floor muscles influences and probably restores or facilitates the detrusor-inhibition reflex, which may restore normal function. ${ }^{19}$

For bladder overactivity, pelvic floor muscle exercises may be combined with biofeedback and/or electrical stimulation. ${ }^{20-21}$ Moreover, some authors suggested that electrical stimulation can be applied as a sole therapy. ${ }^{22-24}$ Biofeedback can support pelvic floor muscle exercises by providing the patient with information about (mostly) unconscious physiological processes. This information comprises the basis for active self-control over the processes which are being monitored.

Electrical stimulation of pelvic floor muscles is suggested to induce a reflex contraction of the striated para- and periurethral muscles, accompanied by a simultaneous reflex inhibition of the detrusor muscle. This reciprocal response depends on a preserved reflex arc through the sacral micturition reflex centre. To obtain a therapeutic effect of pelvic floor stimulation in women with detrusor overactivity, peripheral innervation of the pelvic floor muscles must at least be partly intact. ${ }^{23}$ Electrical stimulation therapy alone, both external or internal, is suggested to permit an effective reduction or inhibition of detrusor activity by stimulating afferents of the pudendal nerve..$^{22-23,25}$ Electrical stimulation is generally administered with a removable device through vaginal or anal stimulation.

Because the value in terms of efficacy of conservative treatment of urge urinary incontinence in women is unknown, we systematically reviewed published reports to determine the efficacy of these treatments.

\section{Materials and methods}

\section{Literature search strategy}

The following computerized bibliographic databases were searched (1980-1999):

Medline, Excerpta Medica, the database of the Dutch National Institute of Allied Health Professions, and the database of the Cochrane Rehabilitation and Related Therapies Field at Maastricht University. Key words representing impairments and 
disabilities were incontinence, urinary incontinence, detrusor instability, urge urinary incontinence, motor urgency and motor urge incontinence, frequency, and nocturia. Key words representing the intervention were conservative management, conservative treatment, surgical and nonsurgical treatment, bladder (re)training, behavioural modification, behavioural treatment, physiotherapy, pelvic floor muscle exercises, and all specific modalities (biofeedback, myofeedback and electrical stimulation). Key words for the design were RCTs, controlled trials, evaluation, effectiveness, efficacy and outcome studies. Citation tracking and review of the proceedings of ICS meetings from 1980 to 1998 were undertaken. Several databases not on computer were also screened (e.g. Physiotherapy Index), with those physiotherapy journals not covered by Medline. Finally, experts in this field were consulted for additional information.

\section{Selectlon criteria}

Studies were included after confirming the following criteria: (i) design: explanatory (placebo or no-treatment comparison) or pragmatic (experimental intervention compared with a standard /active intervention) randomized trial; (ii) results in women with urge urinary incontinence were reported, either exclusively or separately; the study investigated conservative management for the treatment of urge urinary incontinence; (iii) interventions included bladder training or pelvic floor muscle exercises, biofeedback and/or electrical stimulation; (iv) reliable and clinically relevant outcome measures were used of the problem under investigation; (v) the trial report was published in English, German or Dutch. Unpublished studies and abstracts were excluded.

\section{Methodological quality of the studies}

Two independent reviewers (LB, HH) assessed all RCTs for inclusion and methodological quality. Disagreements were resolved by consensus and when required a third reviewer (RdB) made the final decision. Other reviews ${ }^{25 \cdot 28}$ were consulted to validate the list of studies included. The quality of studies was assessed using a modified list of predefined methodological criteria, ${ }^{27-29}$ based on generally accepted principles of interventional research. ${ }^{30-32}$ These criteria assess internal and external validity and statistical power (Table 1).

Table 1. Criteria for assessing methods in randomized clinical trials of conservative treatment of (motor) urge urinary incontinence in women. Adapted from Kleijnen et al. ${ }^{28-20}$

\section{Code Criterion}

A: Well-described inclusion criteria (diagnostic criteria, duration and severity of disease, and previous treatment)

8: At least 50 patients per group

C: Prestratification (prognostic variables)

D: Random allocation procedure described

E: Presentation of relevant baseline characteristics

$\mathrm{F}$ : $\quad<10 \%$ withdrawals and withdrawals described

G: Blinding (patients, therapist, observer) ( 0 of $3=0 \mathrm{pts} ; 1$ of $3=0.5 \mathrm{pts} ; 2$ or 3 of $3=1 \mathrm{pts}$ )

$\mathrm{H}$ : Interventions well described (nature, number, duration of treatments)

I: $\quad$ Effect/outcome measurements relevant and well described

$\mathrm{J}$ : Analysis and presentation of the results so that the analysis can be assessed (intention to treat, depending on the outcome measurement: at least the mean and SD, SEM, or Cl per group, or, if rates or proportions are used, the number of patients with a certain outcome 
A score of one point (+) was given to each criterion fulfilled, and zero (-) if not. Criteria were graded with 0.5 point $( \pm)$ if the description was unclear, or if criteria were incompletely fulfilled. The maximum methodological quality score (MQS) was 10 points. After assessment, a hierarchical MQS list was generated; a higher MQS indicates that a study has a higher methodological quality.

\section{Levels of evidence}

The results of the methodological assessment and the data-extraction were combined in a level-of-evidence synthesis, that allows systematic conclusions about the efficacy of physiotherapeutic interventions for urge urinary incontinence. Several methods for best-evidence synthesis are reported; the present method is partly based on previous work from Bronfor ${ }^{33}$ and Van Tulder et al. ${ }^{34}$ The available evidence was evaluated according to the internal validity of the reviewed trials, the statistical significance of the results and the ratio of positive and negative studies. Studies reaching an internal validity score of $\geq 5.5$ points were regarded as being of sufficient methodological quality, whereas the remainder were considered to have inadequate methodological quality. Consequently, studies where ranked according to the levels-of-evidence principle, in which studies with sufficient methodological quality and statistical significant or clinically relevant results in a 3:1 ratio were considered to deliver strong evidence for effectiveness.

To distinguish levels of evidence the following decision rules were applied:

(i) to conclude there is strong evidence for or against a physiotherapeutic intervention for urge urinary incontinence at least three high-quality studies, i.e. studies with an internal validity score of $\geq 5.5$ points, with consistent results in favour of or opposing the intervention are needed. Such results were considered consistent when the pooled-effect estimate showed a clinically relevant or a statistically significant result in favour of the intervention or opposing it for at least one outcome measure, or when at least $75 \%$ of the included studies were categorized as positive or negative, respectively. A study was considered respectively positive or negative when it showed a clinically important or a statistically significant result in favour of or opposing the intervention for at least one outcome measure.

(ii) To conclude there is weak evidence for a physiotherapeutic intervention for urge urinary incontinence at least three high-quality studies with inconsistent results, or at least three low-quality studies with consistent results in favour of intervention were needed. Results were considered inconsistent across studies when $25-75 \%$ of them were considered positive.

(iii) To conclude there is weak evidence against a physiotherapeutic intervention for urge urinary incontinence at least three low-quality studies with consistent results against the intervention were needed. Such results were considered consistent when the pooled-effect estimate showed a clinically important or a statistically significant result against the intervention for at least one outcome measure, or when $\leq 25 \%$ of these studies were considered positive.

There was insufficient evidence for the intervention when there were low-quality studies with inconsistent results or with fewer than three studies of whatever quality. 


\section{Results}

\section{Included and excluded studies}

The literature search yielded 81 publications, of which 16 were abstracts. A total of 15 RCTs met all inclusion criteria. ${ }^{35-49}$ In four studies only participants having urge urinary incontinence arising from detrusor instability were allowed to enter the study. ${ }^{35-38}$ The remaining 11 papers reported the inclusion of subgroups having urge urinary incontinence from detrusor instability or having mixed urinary incontinence. All RCTs reported the outcomes of various conservative interventions for the treatment of urge urinary incontinence (Table 2). Eight of the $15 \mathrm{RCTs}^{36-41,47-48}$ were considered to be explanatory, and seven were 'pragmatic'. 35,42-46,49

Table 2. The methodological scores assigned to the RCTs on the efficacy of conservative treatment $(N=15)$ of UUI, in order of methodological score.

Reference scores for methodological criteria Total*

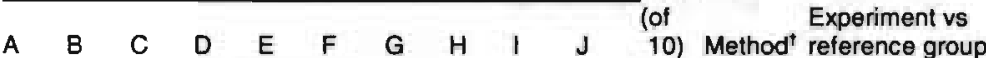

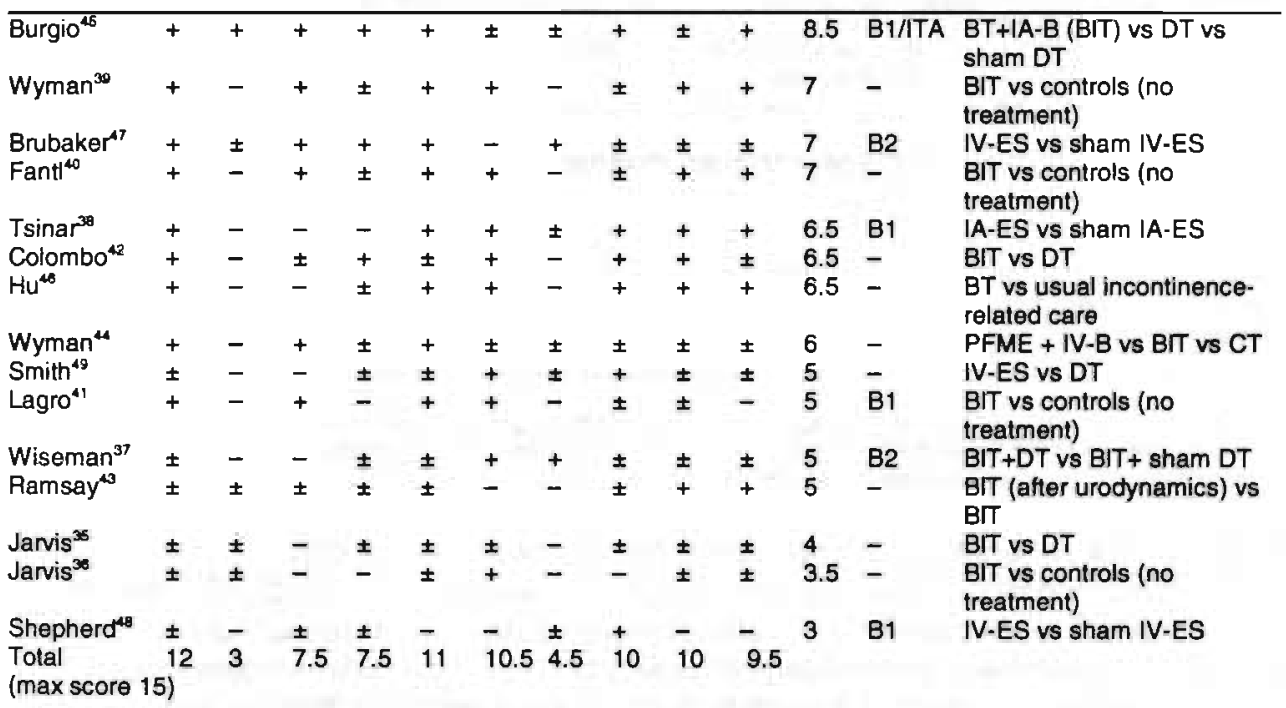

item score; + 1 point, \pm partly scored, 0.5 point, - no points

$\dagger B$, blinded, 1 single, 2 double; ITA, intention-to-treat analysis;

‡ IA, intra-anal; PFME, pelvic floor muscle exercise; IV, intravaginal; EV, extravaginal; BF, biofeedback; ES, electrical stimulation; BIT, bladder (re)training; BT, behavioural techniques; DT, drug therapy; CT, combination therapy; UUI, urge urinary incontinence.

\section{Methodological quality and outcome of the studies}

Table 2 shows the hierarchical order according to the MQS of all 15 included studies. The median (range) was 6 (3-8.5) out of a maximum of 10 points. Of the 10 methodological quality criteria, four $(B, C, D, G)$ had a total score of $\leq 7.5$ points from the maximum possible score of 15 points. Small sample sizes, lack of prestratification on prognostic determinants, lack of description of random allocation procedure, and (sub)optimal blinding were the main methodological shortcomings of the included trials. Eight of the 15 trials $(53 \%)$ scored $\geq 5.5$ points and were therefore 
classified as of 'sufficient' methodological quality. All remaining trials scored $<5.5$ points and were therefore classified as of 'low' methodological quality. Table 3 summarizes each of the included trials, giving a brief description of the participants. Description of outcomes, results and follow-up are complex and full details of these studies can be obtained from the first author on request.

Table 3 Briel details of the included RCTs (full details of treatments and outcome may be obtained from the first author on request).

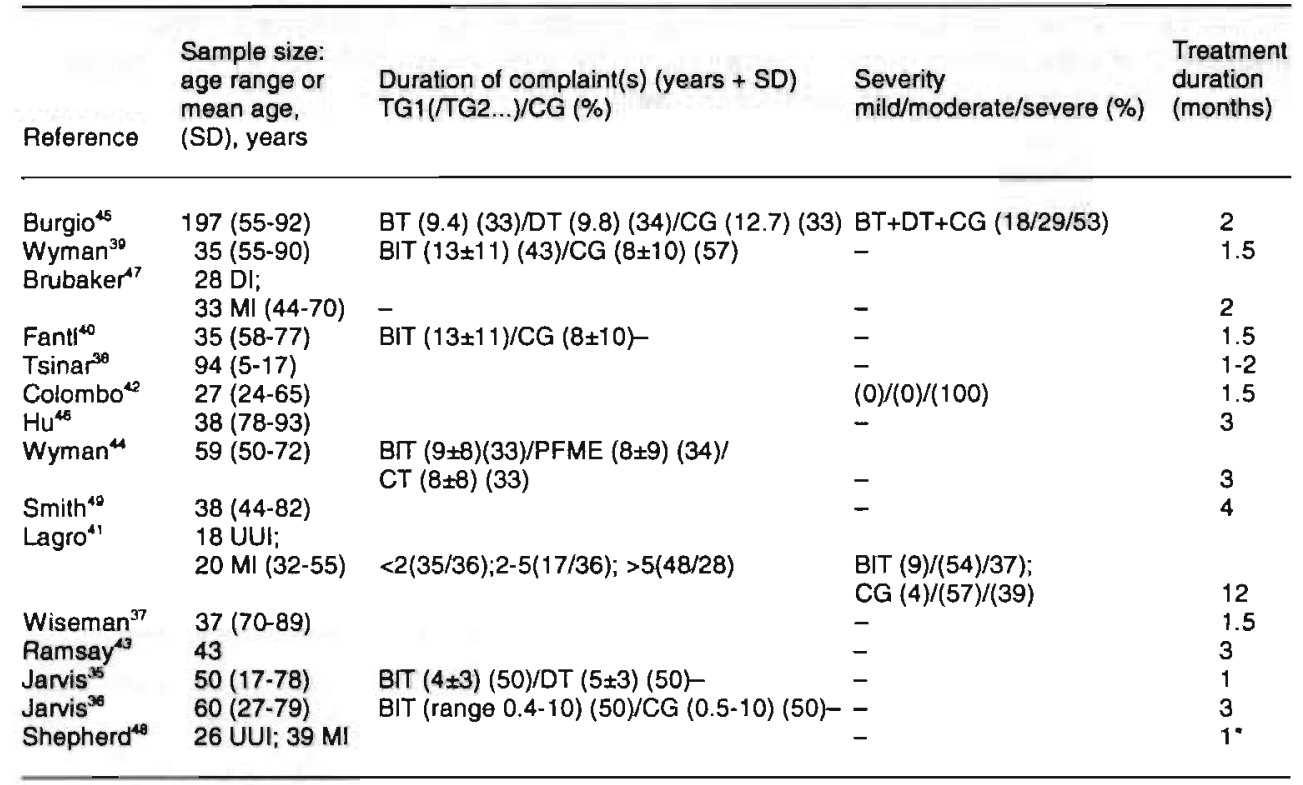

- one single therapy session; TG1, therapy group 1; TG2, therapy group 2; CG, control group; BT, behavioural techniques; DT, drug therapy; PFME, pelvic floor muscle exercises; CT combination therapy; DI, detrusor instability;UUI, urge urinary incontinence; MI, mixed incontinence.

\section{Efficacy of conservative interventions for the treatment of UUI}

Four trials compared bladder (re)training with no treatment (controls); ${ }^{36,39-41}$ two of these trials ${ }^{39-40}$ were of sufficient methodological quality (both with a MQS of 7). With two RCTs of sufficient methodological quality and two low-quality studies reporting results in favour of bladder (re)training, there is weak evidence that bladder (re)training is more effective than no treatment (controls).

Two RCTs of sufficient methodological quality ${ }^{42.45}$ with a MQS of 6.5 points and 8.5 points, respectively, and one RCT of low methodological quality ${ }^{35}$ compared bladder (re)training with drug therapy (oxybutynin in the first two trials and a combination of flavoxate hydrochloride and imipramine in the last). In all three trials it was reported that bladder (re)training was superior to drug therapy. There is weak evidence that bladder (re)training is more effective than drug therapy.

Only one RCT of low quality ${ }^{37}$ was identified that compared bladder (re)training and drug therapy (terodiline) with bladder (re)training and placebo. There is insufficient evidence that a combination of bladder (re)training and drug therapy is more effective than bladder (re)training combined with a placebo.

In a low-quality $\mathrm{RCT}^{43}$ bladder (re)training with prior urodynamics was compared with bladder (re)training with no urodynamics. There was no significant difference for any variable between the groups. With only one RCT of low methodological quality, 
evidence for the efficacy of bladder (re)training with prior urodynamics over bladder (re)training alone is insufficient.

There was one trial of sufficient methodological quality (MQS 6 points) comparing bladder (re)training with biofeedback-assisted pelvic floor muscle exercises and with combination therapy. ${ }^{39}$ Although the combined therapy was the most effective immediately after treatment, each of the three interventions had a similar effect 3 months after treatment. Because only one such trial could be identified, the evidence in favour of one of the three interventions compared with the other two is insufficient. There was one trial comparing bladder (re)training (biofeedback-assisted 'behavioural' treatment) with placebo drug therapy. ${ }^{45}$ This trial was of sufficient methodological quality ( 8.5 points). Biofeedback-assisted bladder (re)training was reported to be significantly more effective than placebo drug therapy. However, with only one such RCT, there is insufficient evidence that (biofeedback-assisted) bladder (re)training is better than placebo drug therapy.

In one trial of sufficient methodological quality (MQS 6.5 points) ${ }^{46}$ the efficacy of 'behavioural' treatment (a programme of hourly checking and prompting of individuals to urinate) was compared with routine incontinence-related care. Although the results were in favour of 'behavioural' treatment, because only one relevant RCT was identified there is insufficient evidence for 'behavioural' treatment is better than routine incontinence-related care.

Table 4. Levels of evidence of efficacy of different conservative treatment modalities.

Level Efficacy

\section{Conservatlve treatment \\ Strong - not found \\ Weak - BIT is more effective than no treatment (controls) \\ - BIT is more effective than drug therapy \\ Insufficient - Combination of BIT and drug therapy is more effective than BIT with placebo \\ - BIT with prior urodynamics is more effective than BIT alone \\ - Combination of BIT and biofeedback-assisted PFME is more effective than BIT or PFME alone \\ - Biofeedback-assisted 'behavioural' treatment is more effective than drug therapy or placebo \\ - 'Behavioural' treatment is more effective than usual incontinence-related care \\ - Electrical stimulation is more effective than sham electrical stimulation \\ - Electrical stimulation is more (or less) effective than drug therapy}

Abbreviations as Table 2.

Three RCTs were identified comparing (intravaginal or intra-anal) electrical stimulation with sham electrical stimulation..$^{38,47-48}$ One trial comparing intravaginal electrical stimulation with sham intravaginal electrical stimulation had a MQS of 7 points and was considered to be of sufficient methodological quality. Another trial comparing intra-anal electrical stimulation with sham intra-anal electrical stimulation had a MQS of 6.5 points. A third RCT comparing intravaginal electrical stimulation with sham intravaginal electrical stimulation was of low quality (MQS 3 points). The two trials of sufficient methodological quality reported results in favour of electrical stimulation, whereas the low-quality study reported that electrical stimulation was not more effective than sham electrical stimulation. ${ }^{48}$ Combined results of the three 
RCTs showed insufficient evidence in favour of electrical stimulation as a treatment modality for urge urinary incontinence. Moreover, there was no consistency between the trials in terms of types and parameters of electrical stimulation.

In one trial of low methodological quality (MQS 5 points), intravaginal electrical stimulation was compared with drug therapy (propantheline bromide). ${ }^{49}$ It was concluded that electrical stimulation is at least as effective as anticholinergic therapy in the treatment of urge urinary incontinence. With only one such RCT, there is insufficient evidence for the efficacy of electrical stimulation compared to drug therapy.

A summary of the levels of evidence for the efficacy of physical therapies in the treatment of urge urinary incontinence in women is presented in Table 4.

\section{Discussion}

The most important methodological aspects of the studies reviewed are only outlined briefly here; the methodological problems and pitfalls related to such reports are discussed more extensively elsewhere. ${ }^{27}$ There are various conservative treatment modalities for the management of bladder overactivity. Unfortunately, many of the reports do not comply with the criteria for a well-conducted RCT. Assessing the results of the treatments shows a lack of consistency in the criteria for evaluation and the methodology used in these reviewed studies. Additionally, the assessor is usually the health care provider and therefore may be biased.

In the present review, a rating system was used that considered three levels of scientific evidence, based on the methodological quality and outcomes of the selected RCTs. There was large variability in the quality of included studies and the use of different measures of effect in most of the trials under review hampered comparisons between studies. The results should therefore be interpreted with caution. Several other aspects should be considered when interpreting the cited studies. Urge urinary incontinence is only one of the functional disorders caused by bladder overactivity. The underlying pathology can be of various origins and is only partly understood. Secondly, the International Continence Society has introduced several descriptive terms like 'a disorder of the filling/storage phase', 'involuntary bladder contractions, while the patient is attempting to inhibit', 'detrusor hyperreflexia' of 'detrusor instability', which illustrate the current confusing in clinical practice. ${ }^{1}$ This is partly understandable because the diagnostic assessment is typically aimed at the function of the lower urinary tract (storage and emptying), while the underlying pathology, which needs to be treated, is often characterized as idiopathic. A diagnosis based on previous terms is in principle qualitative. Thirdly, in research, when attempting to confirm the efficacy of therapy and to compare different therapeutic modalities, there is a demand for quantitative validated assessment of bladder overactivity. Particularly in those patients with symptoms indicative of mixed incontinence, a quantitative measure is also clinically important to optimize the therapeutic programme, defining whether the 'urge' or 'stress' component is more profound. Finally, existing conventional diagnostic tools lack sensitivity and specificity for the overactive bladder. ${ }^{50}$ We suggest that these aspects must have caused a diversity within patient groups, possibly leading to an underestimation of the efficacy of physical therapeutic modalities.

If the future investigation of conservative therapies is to be improved we suggest the following definition is used for bladder overactivity, describing the dysfunction of the bladder, which is related to symptoms of urgency, frequency and urinary incontinence: 'Bladder overactivity is a dysfunction of the bladder in which a subject 
has no or decreased control over sudden contractions of the detrusor muscle, so that this leads to premature leakage of urine'. ${ }^{50}$

To meet the demand for quantitative assessment of this dysfunction, a highly sensitive and specific diagnostic tool with a validated quantitative outcome measure is necessary. ${ }^{50}$ Because general practitioners currently have no adequate diagnostic tools, it is very difficult for them to adequately specify the diagnosis of urge incontinence (or overactive bladder). On the other hand, only a few patients with symptoms of frequency, urgency and/or urge incontinence will be referred by the general practitioner to the urologist immediately after the first consultation; most patients will initially be referred to a physiotherapist. This implies that many patients who probably have urge incontinence (a mostly heterogeneous group) will receive physiotherapy. The lack of adequate criteria for easily selecting patients may diminish the rate of success of the physiotherapeutic treatment, or vice versa. Using urodynamics, the urologist has more chance to correctly diagnosing patients with urge urinary incontinence. Several studies have shown that often no bladder overactivity can be detected in these patients, despite their obvious symptoms and signs of urgency, frequency and urge incontinence. ${ }^{51-53}$ Other studies have shown that ambulatory urodynamic monitoring is far better than conventional filling cystometry if bladder overactivity is involved. ${ }^{52,54}$ However, none of the studies in the present analysis used ambulatory urodynamics.

Physical therapies, when provided by knowledgeable physiotherapists, generally provide some measure of improvement in most individuals with an overactive bladder. They have few reported side-effects ${ }^{13}$ and do not preclude future treatments; however, the relative increase in efficacy and costs is still being debated. Also, physical therapy requires that both the patient and the therapist are highly motivated. A possible explanation for the moderate success rate could be that there is large variation among the treatment series and training programmes in the parameters for stimulation, the frequency and duration of treatments.

From the published reports, there is no consistent terminology for the different treatment modalities for urge urinary incontinence. The term 'behavioural' treatment is particularly confusing. In the trial of Burgio et al. ${ }^{45}$ the term 'behavioural' treatment is used for a bladder (re)training programme. The 'behaviour' treatment programme implemented in the study of $\mathrm{Hu}$ et al. ${ }^{46}$ was based on hourly checking and prompting of individuals to void. In urge urinary incontinence, behavioural treatment is only one aspects of bladder (re)training. We think that within a physical therapy, behavioural treatment is not a full treatment modality, but only part of a larger treatment. Physiotherapists use it to teach and motivate patients to change their behaviour. In bladder (re)training, physiotherapists also try to change the pathophysiological aspects of the health problem as a result of urge urinary incontinence, by reducing/restoring impairments, disabilities and/or handicaps.

Previously, bladder (re)training has been used in an attempt to increase central inhibition. Jeffcoate and Francis ${ }^{55}$ used bladder training in which patients were asked to void 'by the clock' and instructed to maintain continence at all costs. This method was very controversial, because the anxiety caused by trying to force such behaviour led many patients to withdraw. Frewen ${ }^{56}$ reported positive results in patients with urge incontinence by using daily voiding charts as a method of bladder training. In Frewen's first series no urodynamics were used, but later he reported similar results in an uncontrolled study with cystometric results. ${ }^{57}$ In an American review the reported efficacy of bladder training was $47-100 \%{ }^{26}$ but most of the studies in that review were case series; the only RCT was that by Jarvis. ${ }^{35}$ In another review, bladder training is strongly recommended for management urge urinary incontinence 
from detrusor overactivity. ${ }^{13}$ Fantl et al. ${ }^{40}$ conducted a RCT in 131 women with sphincteric incompetence and unstable detrusor function. Patients were treated with a bladder-training programme that included strategies to decrease urge and educate the patient, and a voiding schedule. In the treatment group, $12 \%$ became dry and $75 \%$ at least halved the number of incontinent episodes. The effect of bladder training was maintained after 6 months. ${ }^{13}$ A disadvantage of this treatment modality is that it is not applicable in cognitively impaired patients and may not be successful in the frail elderly. ${ }^{13}$ To our knowledge, currently there is no evidence of a direct relationship between any urodynamic variable and observed beneficial clinical effects.

In an uncontrolled pilot-study of community-resident elderly persons, Flynn $^{58}$ reported that pelvic floor muscle exercises were essentially as effective in reducing urge urinary incontinence as they were in reducing combination stress urinary incontinence/urge urinary incontinence. Additionally, pelvic floor muscle exercises resulted in a significant increase in the time between voiding, thus significantly reducing urinary frequency. Pelvic floor muscle exercises are recommended in patients in conjunction with bladder training for urge urinary incontinence; ${ }^{13}$ they can reduce urgency and prevent urge urinary incontinence.$^{59-64} \mathrm{~A}$ disadvantage is that patients usually require repeated guidance over a long period to derive optimal benefit from pelvic floor muscle exercises. ${ }^{13}$ Further RCTs are needed to determine the optimal programme of pelvic floor muscle exercises in patients with urge urinary incontinence and whether the exercises should be augmented by biofeedback therapy. It is important to identify those patients who will benefit most from pelvic floor muscle exercises alone or combined with other treatment modalities such as biofeedback or electrical stimulation.

Among various series and devices, the parameters for electrical stimulation and the frequency and duration of treatments vary considerably. ${ }^{3}$ Electrical stimulation may be useful for urge urinary incontinence, ${ }^{13}$ but further research is needed to determine whether electrical stimulation should be used alone or combined with other therapies. Standardizing the parameters of the techniques used will allow further comparison of study results.

In conclusion, the methodological quality of the studies included in the present review was moderate. There is weak evidence that bladder (re)training is more effective than no treatment (controls), and that bladder (re)training is better than drug therapy. There is insufficient evidence for the efficacy of biofeedback-assisted pelvic floor muscle exercises, exercises alone, toilet training and electrical stimulation for women with urge urinary incontinence. Despite almost all the included studies reporting positive results in favour of physical therapies for the treatment of urge urinary incontinence in women, more research of optimal methodological quality is required. Therefore, future researchers are recommended to use a well-established methodological criteria list when designing and conducting trials.

\section{References}

1. Abrams P, Blaivas JG, Stanton SL, Andersen JT. The standardization of terminology of lower urinary tract function. Scand J Urol Nephrol 1988; 114: 5-19.

2. Kobelt-Nguyen G, Johannesson M, Mattiasson A, Abrams P. Correlations between symptoms of urge incontinence and scores of a generic quality of life instrument (SF-36) and health status measurements (EuroQol) and between changes in symptoms and QoL scores. Abstract presented at th 27th Annual Meeting of ICS, Yokahama, Japan, September 25-27, 1997.

3. Abrams P, Wein AJ. Introduction to the overactive bladder: from basic science to clinical management. Urology 1997; 50 (suppl 6a): 1-3. 
4. Hampel C, Wienhold D, Benken N, Eggersmann C, Thüroff JW. Definition of overactive bladder and epidemiology of urinary incontinence. Urology 1997; 50 (suppl 6a): 4-14.

5. losif MD, Batra S, Ef A. Astedt B: Oestrogen receptors in the human female lower urinary tract. Am J Obstet Gynecol 1981; 141: 817-820.

6. Urinary Incontinence Guidelines Panel: Urinary incontinence in adults: Clinical Practice Guideline. AHCPR Pub.No.92-0038. Agency for Health Care Policy and Research, Public Health Service, US Department of Health and Human Services, Rockville, MD, 1992.

7. Resnick NM. Urinary incontinence. Lancet 1995; 346: 94-99.

8. Waalwijk van Doorn ESC van. Ambulatory urodynamics. Thesis University of Maastricht, the Netherlands 1990.

9. Grimby A, Milson I, Molander U, Wiklund I, Ekelund P. The influence of urinary incontinence on the QOL of elderly women. Age Ageing 1993; 22: 82-89.

10. Millard RJ, Oldenburg BF. The symptomatic, urodynamic and psychodynamic results of bladder re-education programs. J Urol 1983; 130: 715-719.

11. Ulmsten UI. The role of surgery in women. Abstract presented at the symposium 'Freedom' at the 14th Annual Meeting of EAU, Stockholm, Sweden, April 7-11, 1999.

12. Resnick NM. Improving treatment of urinary incontinence. JAMA 1998; 280: 2034-2035.

13. Fant JA, Newman DK, Colling J, et al. Urinary incontinence in adults: Acute and chronic management. Rockville Md: US Dept of Health and Human Services, Public Health Service, Agency for Health Care Policy and Research; March 1996. AHCPR publication 96-0682 Clinical Practice Guideline No.2, 1996 Update.

14. Messelink EJ. The overactive bladder and the role of the pelvic floor muscles. Br J Urol 1999; 83: 31-35.

15. Colling JC, Ouslander J, Hadley BJ, Campbell EB, Eisch J. Patterned urge-response toileting for incontinence. Research funded by NIH, National Center for Nursing Research under Grant No. NR01554 to Oregon Health Sciences University, Portland, OR, 1992.

16. Engel BT, Burgio LD, McCormick KA, et al. Behavioral treatment of incontinence in the long-term care setting. J Am Geriatr Soc 1990; 38: 361-363.

17. McCormick KA, Celia M, Scheve A, Engel B. Cost-effectiveness of treating incontinence in severely mobility-impaired long-term care residents. QRB Quality Review Bulletin 1990; 16: 439443.

18. Schnelle JF. Treatment of urinary incontinence in nursing home patients by prompted voiding. J Am Geriatr Soc 1990; 38: 356-360.

19. Veken $\mathrm{H}$ van der, Spiegel $\mathrm{H}$ van der. Urinaire incontinentie en kinesitherapie. NFDLK-BWVK $1987 ; 41-45$.

20. Schulz-Lampel D, Richter C, Lampel A, Thüroff JW. Temporãre Elektrostimulation bei Blasenfunktionsstörungen. Urol A 1995; 95 (suppl 1): 111.

21. Tanagho EA. Electrical stimulation. J Am Geriatr Soc 1990; 38: 352-355.

22. Eriksen BC, Eik-Nes SH. Long-term electrical stimulation of the pelvic floor: primary therapy in female stress incontinence? Urol Int 1989; 44: 90-95.

23. Eriksen BC. Electrostimulation of the pelvic floor in female urinary incontinence. Thesis University of Trondheim, Norway 1989.

24. Plevnic S, Janez J, Vrtacnik P, Trsinar B, Vodusek DB. Short-term electric stimulation- home treatment for urinary incontinence. World J Urology 1986; 4:24-26.

25. Fall M, Lindström S. Functional electrical stimulation: physiological basis and clinical principles. Int Urogynecol J 1994; 5: 296-304.

26. Fant JA, Wyman JF, McClish DK, Bump AC. Urinary incontinence in women: clinical urodynamic and severity characteristics. Am J Obstet Gynecol 1990; 162: 946-952.

27. Berghmans LCM, Hendriks HJM, Be K, Hay-Smith, Bie RA de, Waalwijk van Doom ESC van. Conservative treatment of stress urinary incontinence in women: a systematic review of randomized clinical trials. Br J Urol 1998; 82: 181-191.

28. Kleijnen J, Knipschild P. Niacinand vitamin B6 in mental functioning: a review of controlled trials in humans. Biol Psychiatry 1991; 29: 931-941.

29. Kleijnen J, Craen AJM de, Everdingen J van, Krol L. Placebo effect in double-blind clinical trials with medications. Lancet 1994; 344: 1347-1349.

30. Pocock S.J. Clinical trials: a practical approach. Chichester: Wiley 1983.

31. Meinert CL. Clinical trials: design, conduct and analysis. New York: Oxford University Press 1986.

32. Chalmers TC, Smith H, Blackbum B et al. A method for assessing the quality of arandomized control trial. Control Clin Trials 1980; 2: 31-49. 
33. Brønfort G. Efficacy of manual therapies of the spine. Thesis Free University of Amsterdam, the Netherlands 1997.

34. Tulder MW van, Assendelft WJJ, Koes BW, Bouter LM, ed. Board of the CC Back Review Group. Method of guidelines for systematic reviews in the Cochrane Collaboration Back Review Group for spinal disorders. Spine 1997; 22: 2323-2330.

35. Jarvis GJ. A controlled trial of bladder drill and drug therapy in the management of detrusor instability. Br J Urol 1981; 5: 565-566.

36. Jarvis GJ, Millar DR. The treatment of incontinence due to detrusor instability by bladder drill. Female Incontinence 1981; 341-343.

37. Wiseman PA, Malone-Lee J, Raj GS. Terodiline with bladder retraining for treating detrusor instability in elderly people. BMJ 1991; 302: 994-996.

38. Tsinar B, Kralj B. Maximal electrical stimulation in children with unstable bladder and noctural enuresis and/or daytime incontinence: a controlled study. Neurourol Urodyn 1996; 15: 133-142.

39. Wyman JF, Fant JA, McClish DK, Harkins SW, Uebersax JS, Ory MG. Quality of life following bladder training in older women with urinary incontinence. Int Urogynecol J 1997; 8: 223-229.

40. Fant JA., Wyman JF, McClish DK, Harkins SW, Elswick RK, Taylor, JR, Hadley EC. Efficacy of bladder training in older women with urinary incontinence. JAMA 1991; 265: 609-613.

41. Lagro- Janssen ALM, Debruyne FMJ, Smits AJA, Weel C van. The effects of treatment of urinary incontinence in general practice. Family Practice 1992; 9: 284-289.

42. Colombo M, Zanetta G, Scalambrino S, Milani R. Oxybutynin and bladder training in the management of female urinary urge incontinence: a randomized study. Int Urogynecol J 1995; 6: 63-67.

43. Ramsay IN, Ali HM, Hunter M, Stark D, Donaldson K. A randomized controlled trial of urodynamic investigations prior to conservative treatment of urinary incontinence in the female. Int Urogynecol 1995; 6: 277-281.

44. Wyman JF, Fantl JA McClish, Bump RC, and the Continence Program for Women Research Group. Comparative efficacy of behavioral interventions in the management of female urinary incontinence. Am J Obste t Gynecol 1998; 179: 999-1007.

45. Burgio KL, Locher JL, Goode PS, Hardin JM, McDowell BJ, Dombrowski M, Candib D. Behavioral vs drug treatment for urge urinary incontinence in older women. JAMA 1998; 280: 1995-2000.

46. Hu TW, Igou JF, Kaltreider DL, Yu LC, Rohner TJ, Dennis PJ, Craighead WE, Hadley EC, Ory MG. A clincal trial of a behavioral therapy to reduce urinary incontinence in nursing homes. JAMA 1989; 261: 2656-2662.

47. Brubaker L, Benson JT, Bent A, Clark A, Shott S. Transvaginal electrical stimulation for female urinary incontinence. Am J Obstet Gynecol 1997; 177: 536-540.

48. Shepherd AM, Tribe E, Bainton D. Maximal Perineal Stimulation. A controlled study. Br J Urol 1984; 56: 644-646.

49. Smith JJ: Intravaginal stimulation randomized trial. J Urol 1996; 155: 127-130.

50. Waalwijk van Doorn ESC van, Ambergen AW. Diagnostic assessment of the overactive bladder during the filling phase: the detrusor activity index. BUU 1999; 83 (suppl 2): 16-21.

51. Webb RJ, Ramsden WPD, Neal DE. Ambulatory monitoring and electronic measurement of urinary leakage in the diagnosis of detrusor instability and incontinence. J Urol 1991; 68: 148152.

52. Waalwijk van Doorn ESC van, Zwiers W, Wetzels LLAN, Debruyne FMJ. A comparative study between standard and ambulatory urodynamics. Neurourol Urodynam 1987; 6: 159.

53. Kulseng-Hanssen $S$, Klevmark $B$. Ambulatory urethro-cysto-rectometry: a new technique. Neurourol Urodynam 1988; 7: 119.

54. Porru D, Usai E. Standard and extramural ambulatory urodynamic investigation for the diagnosis of detrusor instability-correlated incontinence and micturition disorders. Neurourol Urodyn 1994; 13: 237-242.

55. Jeffcoate TNA, Francis WJA. Urgency incontinence in the female. BMJ 1966; 94, 604-618.

56. Frewen WK. Urgency Incontinence. J Obstet Gynaecol Br Commonw 1972; 79: 77-79.

57. Frewen WK. An objective assessment of the unstable bladder of psychosomatic origin. $\mathrm{Br} \mathrm{J}$ Urol $1978 ; 50: 246-249$.

58. Flynn L. Effectiveness of pelvic muscle exercises in reducing urge incontinence among community residing elders. J Gerontol Nurs 1994; 20: 23-27.

59. Burgio KL, Robinson JC, Engel BT. The role of biofeedback in Kegel exercise training for stress urinary incontinence. Am J Obstet Gynecol 1986; 157: 58-64.

60. Burgio KL Pearce KL, Lucco AJ. Staying dry: a practical guide to bladder control. Baltimore. Md: Johns Hopkins University Press; 1989. 
61. Burgio KL. Behavioral training for stress and urge incontinence in the community. J Gerontol 1990; 36 (suppl 2): 27-34.

62. Burton JR, Pearce $\mathrm{KL}$, Burgio $\mathrm{KL}$, et al. Behavioral training for urinary incontinence in elderly ambulatory patients. J Am Geriatr Soc 1988; 36: 693-698.

63. Klarskov P, Nielsen KK, Kromann-Andersen B, et al. Long-term results of pelvic floor training and surgery for female genuine stress incontinence. Int Urogynecol J 1991; 2: 132-135.

64. McDowell BJ, Burgio KL, Dombrowski M, Locher JL, Rodriquez E. Interdisciplinary approach to the assessment and behavioral treatment of urinary incontinence in geriatric outpatients. J Am Geriatr Soc 1992; 40: 370-374. 
Aan Bary ex Llliam

"Bany wat bees ik blif dat ite aan je anderzack hel meegemerkt.

als dank daarwoon kreeg ik uan Lilian m'n bebkentademspioren versterkt.

gonder jullie fijne begeleiding was me dat niet gelukt.

want na afloop zat it uaak helemaal stuk.

dan werd ik naar kamer zes verbannes.

on daar dan heerlijk in de pakkingen te antspannen.

geker weet it nu waoriaan.

boum 'te dege oefeningen in. in m'n dagelijks bestaan.

want jullie weten oak. 't waren voor mif twée ollegen in één blak.

mifn God. wat hebber jullie ' $m$ dat toch goed gelapt.

steeds weer. wad ite ' $t$ als ' $n$ feest.

mant aan mif is or mag noait zolets 'pasitiefs' geureest.

alleen doon jullie qoeie motivathe en steun ben ite or gekomen.

want uan gulk resultaat. had it moait denven dromen.

alles is nu áfgewerkt' or is nog eén ding waar ik op stá.

ët op mijn gezondheid nu' 'ns 'n lekber stukje clá."

\section{Fartelije Dank}


Chapter 6

\section{Efficacy of physical therapeutic modalities in women with proven bladder overactivity in extramural physical therapy; a randomized clinical trial}

LCM Berghmans, MSc, RPt (1), FHM Nieman, PhD (2), LWH Smeets, RPt (1), WMM ten Haaf, RPt (1), RA de Bie, PhD, MSc, RPt (3), PA van den Brandt, PhD (3), PhEVA van Kerrebroeck, PhD, MD (1)

1 Department of Urology, University Hospital Maastricht, Maastricht, the Netherlands

2 Department of Clinical Epidemiology \& Medical Technology Assessment, University Hospital Maastricht, Maastricht, the Netherlands

3 Department of Epidemiology, Maastricht University, Maastricht, the Netherlands 


\section{Abstract}

Objective Our study object was to assess the efficacy of physiotherapeutic treatment modalities of women with bladder overactivity.

Methods In a single-blind randomized clinical trial we studied the efficacy of three treatment modalities versus a no-treatment group (group I) in women with proven bladder overactivity. Specific physical treatments consisted of lower urinary tract exercises (LUTE) (group II), office and home based functional electrical stimulation (FES) (group III) and office based functional electrical stimulation and lower urinary tract exercises (group IV). After randomization each patient received 9 treatment sessions, once weekly. Lower urinary tract exercises consisted of patient information, bladder (re-)training (BIT), specific pelvic floor muscle exercises (PFME) training and toilet behaviour. Functional electrical stimulation was applied vaginally through plug mounted electrodes. The patient was instructed to use the maximal tolerable level during stimulation. Current characteristics were: frequency modulation of $0.1 \mathrm{sec}$ trains of rectangular biphasic 200 microsec long pulses which varied stochastically between 4 and $10 \mathrm{~Hz}$. Combination therapy consisted of the same lower urinary tract exercises-programme with additional weekly office based functional electrical stimulation immediately following the lower urinary tract exercises. Outcome variables were the Detrusor Activity Index (DAI) and the Incontinence Impact Questionnaire-7 (IIQ-7). The Detrusor Activity Index represents a score between $0-1$, where zero represents no bladder overactivity and one represents severe bladder overactivity.

Results 175 women had an intake interview with the investigator, of which 112 had ambulatory urodynamics ( $A C M$ ). Based on urodynamic variables of $A C M$ and of the micturition diary, the Detrusor Activity Index for each patient was calculated. Eightythree patients were randomized of which 68 women had a Detrusor Activity Index $\geq 0.50$, defined as proven bladder overactivity. 12 Women dropped out of the study because of various reasons. In the total group of 83 women, specified to the differences over treatment groups, in repeated measures ANOVA, both lower urinary tract exercises and functional electrical stimulation groups showed significant decrease in the Detrusor Activity Index-scores ( $p=0.039$ and $p=0.047$, respectively), while there was no effect in the lower urinary tract exercises and functional electrical stimulation-group ( $p=0.918$ ). However, because of a correlation between mean difference in Detrusor Activity Index-scores and the pre-treatment Detrusor Activity Index-scores, in repeated measures ANCOVA the decrease in Detrusor Activity Index-scores of both the lower urinary tract exercises and functional electrical stimulation-group was non-significant. In a subgroup of 68 patients with pretreatment Detrusor Activity Index-scores $\geq 0.50$, in repeated measures ANCOVA there was a statistically significant decrease of Detrusor Activity Index-scores of the functional electrical stimulation-group $(p=0.040)$, while the decrease in Detrusor Activity Index-scores of the lower urinary tract exercises-group was remarkable but not significant $(p=0.099)$. There was no effect of the combination-group compared to the no-treatment group $(p=0.674)$. The results of the IIQ-7 showed overall therapygroup differences $(F=2.92$ with 3 and $71 \mathrm{df} ; p=0.040)$. If the three therapygroups were contrasted with the control group the lowering of perceived impact on daily life was statistically significant $(p=0.006)$. The lower urinary tract exercises group turned out to have statistically significant lower self-professed impact of incontinence on daily life activities $(p=0.009)$, while the functional electrical 
stimulation- and lower urinary tract exercises and functional electrical stimulationgroup were non-significant ( 0.053 and 0.073 , respectively).

Conclusion Our conclusion is that, based on the objective effect parameter, in the homogeneous subset of 68 patients, office- and home based functional electrical stimulation seemed to be an effective treatment modality for the treatment of women with proven bladder overactivity, while lower urinary tract exercises seemed to provide a positive trend in improvement. The combination of functional electrical stimulation and lower urinary tract exercises was not effective. Although there is a positive trend in subjective improvement, results of the IIQ-7 have to be interpreted with caution. More research of high methodological quality is required to support the conclusions of this study.

Key words bladder overactivity, detrusor overactivity, urge urinary incontinence, (functional) electrical stimulation, bladder (re)training, pelvic floor muscle exercises, lower urinary tract (exercises), physical therapy 


\section{Introduction}

Urinary incontinence and voiding disorders, specifically due to bladder overactivity are highly prevalent disorders that greatly impacts the lives of millions of people worldwide. Next to stress incontinence, bladder overactivity is the most frequently observed disorder of the storage function in women. ${ }^{1}$ The symptoms of bladder overactivity consist of urgency and/or frequency and/or nocturia and/or urge incontinence. Urgency or urge incontinence has greater impact on quality of life than stress incontinence, probably because it is a highly unpredictable phenomenon, ${ }^{2-3}$ and has the greatest effect on quality of life in the younger population. ${ }^{4}$ The underlying etiology is only partially understood. Also the clinical terminology used in connection with this storage dysfunction is confusing. ${ }^{5}$ To prevent confusion, in this study bladder overactivity is defined as a dysfunction of the bladder in which a subject has no or decreased control over sudden contractions of the detrusor muscle, leading to premature passage of urine. ${ }^{6}$

At present, only a few studies regarding the efficacy of physiotherapeutic treatment modalities for bladder overactivity are performed. ${ }^{7}$ Our review regarding the efficacy of specific physical therapy for stress urinary incontinence showed strong evidence for the benefits of pelvic floor muscle exercises, ${ }^{8}$ while our review on urge urinary incontinence revealed only weak evidence regarding the efficacy of bladder (re)training and insufficient evidence regarding the efficacy of pelvic floor muscle exercises with or without biofeedback, of electrical stimulation alone or in combination with pelvic floor muscle exercises and of toilet training for women with urge urinary incontinence. ${ }^{5}$

However, these latter findings do not prove the ineffectivity of physical therapy as a treatment modality for urinary incontinence and voiding disorders as a whole. It is our assumption that the lack of efficacy is most likely caused by methodological flaws like heterogeneity of study groups and suboptimal research designs. Although the majority of the reviewed studies did perform conventional urodynamics as part of the patient assessment, the outcome was only used descriptively and not quantitatively. Sensitivity, specificity and test-retest reproducibility of conventional urodynamics is rather low, especially, if urgency or urge incontinence is involved, thus compromising homogeneity of the study groups. ${ }^{6}$ In none of the reviewed studies the investigators achieved to apply a quantitative validated urodynamic measure both as an inclusion criterium and as an effect measurement.

Our main study objective was to assess the efficacy of physical therapeutic treatment in women with bladder overactivity. Next to this, in order to test the assumption mentioned in the paragraph above, we decided to perform a study with strictiy validated quantitative inclusion criteria in order to try to optimize homogeneity of the patient group under study. We included women with proven bladder overactivity as indicated by an ambulatory urodynamic investigation.

Three physical therapeutic modalities were selected. Lower urinary tract exercises, functional electrical stimulation and a combination of lower urinary tract exercises and functional electrical stimulation theoretically stimulate the detrusor inhibition reflex (DIR) and pacify the micturition reflex, resulting in a decrease of overactive bladder dysfunction. Lower urinary tract exercises, by voluntary contractions of the pelvic floor muscles, and functional electrical stimulation, by selective stimulation of afferent pudendal nerve fibres in the pelvic floor or the sacral root, are suggested ${ }^{9 \cdot 10}$ to induce a reflex contraction of the striated para- and periurethral muscles accompanied by a simultaneous reflex inhibition of the detrusor muscle (DIR). This 
recriprocal response depends on a preserved reflex arc through the sacral micturition reflex centre.

\section{Material and methods}

In a single blind randomized clinical trial we studied the efficacy of three treatment modalities versus a no-treatment group (group I) in women with bladder overactivity. Specific physical treatments consisted of a programme with lower urinary tract exercises (group II), a programme with office and home based functional electrical stimulation (group III) and a programme of lower urinary tract exercises and office based functional electrical stimulation (group IV) for women with bladder overactivity. The study took place at the University Hospital Maastricht and in a local extramural practice for physical therapy, in cooperation with the Department of Epidemiology of Maastricht University, the Netherlands.

\section{Study population and recrultment}

The population to be included consisted of women with symptoms of frequency and/or urgency and/or urinary incontinence. Patients were recruited by general practitioners, urologists from our department and by announcements in local papers and other media. The diagnosis of bladder overactivity by the urologist was based on history taking, physical examination, cystometry, uroflowmetry, sonography and (ambulatory) urodynamics. The diagnosis of bladder overactivity by the general practitioner was based on history taking, using the validated questionnaire of LagroJanssen ${ }^{11}$ and the Dutch practice guidelines for general practitioners ${ }^{12}$ and physical examination.

All participants received from their doctor or during intake an extensive patient information form. Approval to participate in the programme was obtained during a two-week qualification period in which inclusion and exclusion criteria were checked, medical history was taken, a micturition diary combined with pad test was obtained and, finally, ambulatory urodynamics were performed.

Table 1 presents the in- and exclusion criteria. At the end of the intake period all preliminary included women had to sign informed consent before they were allowed to continue the qualification period. After intake, in order to get more insight into their drinking and micturition behaviour, all women had to fill in a micturition diary and perform the pad test during one day from 08.00 to 16.00 hours to assess frequency, urgency and incontinence symptoms in order to optimize preselection. During the test, participants were asked to drink at least $200 \mathrm{ml}$./hr. Finally, to ensure homogeneity of the study population, all women underwent ambulatory urodynamics, using the Detrusor Activity Index model. Only Detrusor Activity Index-values larger than 0.50 were considered proven bladder overactivity. This model uses the results of extramural ambulatory cystometry to quantify detrusor activity during several consecutive filling phases. The model has been validated and applied in several drug trials. $^{13-15}$

Preceding this ambulatory investigation, urine-analysis with a bacterial count was carried out to exclude urinary tract infection (UTI). In case of positive urine-analysis ambulatory urodynamics were postponed till the UTI was cured. When proven suitable the patient was again extensively briefed about the intent and manoeuvre of the trial. During the qualification period an impression of the compliance of the recruited women was obtained by scrutinizing completion of the micturition diary and 
keeping of appointments. The data obtained at the end of the qualification period formed the baseline values.

Table 1. Inclusion and Exclusion Criteria

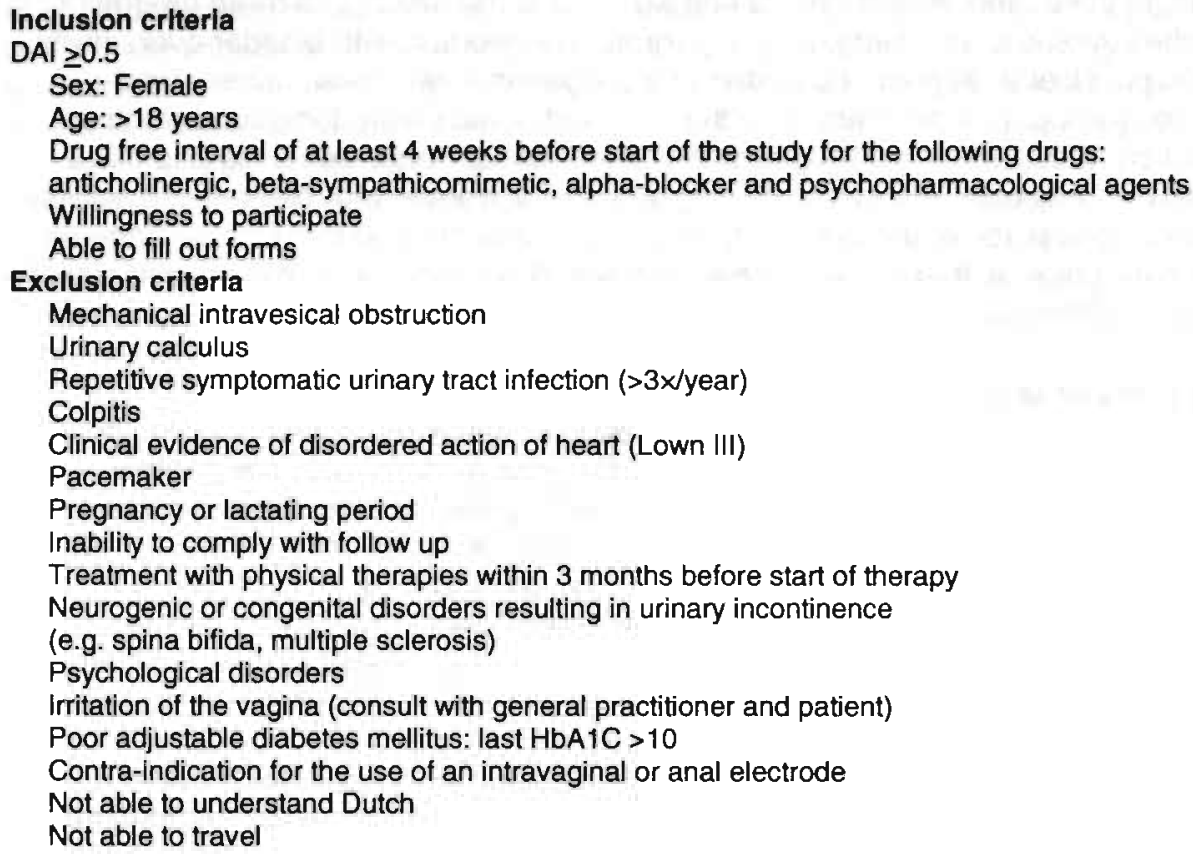

\section{Sample size and randomization}

With the assumption of a one-sided effect ( $\mathrm{H} 1$ hypothesis: Treatment patients are on the average better off than no-treatment patients), a level of significance of $95 \%$ $(a=0.05)$, a power of $80 \%(B=0.20)$, an expected drop-out rate of $10 \%$, and an expected improvement of bladder overactivity status (Detrusor Activity Index) of treatment groups in comparison with the no-treatment group, expressed in a decrease of approximately $30 \%$ in the Detrusor Activity Index, 20 patients in each of the four groups had to be recruited. Therefore, the intended sample size was set on 80 persons.

Randomization was done in blocks of four, using opaque and sealed envelopes, containing a note with group allocation. After opening an envelope the trial managerassistent informed the physical therapist (by phone) to what group the individual patient was allocated. Besides patient and physical therapist all others, involved in registration and evaluation of results, were blinded for group allocation.

\section{Interventlons}

After the randomization each patient received 9 treatment sessions, once weekly. Approximately 30 minutes per visit were spent in group II and III, while group IV had to spent about 60 minutes per visit. In group II and IV the chosen programme was intensive in order to optimize patients' motivation and compliance. ${ }^{16}$ To guarantee that the effect of functional electrical stimulation was specifically due to the 
characteristics of functional electrical stimulation and not (partly) influenced by the way the physical therapist managed the treatment sessions, in group III the patient received information only how to use the functional electrical stimulation-device and the vaginal electrode. In each group efforts were made to create comparable circumstances during the treatment sessions. In group II and IV each patient received an explanation about the pelvic anatomy, the function of the pelvic floor and bladder, the use of pelvic exercises and bladder training. Two physical therapists (L.W.H.S., W.M.M.t.H.), who were especially certified for the treatment of patients with lower urinary tract disorders, provided the treatment sessions. All patients in group II and IV used a diary for training. These patients did the same home exercises programme. The patients in the group III had a special home programme using only the functional electrical stimulation-device. During each treatment session the patient was briefed regarding the duration, execution and frequency of the home programme. Because the efficacy of the various treatment modalities also depends on the results of the home programme, the physical therapist tried to support and promote the compliance with the execution of the home programme. No patients in the no-treatment group received any kind of treatment for bladder overactivity during the period of the trial. At the end of the trial the opportunity to be treated with one of the usual treatment possibilities, i.e. physical therapy or medication, was offered to these patients.

\section{Description of LUTE}

For each individual patient an optimal lower urinary tract exercises programme was provided consisting of the following components:

- Patient information about the lower urinary tract function, the function of the pelvic floor and the way to contract and relax the pelvic floor;

- Bladder (re-)training (BIT) consisting of four components. The first is an educational programme that addresses lower urinary tract function. The next component involves training to inhibit the sensation of urgency and to postpone voiding. The third is to urinate according to a timetable in patients with an interval less than two hours between two consecutive micturitions in order to reach an interval of at least 3 hours between two consecutive voidings and to reach larger voided volumes. Fourthly, reinforcement of patient motivation by the physical therapist.

- Specific pelvic floor muscle exercises training in order to probably facilitate and restore the detrusor inhibition reflex by selective contraction of the pelvic floor muscles. ${ }^{17}$ In patients with an overactive bladder often there is hypertonus of the pelvic floor muscles ${ }^{18}$ The level of activation in these patients is so high that selective contraction of the pelvic floor muscles in order to achieve reciproqual inhibition of the bladder is very difficult or not possible. Teaching of selective contraction and relaxation of the pelvic floor muscles is an important first step. Once this is achieved, selective contraction of the pelvic floor muscles is focused on facilitation of the detrusor inhibition reflex. In this study patients were instructed to hold contractions for at least 20 seconds, followed by a relaxation period of 10 seconds. A more functional training (pelvic floor exercises during daily living activities) completed the exercise programme. If there were relevant postural disorders, exercises to correct these postural disorders were executed. If the symptoms of frequency, urgency and/or urge-incontinence seem to be related to nervous tension, relaxation exercises were part of the programme.

- Toilet behaviour aiming at the aspects of the micturition process itself. 
Full details of the lower urinary tract exercises-programme can be obtained from the authors on request.

\section{Description of FES}

Functional electrical stimulation was applied vaginally through plug mounted electrodes. The maximum level of the current stimulation was $100 \mathrm{~mA}\left(l_{\text {erf }}=6 \mathrm{~mA}\right)$. The patient was instructed to use the maximal tolerable level during stimulation. Current characteristics were: frequency modulation of $0.1 \mathrm{sec}$ trains of rectangular biphasic $200 \mu \mathrm{sec}$ long pulses which varied stochastically between 4 and $10 \mathrm{~Hz}$. In this study a special version of the ProSeco system of Innocept Medizintechnik Inc, Gladbeck, Germany, i.e. the ProUrge system, was used. This portable microprocessor controlled system is a combined functional electrical stimulation- and EMG- (electromyography) device that can be used for the treatment of bladder overactivity in (para-) medical centra and at home.

- Office based functional electrical stimulation sessions lasted approximately 30 minutes;

- Home based functional electrical stimulation consisted of two 20 minutes sessions per day with an interval of more than 6 hours.

\section{Description of LUTE and office based FES}

This programme was the same lower urinary tract exercises-programme with additional weekly office based functional electrical stimulation with a duration of approximately 30 minutes immediately following the lower urinary tract exercises.

\section{Outcome measures}

In this study we used two primary outcome measures, the Detrusor Activity Index and a Dutch version of the Incontinence Impact Questionnaire-7 (IIQ-7). ${ }^{19}$ The Detrusor Activity Index was measured before randomization (during the first ambulatory urodynamic investigation) and within 14 days after the end of the study period (second ambulatory urodynamic investigation).

The IIQ-7 was completed by the patients after the first ambulatory investigation before randomization, at the end of the study period after the second ambulatory investigation (within 14 days) and 3 months after the end of the study period. The Detrusor Activity Index, is a combined parameter that quantifies bladder overactivity by using variables from the analysis of ambulatory cystometry (ACM) during the filling phase (mean number of contractions/hr., mean duration of a contraction and mean amplitude of a contraction) and from the micturition diary: drinking - (mean volume drunk/hr.) and voiding behaviour (mean number of micturitions/hr. and mean volume voided per micturition) in a mathematical rule. The Detrusor Activity Index represents a score between 0 and 1, where zero represents no activity of the bladder during the filling phase and one represents severe overactivity of the bladder. This quantitative index was developed with logistic regression modelling based on ambulatory urodynamic data of healthy volunteers and a patient population. ${ }^{15}$

The Detrusor Activity Index, being a reliable and responsive instrument to quantify the grade of bladder overactivity over time,${ }^{15}$ was used both as an inclusion criterium and as the primary measure of effect.

The nursing staff of the urodynamic laboratory carried out ambulatory cystometry's in accordance with the ICS standards ${ }^{20}$ with event markers at the actual start and end of the recording period and at initiation and cessation of voiding (entering, leaving 
toilet). After instruction and installation patients were allowed to leave the hospital. The average ambulatory cystometry took approximately 6 hours. At the end of the $6-$ hour period they returned to the urodynamic laboratory to finish the investigation. Patients were instructed to register episodes of urgency, time and volume of fluid intake (at least $200 \mathrm{ml} / \mathrm{h}$ ), voiding as well as time and leakage volume of pad and pad change in a diary. Gaeltec equipment (MPR3) and microtip catheters were applied. There were no special provocative tests defined. During the ambulatory urodynamics period a padtest was carried out. The patient was asked to use only pads with sufficient capacity to catch loss of urine. Each pad was weighted before use (dry), and its weight was noted in the micturition diary. Immediately after use the patient put the pads in an airtight bag. A member of the nursing staff of the urodynamic laboratory, who was blinded for allocation of groups, weighted the pads using a digital balance. The data were recorded in the Case Report Form (CRF) and in the micturition diary. If measurements did not fulfill our quality criteria, the results were deemed not reliable for evaluation and were therefore discarded. In such cases patients either had to undergo a new ambulatory cystometry or were excluded because of unreliable results of the first Detrusor Activity Index measurement. If a second ambulatory cystometry failed the measurement was repeated again or we classified the data as missing.

It was important to complete the IIQ-7 questionnaire after the ambulatory urodynamic investigations, because possible influence on the results of the primary effect parameter had to be avoided. An observer (L.C.M.B.) scored the questionnaires while the patient answered the questions. The observer paid special attention to missing values, unclear answers and inconsistencies in the answers.

\section{Statistics}

All collected data were stored in a database. Data analyses were done with SPSS/PC, version 9.0. ${ }^{21}$ Outcome variables were screened for normality: if severe violations were observed a transformation of scores to logarithmic values was made to ensure proper analysis of data. Results were expressed as mean \pm standard deviation. Data were analysed in three steps. As a first step a repeated measures ANOVA was made over pre- and post-treatment means of the Detrusor Activity Index in a mixed model setting, in which 'time' is considered as a within factor and 'therapy group' as a between factor. As a second step an ANCOVA (analysis of covariance) was done in a dummy regression setting, using the difference of pre- and post Detrusor Activity Index measurements as a dependent variable. Therefore, therapy groups were dummified into three contrasts: control group (group I) versus lower urinary tract exercises (group II), control group versus functional electrical stimulation (group III) and control group versus combination therapy (group IV). Dummy regression analysis was done in three steps: first pre-treatment Detrusor Activity Index was entered into the equation, next the 3 therapy dummies were entered as a block and finally all interactions between the pre-treatment Detrusor Activity Index and the therapy dummies were entered. Changes in $\mathrm{R}^{2}$ between the three steps are considered to be important: if the second step introduction turns out to be statistically significant (with $3 \mathrm{df}$ ) overall therapy is severely tested under control of the pretreatment Detrusor Activity Index. If the third step turns out to be not statistically significant (with $3 \mathrm{df}$ ) the overall therapy effect gains in strength because of its higher generalizability. It is then found to be independent of the values of the initial Detrusor Activity Index-score. As a third and final step a multiple comparisons test was made using Dunnett's test (one sided), that may correct for heterogeneity of variances, if necessary. 
Because we wanted to test whether or not the IIQ-7 questionnaire - measuring subjectively interpreted effect of incontinence on daily activities and emotional life was a useful, reliable and valid measure of effect for the study population in this trial, a pre-analysis of quality-of-life data in four steps was performed. First, an itemanalysis was done to study univariate characteristics of each of the 7 items belonging to the scale to be constructed. Next, as a second step, maximum likelihood factor analysis was performed to test for dimensionality within the set of items. One- and two-factormodels were calculated using the loglikelihood chiquare to test for the best fitting factormodel (preferable an one factor model). Factor loadings have to be $>10.30 \mathrm{I}$ and residuals percentage in the expected correlation matrix of the 7 items has to be low $(<20 \%)$. As a third step, Chronbach's alpha was used to test for consistency in item response and a nonadditivity (Tukey) test was used. Finally, as a fourth step, a standardized additive scale construction was performed using the number of non-invalid itemscores in the denominator to the numerator of added scores, so the scale values will be lying within the same 0-3 range, as the items are. These four steps were done for the baseline (pre-treatment) measurement, and twice for the post-treatment period (once at the conclusion of the therapy weeks and once 3 months later than the conclusion). Analysis took place according to the intention-to-treat principle. Missing data in the set of post-treatment effect parameters were substituted with case means of the available data per therapy group.

Firstly, an intention-to-treat analysis of data is presented with all randomized patients. Secondly, we present an analysis of our data on a subset of patients with pre-treatment Detrusor Activity Index $\geq 0.50$.

The reason for this second analysis is that, based on the results of the Detrusor Activity Index, this subgroup represents a more homogeneous group of patients, because all patients in it had proven bladder overactivity, while in the total group of patients unfortunately also women with Detrusor Activity Index $<0.50$ had been included, representing a more heterogeneous group. Nearly at the end of the inclusion period, as a result of a quality improvement project that was executed simultaneously, we discovered a software bug in the computer programme that we use for calculating the input variables for the Detrusor Activity Index-model. Although this bug only occurred under certain technical circumstances, it caused an overestimation of the Detrusor Activity Index in some cases. This had no effect on our analysis of the urodynamic curves. It was only a mathematical inaccuracy. After repair of the software bug all Detrusor Activity Index calculations were checked. After comparison of the recalculated results of the Detrusor Activity Index with the first results, from the total group of 83 randomized women 15 patients turned out to be randomized erroneously, leaving 68 patients with Detrusor Activity Index-score $\geq 0.50$. We expect that a more homogeneous study population, (i.e. patients with proven overactivity in contrast with patients with only symptoms of urgency, frequency and/or urge-incontinence), will show larger improvement- or cure-rate due to therapy. Presentation of both analyses gives the opportunity to check whether or not there are differences in response to therapy between the total group and the subgroup.

\section{Results}

As a response to an announcement in local papers and other media or after referral by a urologist or a general practitioner, 248 women contacted our department for 
more information. One hundred and seventy-five of these women were invited for an intake interview with the investigator (L.C.M.B.). After intake, before the first ambulatory urodynamic investigation was performed, 63 women dropped out for various reasons: spontaneous improvement ( 3 women), illness ( 3 ), the expected burden of the enrollment (4), fear of the ambulatory urodynamic investigation (1), the ambulatory urodynamic investigation was not possible (2), other pathology involved (6), results of the micturition diary (21), or unknown (23). Because of the results of the ambulatory urodynamic investigation another 29 women dropped out. After the first ambulatory urodynamic investigation 83 patients, mean (sd) age 54.5 (13.6), were randomized. Yet, 2 women stopped before start of therapy because of too much burden. During the treatment period 6 women stopped because of illness ( 2 in group II and 2 in group III) or too much burden (1 in group III and 1 in group IV). After treatment, 4 women had no second ambulatory urodynamic investigation because of too much burden ( 3 in group II) or faillure of the investigation ( 1 in group IV). Of the 558 scheduled therapy sessions 516 (93\%) were completed.

\section{Baseline values}

The comparison of baseline values between the four study groups $(\mathrm{N}=83$ ) was based on the information gathered during the qualification period. Comparing the groups on medical history and baseline characteristics, no significant differences $(p<0.05)$ between groups were found, except for mean number of times of toileting during nighttime between Group I and II ( $p=0.03$ ) (Table $2 a$ and $2 b$ ).

Table 2a. Group Comparison based on Medical History

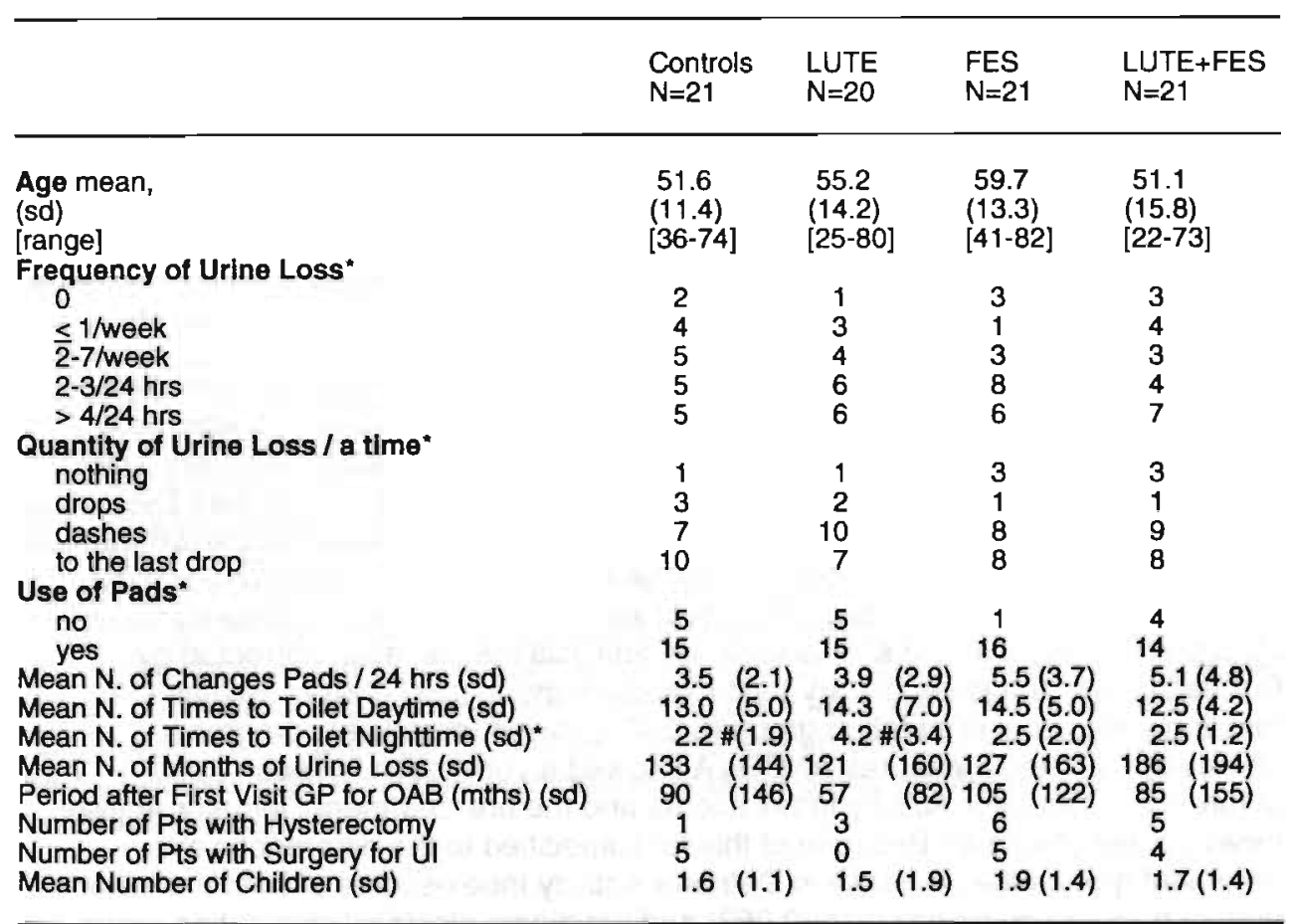

No significant differences $(p<0.05)$ between groups on anamnestical data were found, except $\# p=0.03$ ); ' missing values or answer: 'don't know' or 'not applicable' 
Table 2b. Comparison of Baseline Characteristics of total group $(N=83)$

\begin{tabular}{|c|c|c|c|c|}
\hline & Controls & LUTE & FES & LUTE+FES \\
\hline $\begin{array}{l}\text { Padtest MUDO in ml., mean (sd) } \\
\text { Frequency voidings/hrs, mean (sd) } \\
\text { Volume/voiding (ml), mean (sd) } \\
\text { Dai-1, mean (sd) } \\
\text { IIQ-7, mean (sd) } \\
\text { sd }=\text { standard deviation } \\
\text { ml. }=\text { milliliters } \\
\alpha=0.05\end{array}$ & $\begin{array}{rr}45 & (76) \\
1.13 & (0.49) \\
163 \quad(82) \\
0.69(0.27) \\
0.67(0.66)\end{array}$ & $\begin{array}{r}54 \quad(89) \\
1.21(0.50) \\
166 \quad(93) \\
0.79(0.24) \\
0.89(0.63)\end{array}$ & $\begin{array}{rr}101 & (207) \\
1.18 & (0.49) \\
138 \quad(58) \\
0.75 & (0.26) \\
0.80 & (0.62)\end{array}$ & $\begin{array}{rr}100 & (163) \\
1.04 & (0.42) \\
118 \quad(58) \\
0.79(0.25) \\
0.58(0.55)\end{array}$ \\
\hline
\end{tabular}

In Table 2c baseline characteristics of the subset of 68 patients with Detrusor Activity Index $\geq 0.50$ before start of therapy can be found. There were no significant differences between the groups.

Table 2c. Comparison of Baseline Characteristics of subgroup ( $N=68, D A I \geq 0.50)$

\begin{tabular}{|c|c|c|c|c|}
\hline & $\begin{array}{l}\text { Controls } \\
(N=14)\end{array}$ & $\begin{array}{l}\text { LUTE } \\
(N=18)\end{array}$ & $\begin{array}{l}\text { FES } \\
(N=17)\end{array}$ & $\begin{array}{l}\text { LUTE+FES } \\
(\mathrm{N}=19)\end{array}$ \\
\hline $\begin{array}{l}\text { Padtest MUDO in ml., mean (sd) } \\
\text { Frequency voidings/hrs, mean (sd) } \\
\text { Volume / voiding (ml), mean (sd) } \\
\text { Dai-1, mean (sd) (0-1) } \\
\text { IIQ-7, mean (sd) }(0-3) \\
\mathrm{sd}=\text { standard deviation } \\
\mathrm{ml} .=\text { milliliters } \\
\mathrm{a} \quad=0.05\end{array}$ & $\begin{array}{r}65 \quad(87) \\
1.28(0.52) \\
144 \quad(74) \\
0.85(0.15) \\
0.77(0.74)\end{array}$ & $\begin{array}{rr}51 & (82) \\
1.26 & (0.58) \\
148 \quad(73) \\
0.84 & (0.16) \\
0.99 & (0.75)\end{array}$ & $\begin{array}{rr}107 & (205) \\
1.19 & (0.68) \\
126 \quad(67) \\
0.84 & (0.18) \\
0.91 & (0.69)\end{array}$ & $\begin{array}{rr}99 & (159) \\
1.10 & (0.44) \\
109 \quad(53) \\
0.87 & (0.17) \\
0.61 & (0.58)\end{array}$ \\
\hline
\end{tabular}

\section{Detrusor Activity Index}

In repeated measures ANOVA of Detrusor Activity Index-score differences between pre- and post-treatment conditions overall differences over therapy groups were statistically significant $(F=4.21$ by 3 and $79 \mathrm{df} ; \mathrm{p}=0.008)$ and mean Detrusor Activity Index-scores were posttreatment lower over all groups than pre-treatment Detrusor Activity Index-scores ( $F=12.81$ by 1 and $79 \mathrm{df} ; \mathrm{p}=0.001)$. Specified to the differences over treatment groups both lower urinary tract exercises and functional electrical stimulation groups showed significant decrease in Detrusor Activity Index-scores (i.e. clinical progress). Table 3 shows variance analysis results: even corrected by Dunnett's t-test the lower urinary tract exercises-group $(p=0.039)$ as well as the functional electrical stimulation-group (0.047) showed remarkable progress. However, repeated measures ANCOVA showed a correlation between (mean) difference in Detrusor Activity Index scores and the pre-treatment Detrusor Activity Index-scores (Table 4). Because of this fact, specified to the differences over treatment groups the decrease in Detrusor Activity Index-scores of both the lower urinary tract exercises-group $(p=0.062)$ and functional electrical stimulation-group $(p=0.053)$ was non-significant. So, ANOVA results should be interpreted with caution. 
Table 3 Statistical characteristics / results pre- and posttreatment DAI and difference of DAI $(\mathrm{N}=83 / \mathrm{DAl} 1 \geq 0)$.

\begin{tabular}{|c|c|c|c|c|c|c|}
\hline Egroup & DAl1-means & Sd & DAl2-means & Sd & Diff.DAI & $\mathrm{Sd}$ \\
\hline Control & 0.69 & 0.27 & 0.66 & 0.35 & 0.03 & 0.25 \\
\hline LUTE & 0.79 & 0.24 & 0.55 & 0.35 & 0.24 & 0.31 \\
\hline FES & 0.75 & 0.26 & 0.52 & 0.32 & 0.23 & 0.33 \\
\hline LUTE+FES & 0.79 & 0.25 & 0.82 & 0.29 & -0.03 & 0.31 \\
\hline Total & 0.76 & 0.25 & 0.64 & 0.29 & 0.12 & 0.32 \\
\hline
\end{tabular}

$F$ time: 12.81 by 1 and 79 df $p=0.001$

$F$ time "therapy: 4.21 by 3 and 79 df $p=0.008$

Effect Dunnett

$1 Y 2 \quad 0.21(0.09) p=0.030 \quad p=0.039$

$1 Y 3 \quad 0.20(0.09) p=0.037 \quad p=0.047$

$1 Y 4 \quad-0.06(0.09) p=0.911 \quad p=0.918$

$1 Y 2,3,4 \quad 0.35(0.23) \mathrm{p}=0.133$

Table 4. Parameters of dummyregression model $1(\mathrm{~N}=83 / \mathrm{DAl} 1 \geq 0)$

\begin{tabular}{lrrrrr}
\hline Variable & B & St.err. B & B & T & P \\
\hline Dai1 & & & & & \\
D12 (LUTE-con) & 0.375 & 0.127 & 0.30 & 2.96 & 0.004 \\
D13 (FES-Con) & 0.172 & 0.091 & 0.23 & 1.89 & 0.062 \\
D14 (LUTE+FES-con) & 0.175 & 0.089 & 0.24 & 1.97 & 0.053 \\
Intercept & -0.096 & 0.090 & -0.13 & -1.07 & 0.289 \\
& -0.228 & 0.108 & - & -1.60 & 0.114 \\
\hline
\end{tabular}

In repeated measures ANOVA of Detruser Activity Index-score differences between pre- and afterward treatment conditions for the 68 randomized patient and Detruser Activity Index $\geq 0.50$ overall differences over therapygroups were statistically significant ( $F=3.18$ by 3 and $64 \mathrm{df} ; \mathrm{p}=0.030)$ and mean Detruser Activity Index-scores were posttreatment lower over all groups than pretreatment Detruser Activity Indexscores ( $F=16.16$ by 1 and $64 \mathrm{df} ; p<0.001)$. Specified to the differences over treatment groups only the functional electrical stimulation-group showed significant decrease in Detruser Activity Index-scores ( $p=0.047$ ) (Table 5).

Specified to the differences over treatment groups, also repeated measures ANCOVA showed a statistically significant decrease of Detruser Activity Index-scores of the functional electrical stimulation-group $(p=0.040)(T a b l e ~ 6)$, while the decrease in Detruser Activity Index-scores of the lower urinary tract exercises-group was remarkable but not significant $(p=0.099)$. There was no effect of the lower urinary tract exercises and functional electrical stimulation-group compared to the notreatment group $(p=0.674)$. 
Table 5. Statistical characteristics / results pre- and posttreatment $\mathrm{DAl}(\mathrm{N}=68 / \mathrm{DAl} 1 \geq 0.50)$

\begin{tabular}{|c|c|c|c|c|c|c|}
\hline Egroup & DAl1-means & Sd & DAI2-means & Sd & Diff.DAl & Sd \\
\hline Control & 0.85 & 0.15 & 0.80 & 0.26 & 0.05 & 0.19 \\
\hline LUTE & 0.85 & 0.17 & 0.62 & 0.33 & 0.24 & 0.32 \\
\hline FES & 0.84 & 0.18 & 0.58 & 0.34 & 0.27 & 0.34 \\
\hline LUTE+FES & 0.86 & 0.17 & 0.84 & 0.27 & 0.02 & 0.26 \\
\hline Total & 0.85 & 0.16 & 0.71 & 0.32 & 0.14 & 0.30 \\
\hline
\end{tabular}

F time: 16.16 by 1 and 64 df $p<0.001$

$F$ time "therapy: 3.18 by 3 and $64 \mathrm{df} p=0.030$

Effect Dunnett

$1 Y 2 \quad 0.17(0.11) p=0.110 \quad p=0.123$

$1 Y 3 \quad 0.21(0.10) p=0.047 \quad p=0.057$

$1 Y 4 \quad-0.04(0.10) p=0.684 p=0.859$

$1 Y 2,3,4 \quad 0.34(0.26) p=0.201$

Table 6 Parameters of dummyregression model $2(\mathrm{~N}=68 / \mathrm{DAl} 1 \geq 0,50)$

\begin{tabular}{lrrrrr}
\hline Variable & B & St.err. B & $B$ & $T$ & $P$ \\
\hline Dai1 & & & & & \\
D12 (LUTE-con) & 0.380 & 0.212 & 0.21 & 1.79 & 0.078 \\
D13 (FES-con) & 0.170 & 0.101 & 0.25 & 1.68 & 0.099 \\
D14 (LUTE+FES-con) & 0.214 & 0.102 & 0.31 & 2.09 & 0,040 \\
Intercept & -0.042 & 0.100 & -0.06 & -0.42 & 0.674 \\
& -0.267 & 0.196 & - & -1.36 & 0.179 \\
\hline
\end{tabular}

\section{Pre-analysis of the IIQ-7}

Impact of incontinence on daily life activities as seen by the patient was measured by 7 Likert-type items. Patients could answer on situational aspects of this impact on daily life activities by a four-point scale, in which ' 0 ' stands for: 'no impact at all', ' 1 ' stands for: 'yes, just a little impact', '2' stands for: 'yes, much impact', and ' 3 ' for: 'yes, very much impact'. Next to this, patients could answer that the item was 'not applicable' for their case: this predominantly meant that they felt like being nonincontinent, but in some instances it could mean that they were not used to do the activities mentioned in the item (like: 'going out in town' or 'doing sports'). In both instances patient scores were set missing. Items were scored three times: pretreatment and post-treatment (at 3 and 6 months after start therapy). Patient scores of 6 months in the control group had not been measured: data of 3 months posttreatment scores were substituted instead. Item-analysis was performed for all three measuring moments: means, standard deviation, skewness and number of patients are given in Table 7. Factor analysis was performed using maximum likelihood estimation using both one- and two-factor models. In all three measuring moments the one-factor solution had to be rejected, because the change in log-likelihood chisquare between the two- and one-factor solution results was statistically significant. Nevertheless, the one-factor solution had to be adopted given previous results in literature. For each measuring moment item loadings on the first factor were $\geq 0.40$. Next, Cronbach's alpha was calculated as an internal consistency measure. 
Table 7. Item-analysis for pre- and post-treatment ( 3 and 6 months) measurement moments

\begin{tabular}{|c|c|c|c|c|c|c|c|c|c|c|c|c|c|c|c|}
\hline & \multicolumn{5}{|c|}{ Pre treatment } & \multicolumn{5}{|c|}{ Post treatment 3 months } & \multicolumn{5}{|c|}{ Post treatment 6 Months } \\
\hline & mean & stdv & $\mathbf{N}$ & skew & $\begin{array}{l}\text { mis- } \\
\text { sing }\end{array}$ & mean & stdv & $N$ & skew & $\begin{array}{l}\text { mis- } \\
\text { sing }\end{array}$ & meer & Stdv & $\mathbf{N}$ & skew & $\begin{array}{l}\text { mis- } \\
\text { sing }\end{array}$ \\
\hline housekeeping & 0.39 & 0.81 & 74 & 2.04 & 8 & 0.23 & 0.57 & 73 & 2.84 & 2 & 0.27 & 0.54 & 66 & 1.90 & 9 \\
\hline sport & 1.05 & 1.10 & 74 & 0.60 & 8 & 0.49 & 0.85 & 70 & 1.96 & 5 & 0.49 & 0.88 & 66 & 1.93 & 9 \\
\hline going out & 0.96 & 1.03 & 73 & 0.63 & 9 & 0.39 & 0.72 & 72 & 2.01 & 3 & 0.48 & 0.81 & 67 & 1.79 & 8 \\
\hline travelling & 0.90 & 1.04 & 76 & 0.73 & 6 & 0.52 & 0.84 & 73 & 1.40 & 2 & 0.46 & 0.73 & 67 & 1.49 & 8 \\
\hline social & 0.20 & 0.57 & 76 & 3.18 & 6 & 0.11 & 0.36 & 73 & 3.45 & 2 & 0.15 & 0.40 & 68 & 2.75 & 7 \\
\hline emotion & 0.80 & 0.97 & 76 & 0.87 & 6 & 0.41 & 0.68 & 73 & 1.40 & 2 & 0.47 & 0.66 & 68 & 1.09 & 7 \\
\hline frustration & 0.83 & 0.96 & 76 & 0.92 & 6 & 0.53 & 0.69 & 73 & 1.18 & 2 & 0.65 & 0.74 & 69 & 1.11 & 6 \\
\hline
\end{tabular}

Pre-treatment alpha for all items was 0.79 , the one at 3 months was 0.85 and at 6 months it was 0.82 . Finally, additive scales were constructed, in such a manner that patients at least had to have four of the seven items non-missing. The eventual scales were standardized to the same four-point scale as mentioned above (0-3). A high score meant a 'high impact' of incontinence on daily activities, a low (or zero) score a 'low impact (or no impact at all)' of incontinence as regarded by the patient. The distributions of impact scales tended to resemble an inversed J-curve, especially both post-treatment measures:this can also be seen from the high level of skewness in the distributions. To analyse the three perceived impact-on-daily-life scales within time over the four therapy groups we use repeated measures ANOVA, which requires an approximately normal distribution in the dependent variables. So, a log transformation was used to normalize the impact scale scores to a more acceptable shape. Means, standard deviations, and number of patients of each impact scale for each therapygroup for the total group of randomized patients are given in Table 8 , and for the subgroup of patients with Detrusor Activity Index $\geq 0.50$ in Table 9.

Table 8. Means, standard deviations, number of patients pre- and post-treatment/therapy group $(\mathrm{N}=75)$

\begin{tabular}{lllll}
\hline & Therapy group & Mean & Stdv & N \\
\hline IIQ-7 pre-treatment & 1 & 0.67 & 0.66 & 20 \\
& 2 & 0.89 & 0.63 & 19 \\
& 3 & 0.83 & 0.62 & 18 \\
IIQ-7 at 3 months & 4 & 0.62 & 0.53 & 18 \\
& Total & 0.75 & 0.61 & 75 \\
& 1 & 0.52 & 0.56 & $20^{*}$ \\
IIQ-7 at 6 months & 2 & 0.35 & 0.43 & 19 \\
& 3 & 0.40 & 0.42 & 18 \\
& 4 & 0.32 & 0.53 & 18 \\
& Total & 0.40 & 0.49 & 75 \\
& 1 & 0.52 & 0.56 & $20^{*}$ \\
& 2 & 0.53 & 0.47 & 19 \\
& 3 & 0.35 & 0.34 & 18 \\
& 4 & 0.31 & 0.40 & 18 \\
& Total & 0.43 & 0.45 & 75 \\
\hline
\end{tabular}

\footnotetext{
" substitution data IIQ-7 at 3 months $Y \| Q-7$ at 6 months
} 
Table 9. Means, standard deviations, number of patients pre- and post-treatment/therapy group $(\mathrm{N}=61)$

Therapy group Mean Stdv N

$\begin{array}{lllll}\text { IIQ-7 pre-treatment } & 1 & 0.77 & 0.74 & 13 \\ & 2 & 0.92 & 0.66 & 17 \\ & 3 & 0.93 & 0.63 & 15 \\ \text { IIQ-7 at 3 months } & 4 & 0.64 & 0.55 & 16 \\ & \text { Total } & 0.82 & 0.64 & 61 \\ & 1 & 0.51 & 0.52 & 13^{*} \\ \text { IIQ-7 at } 6 \text { months } & 2 & 0.37 & 0.45 & 17 \\ & 3 & 0.46 & 0.44 & 15 \\ & 4 & 0.32 & 0.56 & 16 \\ & \text { Total } & 0.41 & 0.49 & 61 \\ & 1 & 0.51 & 0.52 & 13^{*} \\ & 2 & 0.54 & 0.50 & 17 \\ & 3 & 0.38 & 0.36 & 15 \\ & 4 & 0.31 & 0.42 & 16 \\ & 4 & 0.43 & 0.45 & 61^{*}\end{array}$

* substitution data IIQ-7 at 3 months $Y$ IIQ-7 at 6 months

\section{IIQ-7}

At first pre-treatment and post-treatment ( 3 months) impact scales were analyzed for 75 of the 83 included patients. Eight included patients had urgency and/or frequency only, but were not incontinent, so the IIQ-7 was not applicable for these patients! General trend over all therapygroups showed a significant lowering in mean scores (overall $\mathrm{F}$ for time $=57.03$ with 1 and $71 \mathrm{df} ; \mathrm{p}<0.001$ ) for the 75 patients who had valid scores on both occasions. Perceived impact score differences between pre- and post-treatment conditions showed overall therapy group differences $(F=2.92$ with 3 and $71 \mathrm{df} ; \mathrm{p}=0.040$ ). If the three therapy groups were contrasted with the control group this lowering of perceived impact on daily life was statistically significant $(p=0.006)$. The lower urinary tract exercises group turned out to have statistically significant lower self-professed impact of incontinence on daily life activities, even if we use Dunnett's multiple comparison correction $(p=0.009)$. The functional electrical stimulation- and the lower urinary tract exercises and functional electrical stimulationgroup were non-significant $(0.053$ and 0.073 , respectively)

An ANCOVA-model showed a significant positive relationship between pre-treatment impact scores and the self-professed improvement in impact-scores. Addition of therapy groups in terms of dummy variables does not improve prediction of impact scores, if the pre-treatment scores are already entered within the regression analysis (Fchange $=2.16$ with 3 and $70 \mathrm{df} ; \mathrm{p}=0.10$ ). The slight, but not significant higher means of both the lower urinary tract exercises- and functional electrical stimulationgroups in the pre-treatment measurement tend to undermine treatment effects in both groups.

Next, pre-treatment and post-treatment (6 months) impact scales were analysed. Over all therapy-groups a general lowering was observed within the self-professed impact scores for the total group of patients ( $F=36.57$ by 1 and $71 \mathrm{df} ; p<0.001)$. However, there were no differences over therapy groups in the improvement of perceived impact on daily activities ( $F=1.66$ with 3 and $71 \mathrm{df} ; \mathrm{p}=0.183$ ). This was due 
to the relative failure of the lower urinary tract exercises-group to maintain their improvement in the impact scores, as perceived by the patient. On the other hand a strong but non-significant indication of IIQ-7 scale improvement between pretreatment and post-treatment ( 6 months) for the functional electrical stimulationgroup may be observed.

Then pre-treatment and post-treatment ( 3 months) impact scales were analyzed for 61 of the 68 included patients with Detrusor Activity Index-scores $\geq 0.50$. In this group 7 women were not incontinent, so the IIQ-7 could not be used as outcome measure. General trend over all therapygroups showed a significant lowering in mean scores (overall $F$ for time $=43.26$ with 1 and $57 \mathrm{df} ; p<0.001$ ) for the 61 patients with valid scores on both occasions. Perceived impact score differences between pre- and post-treatment conditions showed no overall therapygroup differences ( $F=1.35$ with 3 and $57 \mathrm{df} ; p=0.268$ ). If the three therapygroups were contrasted with the control group this lowering of perceived impact on daily life was not statistically significant $(p=0.067)$. The lower urinary tract exercises-, functional electrical stimulation- and lower urinary tract exercises and functional electrical stimulation-group turned out to have no statistically significant lower self-professed impact of incontinence on daily life activities $(0.054,0.166$ and 0.189 , respectively)

Next, pre-treatment and post-treatment ( 6 months) impact scales were analyzed.

Over all therapy- groups a general lowering was - again - observed within the selfprofessed impact scores of this subgroup of patients with Detrusor Activity Indexscores $\geq 0.50$ (F overall $=31.94$ with 1 and $57 \mathrm{df} ; p<0.001$ ). No differences over therapygroups in the improvement of perceived impact on daily activities were found ( $F=1.00$ with 3 and $57 \mathrm{df} ; \mathrm{p}=0.401$ ).

\section{Discussion}

To date, the ICS has provided no clear definition of the term bladder overactivity. ${ }^{22}$ Moreover, in the literature various terms related to bladder overactivity can be found. All kinds of terms like overactive bladder, bladder overactivity, unstable bladder, bladder instability, detrusor instability, detrusor overactivity, detrusor hyper-reflexia are used to classify - but also confuse - this bladder control problem. The term 'overactive bladder' is originally a pure history based diagnosis, while the term 'overactive detrusor' is an urodynamically-based conclusion. Descriptive terms like 'a disorder of the filling/storage phase', 'detrusor hyperreflexia', 'detrusor instability' or 'involuntary bladder contractions, while the patient is attempting to inhibit' are currently confusing clinical practice. ${ }^{22}$

Therefore, it is suggested to describe the dysfunction of the bladder which is related to symptoms of frequency, urgency and urinary incontinence as follows; 'bladder overactivity is a dysfunction of the bladder in which a subject has no or decreased control over suddenly occuring contactions of the detrusor muscle in such a way that this leads to premature voiding'. ${ }^{6}$ With most of the terms only a qualitative state of the patient can be described while research demands a need for a quantitative assessment of bladder overactivity. ${ }^{6}$ This assessment can provide data not only for a more specific diagnosis of bladder overactivity but also for evaluation of the effects of the various possible therapies. The Detrusor Activity Index, as a result of ambulatory urodynamic monitoring, is suggested to be very useful to quantify the severity of bladder overactivity during storage. ${ }^{6}$ The development of the Detrusor Activity Index model and report of the findings and experiences during validation of the Detrusor Activity Index have been described 
previously. ${ }^{6,23}$ Although the Detrusor Activity Index is not a completely reliable 'gold standard' to determine whether or not patients suffer from bladder overactivity, ${ }^{24}$ this diagnostic and evaluation tool has sufficient accurary to be used as the primary measure of outcome of this study. A disadvantage is the complicated way of collecting the necessary data. The preparation, the instruction of the patient, and the analysis of the data are time-consuming. A 'quality-control' protocol for the ambulatory urodynamic monitoring was used to optimalize the results of the test and its acceptance by the patient.

During the one-year-inclusion period 248 persons with possible bladder overactivity applied as candidates for the trial. As stated before, finally 83 subjects met all inclusion criteria and were included in the study. At the end of the standardized intake the observer selected all relevant candidates for the micturition diary test. Using the results of the micturition diary the observer was able to get a reliable impression whether or not the candidate might have an overactive bladder. Only candidates with a positive result of this test were selected for the ambulatory urodynamic test in order to quantify and eventually to prove bladder overactivity. Of the 114 persons with a positive result on the micturition test, 86 had involuntary bladder contractions during ambulatory cystometry $(76 \%)$ of which 68 had proven bladder overactivity (Detrusor Activity Index $\geq 0.50$ ), indicating that this micturition test can serve as a sensitive tool in the diagnosis of bladder overactivity. Because of the limited direct access to ambulatory urodynamics, the micturition test can be very useful for general practitioners, especially for patients with mild or moderate bladder overactivity.

In most cases, after diagnosing bladder overactivity based on history taking and physical examination, the general practitioner refers patients directly to the physical therapist without urodynamic evaluation. Because the general practitioner normally has limited direct access to urodynamics and only can rely on symptoms, there is no proof that patients with symptoms of urgency, frequency and/or urge-incontinence really suffer from bladder overactivity. As a consequence of the computer-software bug 15 patients with symptoms of frequency, urgency and/or urine-incontinence but with Detrusor Activity Index $<0.50$ were included. So, in this trial we included patients with Detrusor Activity Index $<0.50$ (possible bladder overactivity) and with Detrusor Activity Index $\geq 0.50$ (proven bladder overactivity). Because of this, comparing both categories of patients, it was possible to evaluate whether or not the degree of bladder overactivity and the effect of lower urinary tract exercises and functional electrical stimulation were related. Patients with proven bladder overactivity, i.e. the more homogeneous group, had a better response to therapy than the patients with Detrusor Activity Index $<0.50$. In all patients involuntary bladder contractions were identified. However, we feel it is necessary not only to qualify but also to quantify involuntary bladder contractions. It is possible that in this study some patients with Detrusor Activity Index $<0.50$, which were included because of their symptoms of urgency, frequency, urinary incontinence and involuntary bladder contractions, actually did not have bladder overactivity but suffered from other problems, like urethral relaxation or sensory urge. In these cases, it might be that physical therapy modalities, like lower urinary tract exercises or functional electrical stimulation, are not as efficaous as in patients with proven bladder overactivity. Therefore, to assess the real value of these kind of treatment modalities and to guarantee an optimal chance of success, we suggest that in future studies only patients with Detrusor Activity Index $\geq 0.50$ must be included. 
The randomization was reasonably successful. The relevant prognostic data appeared to be equally divided between the groups (see Table $2 \mathrm{a}$ and $2 \mathrm{~b}$ ). It might be possible that the high compliance was the consequence of the very high motivation among the patients and a very enthusiastic supervision during the treatments. ${ }^{16,25,26}$ Protocol deviations were almost non existent. Harmful side-effects were neither reported by patients, nor by therapists.

Blinding was not possible at all levels. Because exercises were performed in the lower urinary tract exercises-group and because of the use of an intravaginal or intraanal electrode during functional electrical stimulation no blinding of patient and therapist was possible. Often in physical therapy it is unrealistic to perform double blind research. ${ }^{27}$ However, effect measurements and data analysis were blinded. This study was based on two counts of effect measurements to measure objectively the quantitative severity of bladder overactivity by using the Detrusor Activity Index (see above) and subjectively the consequences as a result of bladder overactivity by using the IIQ-7. Despite the fact that the original versions of the used questionnaire were validated, to date there are no validated Dutch versions. Another disadvantage of the used questionnaire was that only the influence of involuntary loss of urine on quality of life and on daily activities could be assessed, while it was possible that patients with an overactive bladder only had symptoms of frequency and urgency. As far as we know there are no specific questionnaires focused only on symptoms of frequency and urgency related to bladder overactivity. Another disadvantage was that patients might become nonchalant during routine reporting. Therefore, the observer scored the questionnaires while the patient answered the questions. During the qualification period a high emphasis was laid on the exact and accurate record keeping of micturition diaries, and, patient's compliance was repeatedly checked by the therapist during the treatment phase.

In literature some suggestions can be found that combination of different therapies or therapy modalities have more effect than each therapy (modality) separately. ${ }^{28-2 \theta}$ Although no publications have confirmed that combinations of exercise regimens and functional electrical stimulation improved the final results, these combinations might be effective as treatment options for women with bladder overactivity. ${ }^{2 \theta}$ However, in this study the combination of lower urinary tract exercises and functional electrical stimulation was (almost) non-effective in comparison with no-treatment. It is possible that functional electrical stimulation, applicated directly after lower urinary tract exercises, neutralized the effect of the intensive lower urinary tract exercisesprogramme.

In patients with bladder overactivity the aim of therapy is different as compared to women with stress urinary incontinence (SUI). In patients with stress urinary incontinence lower urinary tract exercises and functional electrical stimulation aim at the functional improvement/restoration of the strenght of the pelvic floor muscle (PFM). Here physical therapy is mainly focused on optimalizing the condition of peripheral muscles, rather than on restoring a central nervous dysfunction affecting the inhibitory control of the micturition reflex. In women with bladder overactivity central modulation seems to be the key-word. The main goal is to achieve central inhibition of the bladder overactivity by teaching the patient selective attention to and voluntary control of the detrusor inhibition reflex by selective relaxation and contraction. The effect of a contraction of the pelvic floor on the bladder is inhibition of the detrusor contraction. ${ }^{30}$ Lower urinary tract exercises are suggested to provide central inhibition of bladder overactivity by way of inhibition of the periaqueductal 
grey (PAG) on a pontine region, i.e., the medial (M-)region (or pontine micturition center (PMC), ${ }^{31}$ i.e. the inhibition component. Another pontine region, the lateral (L-)region (or pontine storage center) has direct projections on the nucleus of Onuf in the sacral cord and in this way initiates contraction of the pelvic floor including the external urethral sphincter. ${ }^{31}$ Functional electrical stimulation is more likely focussed on facilitating the detrusor inhibition reflex by activating existing inhibitory reflexsystems between the bladder, the sacral spine and the PAG. Functional electrical stimulation is suggested to bring down the level of activation of the lower urinary tract which is often too high in patients with urgency, frequency and/or urgeincontinence, i.e. the activation component. Separately, lower urinary tract exercises are suggested to provide central inhibition of bladder overactivity by inhibition of the PAG on the PMC, functional electrical stimulation 'regional' inhibition by (supra)spinal reflexes. It is possible that a combination of these two different pathways interfere negatively - possibly at PAG-level -, which was clearly the case in this study if we look at the negative results of the lower urinary tract exercises and functional electrical stimulation-group in comparison with the control-group. It might be that other combinations of therapy modalities or other protocols of different duration and/or intensity have more effect than the combination, used in this study. It appeared to be very difficult to assess in literature the efficacy of lower urinary tract exercises and functional electrical stimulation as a treatment modality for women with urge urinary incontinence. As far as we know, for the treatment of women with bladder overactivity, this is the first RCT comparing lower urinary tract exercises or office and home-based functional electrical stimulation with no treatment. In our review on the efficacy of conservative treatment modalities for women with urge urinary incontinence two RCTs of sufficient ${ }^{32-33}$ and two of low methodological quality ${ }^{34-35}$ were identified comparing bladder (re)training with no treatment (controls), suggesting that there is only weak evidence that bladder (re)training is more effective than no-treatment (controls). However, the lower urinary tract exercises protocol used in this study was different compared to these studies, because it also included pelvic floor muscle exercises focused on selective contraction of the pelvic floor in order to increase the detrusor inhibition reflex.

We only could identify four RCTs ${ }^{10,36-38}$ comparing intravaginal electrical stimulation vs sham intravaginal electrical stimulation. Three trials reported results in favour of electrical stimulation, ${ }^{10,36-37}$ whereas the low quality study of Sheperd reported that electrical stimulation was not more effective than sham electrical stimulation. ${ }^{38}$ In the well-designed study of Yamanishi 32 patients in the active group and 28 in the sham group completed the study. On the cystometrogram, the bladder capacity at the first desire to void and the maximum desire to void increased significantly in the active group, but not in the sham group. It was concluded that functional electrical stimulation was superior to sham treatment and proved its efficacy for the treatment of urinary incontinence due to bladder overactivity. ${ }^{10}$

Because there was no consistency between the trials in terms of types and parameters of functional electrical stimulation, it was clear that momentarily no standard protocol or 'best' methodology of functional electrical stimulation for the treatment of women with bladder overactivity exists. The treatment parameters of electrical stimulation in this study were empirical and in accordance with functional electrical stimulation protocols usually employed in studies with the choice for a high intensity treatment. ${ }^{9}$

It seemed reasonable to have patients attend once a week for treatment in the physical therapy practice and once (Group II and IV) or twice (Group III) a day at home. A treatment interval of 9 weeks was chosen because this would be enough to 
measure change, but not so long that it would encourage women to drop out of the study. It could be that a longer interval of treatments would have a greater impact on symptoms. This means that a number of patients could have reached a higher level of improvement than was the case in this study. In clinical practice, we should expect that treatments would continue until no further improvement was noted.

In the total group of 83 randomized patients, comparing the lower urinary tract exercises-, functional electrical stimulation- and combination-group with the notreatment group, using repeated measures ANOVA, there was a statistical significant decrease in Detrusor Activity Index-scores in both the lower urinary tract exercisesand the functional electrical stimulation-group, while in the combination-group this improvement could not be realized. However, repeated measures ANCOVA showed a correlation between (mean) difference in Detrusor Activity Index scores and the pre-treatment Detrusor Activity Index-scores. Because of this correlation, the decrease of mean differences of pre-and post-Detrusor Activity Index-scores was no longer significant. The total group of 83 of patients represented a more heterogeneous group of patients with 15 patients with a Detrusor Activity Index-score $<0.50$ and 68 patients with a Detrusor Activity Index $\geq 0.50$. Patients with a lower pretreatment Detrusor Activity Index-score tended to have a lower progression in difference of pre-and post-treatment Detrusor Activity Index-scores than patients with higher pre-treatment Detrusor Activity Index-scores. So, an adequate diagnostic tool that quantifies bladder overactivity, like the Detrusor Activity Index, can be very supportive in selecting those patients that will respond to physical therapy. In the subset of 68 patients with Detrusor Activity Index $\geq 0.50$ there was no statistically significant correlation between pre-and post treatment scores of the Detrusor Activity Index. In this homogeneous subgroup, comparing the functional electrical stimulation-group with the no-treatment group, there was a remarkable improvement of mean difference in pre-and post-treatment Detrusor Activity Index-scores $(p=0.047)$. The efficacy of physical therapy for women with bladder overactivity can also be assessed by calculating the standardized effect for the most promising therapy group, the functional electrical stimulation-group, versus the control-group. ${ }^{39}$ If $d$ expresses the differences between two sample means in standard deviation units, $d=\left(X_{1}^{\prime}-X_{2)}^{\prime}\right) / s$, in which $d$ is the effect size index, $X_{1}^{\prime}$ and $X_{2}^{\prime}$ are the Detrusor Activity Index-score progression group means and $s$ is the root mean square of $s_{1}$ and $s_{2}$ (standard deviations of both groups). $S$ can be calculated as: square root of $\left(s_{1}{ }^{2}+s_{2}{ }^{2}\right) / 2$. For the control group and the functional electrical stimulation-group $\mathrm{d}=0.80$, which can be defined as a 'large' effect. ${ }^{39}$

It was striking that, in general, mean scores of the IIQ-7-items were rather low, mostly not exceeding score ' 1 '. This could mean that in this patient population bladder overactivity only had a little impact on daily life activities. It is also possible that the IIQ-7 is not a sufficiently adequate and responsive tool to measure differences in effect of therapy in women with bladder overactivity. Comparing the lower urinary tract exercises-, functional electrical stimulation- and lower urinary tract exercises and functional electrical stimulation-group with the no-treatment group, using repeated measures ANOVA, the decrease in IIQ-7-scores in the lower urinary tract exercises- group turned out to be statistically significant, while in the functional electrical stimulation this improvement almost was significant and in the lower urinary tract exercises and functional electrical stimulation-group non-significant. However, using repeated measures ANCOVA, in the total group of 83 included patients there was a correlation between (mean) difference in IIQ-7-scores pre- and posttreatment, as was seen in the Detrusor Activity Index-scores. Because of this correlation, the decrease of mean differences of pre-and post-IIQ-7-scores was no longer significant. 
In the more homogeneous subgroup of patients with Detrusor Activity Index-scores $\geq 0.50$, the mean pre-treatment IIQ-7-scores were higher than in the total group of included patients, indicating that in patients with proven bladder overactivity the impact on daily activities was higher, while post-treatment ( 3 months) these means were comparable with the post-treatment mean results of the total group. However, this larger progress in impact-scores was not statistically significant, because of lack of power.

\section{Conclusions}

Although power in the total group of 83 randomized patients was in accordance with our power calculation, using repeated measurements ANCOVA, this group represented a too heterogeneous sample of patients with respect to their Detrusor Activity Index-score to reach a statistical significant effect of functional electrical stimulation, while in the homogeneous subset of 68 patients this effect was significant.

Based on the objective effect parameter, office- and home based functional electrical stimulation seemed to be an effective treatment modality for the treatment of women with bladder overactivity, especially if bladder overactivity is proven. Lower urinary tract exercises seemed to provide a positive trend in improvement. The combination of functional electrical stimulation and lower urinary tract exercises was not effective. Although there is, especially in the lower urinary tract exercises- (at 3 months) and functional electrical stimulation-group (at 3 and 6 months), a positive trend in subjective improvement, as measured by the IIQ-7, results have to be interpreted with caution.

More research of high methodological quality is required to support the conclusions of this study.

\section{Acknowledgments}

We would like to express our sincere gratitude to Michael D.I. Lansbergen, MSc MTD, and Joe Lai, MD, for their very important support in analysing the results of the ambulatory cystometry.

\section{References}

1. Resnick NM. Urinary incontinence. Lancet 1995; 346: 94-99.

2. Hunskaar et al. J Am Geriatr Soc 1991; 39: 378.

3. Grimby A, Milson I, Molander U, Wiklund I, Ekelund P. The influence of urinary incontinence on the QOL of elderly women. Age Ageing 1993; 22: 82-89.

4. Norton P et al. Br Med J 1988; 297: 1187.

5. Berghmans LCM, Hendriks HJM, de Bie RA, van Waalwijk van Doorn ESC, Bø K, van Kerrebroeck PhEV. Conservative treatment of urge urinary incontinence in women: a systematic review of randomized clinical trials. Br J Urol 2000; 85: 254-263.

6. Van Waalwijk van Doom ESC, Ambergen AW. Diagnostic assessment of the overactive bladder during the filling phase: the detrusor activity index. $\mathrm{Br} J$ Urol 1999; 83 (suppl 2): 16-21.

7. Mattiasson A. Discussion: Bladder and pelvic floor muscle training for overactive bladder. Urology 2000; 55: 12-13.

8. Berghmans LCM, Hendriks HJM, Bø K, Hay-Smith, De Bie RA, Van Waalwijk van Doorn ESC. Conservative treatment of stress urinary incontinence in women: a systematic review of randomized clinical trials. Br J Urol 1998; 82: 181-191.

9. Eriksen BC. Electrostimulation of the pelvic floor in female urinary incontinence. Thesis University of Trondheim, Norway 1989. 
10. Yamanishi T, Yasuda K, Sakakibara R, Hattori T, Suda S. Randomized, double-blind study of electrical stimulation for urinary incontinence due to detrusor overactivity. Urology 2000; 55: 353357.

11. Lagro-Janssen ALM. Urine-incontinentie bij vrouwen in de huisartspraktijk. Thesis University of Nijmegen, the Netherlands 1991.

12. Lagro-Janssen ALM, Breedveldt Boer HP, Dongen JUAM van, Lemain TJJ, Steeneken F, Dijkstra RH, Wiersma Tj: NHG-Standaard Incontinentie voor Urine. Nederlandse Huisartsen Genootschap, 1995.

13. Van Waalwijk van Doom ESC, Remmers A, Janknegt RA. Extramural ambulatory urodynamic monitoring during natural filling and normal daily activities:evaluation of one hundred patients. J Urol 1991; 146: 124.

14. Van Waalwijk van Doom ESC, Remmers A, Janknegt RA. Conventional and extramural ambulatory urodynamic testing of the lower urinary tract in female healthy volunteers. J Urol 1992; 147: 1319.

15. Van Waalwijk van Doom, Ambergen AW, Janknegt RA. Detrusor Activity Index: Quantification of detrusor overactivity by ambulatory monitoring. J Urol 1997; 157: 596-599.

16. Bø, K., Hagen, R. H., Kvarstein, B., Jorgensen, J. and Larsen, S.: Pelvic floor muscle exercise for the treatment of female stress urinary incontinence: III. Effects of two different degrees of pelvic floor muscle exercises. Neurourol Urodyn 1990; 9: 489-502.

17. Houston KA. Incontinence and the older woman. Clinics in geriatric medicine $1993 ; 9 ; 157-171$.

18. Messelink EJ. The overactive bladder and the role of the pelvic floor muscles. Br J Urol 1999; 83 (suppl 2); 31-35.

19. Uebersax JS, Wyman JF, Shumaker SA, McClish DK, Fant JA, and the Continence Program for women research group. Short forms to assess life quality and symptom distress for urinary incontinence in women: the Incontinence impact Questionnaire and the Urogenital Distress Inventory. Neurourol Urodyn 1995; 14: 131-139.

20. Van Waalwijk van Doorn ESC, Anders K, Khullar V, Kulseng-Hanssen S, Pesce F, Robertson A, Rosario D, Schäfer W. Standardisation of ambulatory urodynamic monitoring: Report of the Standardisation Sub-committee of the International Continence Society for ambulatory urodynamic studies. Neurourol Urodyn 2000; 19: 113-125.

21. SPSS/PC, version 9.0. SPSS Inc., Chicago, Illinois, USA 1998.

22. Hampel C, Wienhold D, Dahms SE. Thuroff JW. Heterogeneity in epidemiological investigations of bladder control problems: a problem of definition. Br J Urol 1999; 83 (suppl 2): 10-15.

23. Van Waalwijk van Doom ESC. Ambulatory urodynamics. Thesis University of Maastricht, The Netherlands 1990.

24. Van Waalwijk van Doom ESC, Zwiers W, Wetzels LLAN, Debruyne FMJ. A comparative study between standard and ambulatory urodynamics. Neurourol Urodynam 1987; 6: 159.

25. Wall LL \& Davidson TG: The role of muscular re-education by physical therapy in the treatment of GSI. Obstet Gynecol Surv 1992; 47: 322-331.

26. Susset JG, Galea G, Read L. Biofeedback therapy for female incontinence due to low urethral resistance. J Urol 1990; 143: 1205-1208.

27. Deyo RA, Walsh NE, Schoenfeld LS, Rama-Murthy S. Can trials of physical therapy be blinded? The example of transcutaneous electrical nerve stimulation for chronic pain. Am J Phys Med Rehabil 1990; 69: 6-10.

28. Fantl JA, Newman DK, Colling J, et al. Urinary incontinence in adults: Acute and chronic management. Rockville Md: US Dept of Health and Human Services, Public Health Service, Agency for Health Care Policy and Research; March 1996. AHCPR publication 96-0682 Clinical Practice Guideline No.2, 1996 Update.

29. Van Kerrebroeck PhEV. A treatment algorithm for the overactive bladder. $\mathrm{Br}$ J Urol 1999; 83 (suppl 2): 29-30.

30. Vodusek DB, Plevnik S, Vrtacnik $P$, Janez J. detrusor inhibition on selective pudendal nerve stimulation in the perineum. Neurourol Urodynam 1988; $6: 389-393$.

31. Holstege G. Neuronal organisation of micturition. In 'Lower Urinary Tract Dysfunction: from All to Clinical Approach'. Microsymposium, Erasmus University Rotterdam, Rotterdam, the Netherlands, 1998.

32. Fantl JA., Wyman JF, McClish DK, Harkins SW, Elswick RK, Taylor, JR, Hadley EC. Efficacy of bladder training in older women with urinary incontinence. JAMA 1991; 265: 609-613.

33. Wyman JF, Fantl JA, McClish DK, Harkins SW, Uebersax JS, Ory MG. Quality of life following bladder training in older women with urinary incontinence. Int Urogynecol J 1997; 8: 223-229. 
34. Jarvis GJ, Millar DR. The treatment of incontinence due to detrusor instability by bladder drill. Female incontinence 1981; 341-343.

35. Lagro- Janssen ALM, Debruyne FMJ, Smits AJA, Weel C van. The effects of treatment of urinary incontinence in general practice. Family Practice 1992; 9: 284-289.

36. Tsinar B, Kralj B. Maximal electrical stimulation in children with unstable bladder and noctural enuresis and/or daytime incontinence: a controlled study. Neurourol Urodyn 1996; 15: 133-142.

37. Brubaker L, Benson JT, Bent A, Clark A, Shott S. Transvaginal electrical stimulation for female urinary incontinence. Am J Obstet Gynecol 1997; 177: 536-540.

38. Shepherd AM, Tribe E, Bainton D. Maximal Perineal Stimulation. A controlled study. Br J Urol 1984; 56: 644-646.

39. Portney LG, Watkins MP. In: Portney LG, Watkins MP (eds). Foundations of clinical research, pg. 653. Norwalk, Connecticut, USA, Appleton \& Lange 1993. 


\section{Chapter 7}

\section{General discussion}

In this chapter we focus on the findings of this thesis. First, the evidence derived from the two systematic reviews that have been described in the chapters 2 and 5 will be discussed. Next, we will reflect on the internal and external validity of the two randomized clinical trials, described in chapters 3 and 6 . Then we will reflect on the applicability of the evidence in developing relevant guidelines, described in chapter 4. At the end of this chapter my personal conclusions on the efficacy of conservative treatment for stress urinary incontinence and bladder overactivity can be found.

Assessment of trial quality is often a part of the process of a systematic review. To date, more than 60 different criteria lists exist. ${ }^{1}$ A criteria list is useful to get insight into relevant quality components of the topic of research. In the two systematic reviews, described in this thesis, the same list of predefined methodological criteria was used, ${ }^{2,3}$ based on generally accepted principles of intervention research. These methodological assessment criteria were chosen to measure internal validity (e.g., randomization, blinding, loss-to-follow-up, the relevance of choices with respect to study population, interventions and outcome measures) and precision of included studies (e.g., sample size and variability). Consequently, the list provides an impression of the suitability of each study for reviewing purposes. As far as we know, in the field of urology these were the first two reviews to feature a list.

In the assessment of the evidence of conservative treatment trials for stress urinary incontinence and bladder overactivity, several problems occurred. Between the various studies there was quality range from low to rather high. It is suggested that low quality studies tend to overestimate effect estimates. ${ }^{1}$ Often investigators are assumed to be biased in favour of the intervention under research. On the other hand, Verhagen ${ }^{1}$ stated that low study quality can both underestimate and overestimate the effect. If the methodological quality of the studies and the effect sizes $^{4}$ are related, the rationale is that the higher the quality of the study, the greater the influence is on the final conclusion about the effect. If there is no relationship, the final conclusion should be based on the outcome of all included studies. In our reviews, the best quality studies had the greatest impact on the conclusions, but we are aware of the fact that choices about cut-off points between higher and lower quality studies are always debatable.

Many different effect measures were found in the various studies under review. Because of this, it was hardly possible to combine the results of the different studies and to make a quantitative analysis of the outcomes. For this reason a qualitative analysis was performed, after considering the possibility to combine the outcomes of studies based on similar participants, interventions and effect measures in each of the trials. ${ }^{5}$

In the review on stress urinary incontinence (chapter 2) the overall methodological quality was low to moderate. Only eleven of the 22 trials scored 6 or more points (out of 10) implying that half of the studies under review appeared to be methodologically inadequate. Since several errors in the design, execution and analysis of the trials 
easily could have been avoided, it is surprising that so little effort was made to do so. The main methodological shortcomings of the included trials were small sample sizes, lack of (pre-)stratification on prognostic determinants, proper blinding and lack of proper description of analysis and presentation of results. In order to obtain adequate answers to the hypotheses of the studies, adequate sample sizes are necessary. Moreover, small positive studies tend to be more easily published than small negative ones, introducing publication bias. ${ }^{6}$ It is important to (pre-) stratify on relevant prognostic determinants to avoid that these factors will be unequally distributed over each group. Because of lack of (pre-)stratification, unequal distribution of these factors often can have led to incomparability of the study groups for baseline characteristics. Lack of proper blinding easily introduces bias and should be prevented as much as possible. Although we are aware of the fact that in physiotherapy trials for the treatment of stress urinary incontinence and bladder overactivity blinding of therapists and patients often was not possible, blinding of the observer and of the analist should always have been pursued. Inadequate description of analysis and presentation of the results made it difficult to interprete the findings of the trials and the way investigators reached their conclusions. In the review on stress urinary incontinence a rating system that considered four levels of scientific evidence based on quality and the outcome of studies was used. ${ }^{7-8}$ For the review on bladder overactivity we choosed a synthesis with three levels of evidence. Both rating systems were used in former studies and appeared to be valid..$^{70}$ Both systems allowed for systematic conclusions regarding the efficacy of physiotherapeutic interventions for stress urinary incontinence and urge urinary incontinence. The second synthesis seemed to be a little bit more accurate because of the fact that at least 3 studies with a certain degree of quality were necessary to conclude the level of evidence, where in the first system less studies were needed or no minimum of studies was specified in order to make conclusions. On the other hand, the first system allowed to rate on 4 different levels of evidence instead of 3 in the second system. As far as we know there is still no consensus about the most optimal and valid rating system. It is possible that conclusions about the level of evidence were different depending on what system was used. For instance, using the first system, one of the conclusions was that there was strong evidence that biofeedback as an adjunct to pelvic floor muscle exercises was no more effective than pelvic floor muscle exercises alone. With the second system the conclusion would have been that there was only weak evidence because only 2 high quality studies could be identified instead of 3 studies that were necessary to conclude for strong evidence. For the future, more efforts should be made to develop a rating system that is based on broad consensus regarding its validity and reliability. In assessing the quality of the available studies it was possible that the quality of the reported material was not representative for the quality of the primary research. ${ }^{1}$ Yet, there is no other way for assessing the available evidence regarding the efficacy of conservative treatment than to rely on what is published in relevant scientific journals. We concluded that because of the enormous variability in the quality of the included studies and the use of different measures of effect in most of the trials under review comparisons between studies was difficult and that results should be interpreted with caution. Therefore, well-designed and well-conducted trials according to well-established methodological criteria are necessary.

Based on the conclusions of the systematic reviews, we decided to perform a randomized clinical trial on the efficacy of biofeedback as an adjunct to pelvic floor muscle exercises for women suffering from genuine stress incontinence. Also a trial on the efficacy of functional electrical stimulation, pelvic floor muscle exercises (i.e. 
lower urinary tract exercises = LUTE) and bladder training and a combination of electrical stimulation and pelvic floor muscle exercises and bladder training in women with bladder overactivity was performed. In these trials we tried to avoid the pitfalls and errors as they were identified in the reviews. Items regarding internal and external validity of the two trials will be discussed. In order to assure high internal validity it is necessary that the study population is well randomized and that there is an adequate procedure for blinding. Also avoidance of drop-out and unequal distribution of prognostic variables is essential.

In both trials a rather conscientious assignment method was used. An independent person prepared a randomization scheme before the start of the trials. In the trial on biofeedback stratification was done by seriousness of incontinence and by referral because of differences in diagnostic possibilities between the general practitioner and the urologist and therefore prognostic imcomparability. Randomization was done in blocks of four (in the trial on biofeedback within strata), using sealed envelopes containing a note with group assignment. Each envelope was opened just before each included individual started the therapy. The observer and the analist were blinded for allocation of treatment. After the trials were finished we checked the comparability of the study groups for baseline characteristics and found out that the randomization was successful. In any RCT the comparison of treatments may be distorted if those responsible for treatment and evaluation know which treatment is being used. In physiotherapy trials it is often infeasable to conduct a double-blind trial. " Also in our trials it was not possible to blind the patient and the physiotherapist. On the other hand, blinding of the observer and the data analysis procedure appeared to be successful. Basically, knowledge of patient's therapy puts considerable pressure on the observer's and analist's ability to remain objective. The successful blinding procedure avoided suchs bias during the interpretation of the results.

In the trial on the efficacy of biofeedback there were no drop-outs and compliance was $100 \%$. So, the results of this trial were not biased by selective withdrawals. In the trial on the efficacy of electrical stimulation, during the qualification period, before randomisation, 94 out of 175 patients dropped out of the trial (54\%). After randomisation, during the treatment period, $7 \%$ of the patients dropped out. During the evaluation period $5 \%$ were lost. All missing data were accounted for in an intention to treat analysis. Outcomes of the intention to treat analysis and the per protocol analysis were similar. So, conclusions, based on the results of the trial, were not distorted by selective withdrawal rates.

Unequal distribution of prognostic variables between the treatment groups can easily lead to misinterpretation of the results of the therapy. A sufficient sample size helps to avoid such bias. ${ }^{12}$ In both trials we made sample size calculations based on the formulated hypotheses of the trials. Although the number of patient in the trial on the efficacy of biofeedback was rather small, there appeared to be a comparable distribution of prognostic variables between the study groups. Moreover, we feel that the power in both trials was sufficient to detect relevant differencies in outcome between the study groups.

The external validity of a trial depends on the proper choice of patients, interventions and measures of outcome. To assure as much as possible homogeneity of our study groups regarding the maximal sensitivity to the interventions under study, we used strict entry criteria and we successfully stratified for referral and for severity of the incontinence.

With respect to bladder overactivity, most existing diagnostic tools are lacking sensitivity and specificity. ${ }^{13}$ 
In the study on the efficacy of functional electrical stimulation in women with bladder overactivity the Detrusor Activity Index was used. This index, established by van Waalwijk van Doorn et al., ${ }^{13}$ is suggested to be a valid diagnostic tool to prove bladder overactivity. The use of this diagnostic test, together with the use of strict inclusion and exclusion criteria, made homogeneity of the study population, at least for the sub-group of 68 patients with Detrusor Activity Index $\geq 0.50$, feasable. The interventions used in both trials were according to criteria and parameters, generally accepted by experts in this field. Although there is still no consensus about the most optimal programme, a choice was made for frequent and intensive standardised programmes providing the patient an optimal chance for responding to the interventions.

The trial on the efficacy of biofeedback in women with genuine stress incontinence was based on three effect measurements to measure subjectively and objectively the involuntary loss of urine, i.e., the Inco-test (pad test), the Patient's Diary and the Symptoms Questionnaire. In general, pad tests are a relatively crude way to estimate urine loss and have methodological shortcomings as described in Chapter 3. Yet, the Inco-test was tested on reliability and acceptability and was suitable for evaluation of the urine-loss. During the trial emphasis was put on the exact and accurate record keeping of the Patient's Diary and the Symptoms Questionnaire in order to prevent that patients might get sloppy during routine reporting. Compliance was checked by the physiotherapist.

The study on the efficacy of functional electrical stimulation in women with overactive bladder was based on two counts of effect measurements, i.e., the Detrusor Activity Index and the IIQ-7. The Detrusor Activity Index is suggested to be very useful to quantify the severity of bladder overactivity during storage. ${ }^{13}$ Although the Detrusor Activity Index is not a reliable 'gold standard' yet, to determine whether or not patients suffer from bladder overactivity, this evaluation tool has sufficient accurary to be used as the primary measure of outcome of this study. Despite the fact that the original version of the used questionnaire was validated, to date there is no validated Dutch version. Another disadvantage of the used questionnaire was that only the influence of involuntary loss of urine on daily activities could be assessed, while it was possible that patients with overactive bladder only had symptoms as frequency and urgency and no involuntary loss of urine. So, this questionnaire was not responsive for the latter category of patients. Moreover, overviewing the rather low mean pre-treatment results of the scores of the IIQ-7, most of the patients subjectively seemed not much to be influenced because of their health problem. Another explanation for the low mean pre-treatment IIQ-7-scores might be that the IIQ-7 is not a very responsive list for this category of patients. As far as we know there are no specific questionnaires only focused on symptoms as frequency, urgency related to bladder overactivity. To avoid that patients might have got sloppy during routine reporting, the observer scored the questionnaire while the patient answered the questions.

Development of guidelines for stress urinary incontinence was important not only to ensure the quality of physiotherapy practice, but also because evidence-based physiotherapeutic management would be stimulated. Besides, these guidelines could provide more insight into this kind of treatment to other involved health care providers. A systematic approach is a prerequisite for making explicit choices and decisions during physiotherapeutic management. In chapter 4 we described an evidence-based and systematic approach to the management of stress urinary incontinence in order to assess its effectiveness and to justify the rationale for this kind of treatment. To shed some light on the present lack of standardization in the 
terminology and how this could be improved, relevant nomenclature, terminology and classification systems related to stress urinary incontinence were discussed. It was recommended to make more efforts to achieve standardization of terminology, based on the specific requirements of physiotherapists. Because application of physical therapies should be preceded by evidence that these kind of treatments are effective, the results of the systematic review and the RCT on genuine stress incontinence were incorporated in the guidelines. In the case that there was no or insufficient evidence, experts in the field were consulted systematically. The objective of the physiotherapist's diagnostic process was to assess the severity and the nature of the condition of genuine stress incontinence, and to what extent this condition could be influenced by physiotherapeutic intervention. Based on the physiotherapist's diagnosis, objectives of the therapy could be formulated and a treatment plan could be devised. To date, the underlying pathology causing genuine stress incontinence still remains more or less unclear. Therefore, the answer whether or not physiotherapy is helpful in the management of genuine stress incontinence cannot always be given. In these cases, physiotherapy should be given as a 'pilot treatment'. We identified three different problem areas, in which physiotherapeutic treatment could be regarded as a pilot treatment. Decisions on the physiotherapeutic management were made taking into account the problem area, prognostic and patient variables. It was concluded that pelvic floor muscle exercises, with and without biofeedback, were effective, but that there still was no consensus about the most optimal programme. In the RCTs, described in this thesis, we used only evidence-based exercise protocols in order to optimalisize the treatment and to evaluate the effects of physiotherapy on genuine stress incontinence and bladder overactivity.

In this thesis we investigated the current state of the evidence regarding the efficacy of conservative treatments for women with genuine stress incontinence and/or bladder overactivity. In general, the methodological quality of the included studies in both reviews was low to moderate. We concluded that more RCTs of high methodological quality, assessing the efficacy of physiotherapy, are necessary. Based on the results of the review and the RCT on the efficacy of biofeedback for women with genuine stress incontinence, it was concluded that pelvic floor muscle exercises alone and pelvic floor muscle exercises with biofeedback are equally effective for the treatment of genuine stress incontinence, although there was uncertainty about the most effective programme. Biofeedback as an adjunct to pelvic floor muscle exercises did not seem to be more effective than pelvic floor muscle exercises alone, although this strategy might be more effective in the first period of treatment. With respect to all other conservative treatment modalities and prevention no firm conclusions on the efficacy of conservative treatment of stress urinary incontinence could be drawn.

Regarding the efficacy of conservative treatment for women with bladder overactivity, based on the Detrusor Activity Index, office- and home based electrical stimulation seemed to be an effective treatment modality for the treatment of women with bladder overactivity, especially if bladder overactivity is proven. Lower urinary tract exercises seemed to provide a positive trend in improvement. The combination of electrical stimulation and lower urinary tract exercises was not effective.

Furthermore, there was only weak evidence that bladder (re-)training was more effective than no treatment and that bladder (re-)training was superior to drug therapy.

The guidelines for the physiotherapeutic management of stress urinary incontinence reflect the current state of knowledge, but are continuously subject of integration of 
new views and information. At present, the process of implementation of the guidelines into the Dutch field of physiotherapy is well under way.

\section{References}

1. Verhagen AP. Quality assessment of randomised clinical trials. Thesis University of Maastricht, the Netherlands 1999.

2. Kleijnen J, Knipschild $P$. Niacin and vitamin $B 6$ in mental functioning: a review of controlled trials in humans. Biol Psychiatry 1991; 29: 931.

3. Kleijnen J. Craen AJM de, Everdingen J van, Krol L. Placebo effect in double-blind clinical trials with medications. Lancet 1994; 344: 1347.

4. Detsky AS, Naylor CD, Rourke K, McGeer AJ, L'Abbe KA. Incorporating variations in the quality of individual randomized controlled trials into meta-analysis. J Clin Epid 1992; 45: 255-265.

5. Bie RA de. Methodology of systematic reviews: an introduction. Phys Ther Rev 1996; 1: 47-51.

6. Bie RA de. Efficacy of $904 \mathrm{~nm}$ laser therapy in acute lateral ankle sprains. Thesis Maastricht University, the Netherlands 1998.

7. Bigos S, Bowyer O, Braen G, et al. Acute low back problems in adults. Clinical practice guideline no. 14. AHCPR Publication no. 95-0642. Rockville, MD: Agency for Health Care Policy and Research, Public Health Services, U.S. Department of health and Human Services. December, 1995.

8. Tulder MW van. Diagnostics and treatment of chronic low back pain in primary care (Thesis VU Amsterdam). Amsterdam, Thesis Publishers, 1996.

9. Brenfort G. Efficacy of manual therapies of the spine. Thesis Free University of Amsterdam, the Netherlands 1997.

10. Tulder MW van, Assendelft WJJ, Koes BW, Bouter LM, ed. Board of the CC Back Review Group. Method of guidelines for systematic reviews in the Cochrane Collaboration Back Review Group for spinal disorders. Spine 1997; 22: 2323-2330.

11. Pocock SJ. Clinical trials: a practical approach. Chisester: Wiley, 1983. in de huisartspraktijk. Thesis University of Nijmegen, the Netherlands, 1991.

12. Bouter LM, Dongen MCJM van. Epidemiologisch onderzoek: opzet en interpretatie. Houten/Antwerpen. Bohn Stafleu van Loghum, 1991; p. 174.

13. Waalwijk van Doorn van ESC van, Ambergen AW. Diagnostic assessment of the overactive bladder during the filling stage: the Detrusor Activity Index. BJU 1999; 83 (suppl 2): 16-21. 


\section{Summary}

This thesis focuses on the physiotherapeutic management of lower urinary tract disorders, resulting in stress urinary incontinence, and on the conservative treatment of women with symptoms of urgency, frequency and/or motor urge urinary incontinence due to detrusor instability or bladder overactivity.

The aim of this thesis is to make an inventarisation of the current state and the art of the conservative treatment. Next to this, we have tested the efficacy of conservative treatments for women with stress urinary incontinence or bladder overactivity.

The International Continence Society defines urinary incontinence as the objectively demonstrable involuntary loss of urine, to such a degree of severity that it is a social or hygienic problem.

In the Netherlands (total population 15 millions) the estimated prevalence of urinary incontinence in women of 5 years and older is $8.5 \%$ and in men $2.5 \%$. In community dwelling women of 60 years and older, prevalence of UI was $23.5 \%$. Because urinary incontinence affects women more often than men, this thesis will only focus on women with urinary incontinence, more specific stress urinary incontinence and bladder overactivity.

There are various types of urinary incontinence. Stress urinary incontinence is the most common form of urinary incontinence in women. In the literature we found that nearly half of all women with urinary incontinence had stress urinary incontinence (49\%). Stress urinary incontinence is the involuntary loss of urine during physical exertion, e.g., coughing, sneezing, laughing, running, jumping and lifting. Genuine stress urinary incontinence is defined as the involuntary loss of urine which occurs when, in absence of a simultaneous detrusor contraction, the intravesical pressure exceeds the maximum urethral pressure. Besides stress incontinence, bladder overactivity is the most frequently observed disorder in women $(22 \%)$. Bladder overactivity is defined by the International Continence Society as a disorder of filling/storage in which involuntary bladder contractions are demonstrated while the patient is attempting to inhibit these contractions. The symptoms of bladder overactivity consist of urgency and/or frequency and/or nocturia and/or urge incontinence. They may exist as a single entity or in combination.

Incontinence therapy has mainly been based on multiple surgical methods, a variety of pharmacological agents, and various behavioural methods. In the prevention and the conservative treatment of stress urinary incontinence and bladder overactivity several treatment modalities, like pelvic floor muscle exercises, with or without biofeedback and electrical stimulation, or electrical stimulation alone are performed by physiotherapists. In order to justify in society the rationale for these kind of treatments, there is a growing need to proof that physiotherapy does have clinically relevant effects on the natural course of disease, and impact on the patient's condition.

Widespread application of conservative treatments should be preceded by evidence of improvement in function attributable to their use. Randomized clinical trials can serve this vital purpose. Systematic reviews on the basis of methodological criteria put much emphasis on the quality of the randomized clinical trials involved and are very useful to support evidence for the effectiveness of therapy. 
Guidelines in physical therapy for diagnosis, treatment and prevention in patients with urinary incontinence improve the quality of conservative treatment for these disorders. After an introduction in chapter 1, chapter 2 holds a systematic review of randomized clinical trials with the aim to assess the efficacy of conservative treatment and prevention in adult women with stress urinary incontinence. Twenty-four randomized clinical trials were identified of which 22 discussed treatment and two prevention. In general, the methodological quality of the included studies was moderate. However, based on the quality of the studies regarding pelvic floor muscle exercises, there is strong evidence that pelvic floor muscle exercises are effective in reducing the symptoms of stress urinary incontinence. There is limited evidence for the efficacy of high intensity versus a low intensity regimen of pelvic floor muscle exercises. Despite significant post test effects of biofeedback as an adjunct to PFME, there is no evidence that biofeedback as an adjunct to pelvic floor muscle exercises is more effective than pelvic floor muscle exercises alone. There is strong evidence that intravaginal electrical stimulation is superior to sham intravaginal electrical stimulation, and there is limited evidence to suggest that there is no difference between electrical stimulation and other physical therapies. The efficacy of pelvic floor muscle exercises with or without other adjuncts to prevent stress urinary incontinence is unclear.

Chapter 3 presents the results of a randomized clinical trial in 40 women, aged 18 to 70 years. The study objective was to assess whether or not a physical therapeutic training program as the standard treatment combined with biofeedback was more effective than the same program without biofeedback in patients with mild or moderate stress incontinence. The results of the padtest for both the standard treatment and biofeedback showed a mean improvement of $55 \%(p<0.01)$ after 12 treatments, however for biofeedback, the same results were reached already after 6 treatments.

After 12 treatment sessions in the group with the standard treatment 3 patients were cured $(15 \%), 14$ patients were improved $(70 \%)$ and 3 patients were worse $(15 \%)$. In the biofeedback- group 5 patients were cured, 14 were improved and only 1 patient was worse $(25 \%, 70 \%, 5 \%)$. On the symptoms questionnaire the difference in improvement between both groups after 6 and 12 treatment sessions was not significant. The greatest improvement in the biofeedback-group, in comparison with the group with the standard treatment, was realized in the first 6 treatments. This corresponds with the findings of the padtest. In the patient's diary among other items the pattern of the daily occurrence of involuntary urine loss was noted. The difference in decrease between both groups after 6 and 12 treatment sessions was not significant. Based on the results of the combined measure of effect, there was no difference between both groups. However, after consideration of liquid intake and body weight with the aid of the linear regression analysis, it was apparent that there was a significant difference in favour of biofeedback after 6 treatments. After 12 treatments the findings failed to reach a significant difference. Biofeedback and standard treatment are effective treatment modalities for involuntary urine loss in patients with mild or moderate stress incontinence. It is clear from the analysis that biofeedback as a support to therapy is most important in the first two weeks, during the first 6 treatments. Biofeedback results seem to be achieved faster and could be cost effective. In chapter 4 evidence-based and systematic guidelines for physiotherapy in women with genuine stress incontinence are given. Professional cooperation between referring physicians and physiotherapists is required in order to determine the indication for physiotherapy. Based on the diagnostic process, determining the nature of the underlying pathology causing genuine stress 
incontinence stills remains unclear. Therefore, the question as to whether or not, and to what extent, physiotherapy can be helpful in the management of genuine stress incontinence cannot always be answered definitively. In these cases, physiotherapy is given as a 'pilot treatment'. The assessment of the efficacy of physical therapies for first-line use in the treatment of urge urinary incontinence in adult women, using a systematic review of randomized clinical trials, is described in chapter 5 . Fifteen randomized clinical trials were identified. Generally speaking, the methodological quality of the studies was moderate. Based on the levels-of-evidence criteria there was weak evidence to suggest that bladder training was more effective than no treatment. There was also weak evidence that bladder training was superior to drug therapy. Stimulation types and parameters in the studies of electrical stimulation were heterogeneous. There was insufficient evidence that electrical stimulation was more effective than sham electrical stimulation. To date there are not enough studies to evaluate the effects of exercise with or without biofeedback and of toilet training for women with urge urinary incontinence. In chapter 6 we assessed the efficacy of three physiotherapeutic treatment modalities in 83 women, aged between 22 and 82 years, with bladder overactivity. In a single-blind randomized clinical trial we studied the efficacy of specific lower urinary tract exercises, office and home based electrical stimulation and a combination of the same lower urinary tract exercises and office based electrical stimulation in comparison with a no-treatment group. Based on the objective effect parameter, the Detrusor Activity Index (DAI), office and home based electrical stimulation seemed to be an effective treatment modality for the treatment of women with bladder overactivity. Lower urinary tract exercises seemed to provide a positive trend in improvement. The combination therapy was not effective.

Although there is a positive trend in subjective improvement, as measured by the $\mathrm{IIQ}-7$, an effect parameter regarding the subjective influence of urinary incontinence on daily activities, results have to be interpreted with caution. More research of high methodological quality is required to support the conclusions of this study. Chapter 7 presents a general discussion and conclusions with respect to the conservative treatment of stress urinary incontinence. In general, the methodological quality of the included studies in both reviews was moderate. We concluded that more RCTs of high methodological quality, assessing the efficacy of physiotherapy, are necessary. Based on the results of the review and the randomized clinical trial on the efficacy of biofeedback for women with genuine stress incontinence, it was concluded that pelvic floor muscle exercises alone and pelvic floor muscle exercises with biofeedback are equally effective, although there was uncertainty about the most effective program. Biofeedback as an adjunct to pelvic floor muscle exercises did not seem to be more effective than pelvic floor muscle exercises alone, although this strategy might be more effective in the first period of treatment. With respect to all other conservative treatment modalities and prevention no firm conclusions on the efficacy of conservative treatment of stress urinary incontinence could be drawn. Regarding the efficacy of conservative treatment for women with bladder overactivity, based on the DAl, office- and home based electrical stimulation seemed to be an effective treatment modality for the treatment of women with bladder overactivity. Lower urinary tract exercises seemed to provide a positive trend in improvement. The combination of electrical stimulation and lower urinary tract exercises was not effective. Furthermore, there was only weak evidence that bladder (re-)training was more effective than no treatment or drug therapy. 
Aan Bary en Lillan

"Graag wil ik uertellen aver de "Overacticue Blaas"

dege klacht kreeg th gelf niet de baas.

ouk brengt 't heel weel ongemale.

wat maar n's goed moest curden aangepakt.

daaram deed th mee aax je Ondersack.

beste Bary. wat is dat goed.

met kulp wan Lillan. pabte ik de therapie steuig aan.

en doon m'n motivatie en inget, wist ik goed waoruit te gaan.

ga deed ik megen weken mifn witerste best.

ex de thorapie deed de rest.

ack uare de laatste meting stand ik "Paf"

Uitalag. ik ben on kelemaal van of.

eindelifk boreikie ik m'n doel.

als waornaamote "dat geker qewael".

graag wil ik jullie hierwaor bedanken.

als dit me ooit rog overkamt. weet ik wan cuanten."

Harteligk Danke

'A Patiente 


\section{Nederlandse samenvatting}

Dit proefschrift richt zich op de fysiotherapeutische behandeling van disfuncties van de lagere urinewegen bij vrouwen met als gevolg inspanningsgebonden (stress-) urine-incontinentie, aandrangklachten, frequent toiletgebruik en/of aandrangs (urge-) urine-incontinentie vanwege een overactieve blaas. In dit proefschrift is een inventarisatie gemaakt van de huidige stand van kennis en kunde betreffende de conservatieve therapie. Tevens is getoetst of de conservatieve behandeling van vrouwen met stress urine-incontinentie en/of een overactieve blaas effectief is. De International Continence Society definieert urine-incontinentie als objectief aantoonbaar onvrijwillig urineverlies dat een sociaal en hygiënisch probleem vormt. Op een totale bevolking van 15 miljoen wordt de prevalentie van urine-incontinentie in Nederland bij vrouwen ouder dan 5 jaar geschat op 8,5\% en bij mannen op 2,5\%. Bij thuiswonende vrouwen van 60 jaar en ouder was de prevalentie van urineincontinentie $23,5 \%$. Omdat urine-incontinentie zich veel vaker voordoet bij vrouwen dan bij mannen, zal dit proefschrift zich uitsluitend richten op vrouwen met urineincontinentie, met name vrouwen met stress urine-incontinentie en/of een overactieve blaas.

Er zijn een aantal vormen van urine-incontinentie. Stress urine-incontinentie komt het meest voor bij vrouwen. Uit de literatuur bleek dat bijna de helft van de vrouwen met urine-incontinentie stress urine-incontinentie had (49\%). Bij stress urine-incontinentie treedt urineverlies op bij plotse intra-abdominale drukverhoging. Er is sprake van stress urine-incontinentie als onwillekeurig urineverlies optreedt indien bij fysieke inspanning de intravesicale druk de maximale urethradruk overschrijdt in de afwezigheid van activiteit van de blaasspier ( $m$. detrusor vesicae). Na stress urineincontinentie is detrusorinstabiliteit of een overactieve blaas de meest voorkomende disfunctie bij vrouwen (22\%). Een overactieve blaas wordt door de International Continence Society gedefinieerd als een disfunctie in de vulling/opslag waarbij onwillekeurige blaascontracties worden aangetoond terwijl de patiënt probeert deze te onderdrukken. De symptomen bij een overactieve blaas zijn aandrang en/of frequent toiletgebruik en/of nachtelijk plassen (nycturie) en/of aandrang-incontinentie (urge urine-incontinentie). Deze symptomen kunnen apart voorkomen of in combinatie.

Behandelmethoden voor urine-incontinentie zijn over het algemeen gebaseerd op een aantal chirurgische interventies, geneesmiddelen en verschillende vormen van conservatieve therapie.

In de preventie en de conservatieve behandeling van stress urine-incontinentie en een overactieve blaas worden verschillende behandelingsvormen, zoals oefentherapie in combinatie met of zonder biofeedback en electrostimulatie of electrostimulatie alleen, uitgevoerd door fysiotherapeuten. Om de rationale voor deze behandelvormen maatschappelijk te kunnen rechtvaardigen moet aangetoond worden dat fysiotherapie daadwerkelijk invloed heeft op het ziekteverloop en de conditie van de patiënt. Een uitstekende mogelijkheid om de effectiviteit van conservatieve behandelmethoden aan te tonen is een gerandomiseerde effectstudie. Daarnaast bieden systematische overzichten op basis van methodologische criteria de mogelijkheid de kwaliteit van de geïncludeerde gerandomiseerde effectstudies te beoordelen en zo de bewijskracht voor de effectiviteit van de ingestelde therapie te ondersteunen. Richtlijnen op het gebied van de fysiotherapie gebruikt bij diagnostiek, 
behandeling en de preventie van patiënten met lage urineweg disfuncties leveren een bijdrage aan de verbetering van de kwaliteit van de conservatieve behandeling van deze klacht.

$\mathrm{Na}$ een inleiding in hoofdstuk 1 wordt in hoofdstuk 2 een systematisch overzicht van gerandomiseerde effectstudies beschreven met het doel inzicht te verschaffen in de effectiviteit van conservatieve behandeling en preventie bij volwassen vrouwen met stress urine-incontinentie. In totaal werden 24 studies (22 interventiestudies en twee ter preventie) geïncludeerd. In het algemeen was de gemiddelde methodologische kwaliteit van de studies matig. Echter, op basis van de kwaliteit van de studies met betrekking tot bekkenbodemspieroefeningen, bleek dat er sterk bewijs was dat bekkenbodemspieroefeningen effectief zijn bij het verminderen van de aan stress urine-incontinentie gerelateerde symptomen. Het bewijs was beperkt voor bekkenbodemspieroefeningen met een hoge versus een lage intensiteit. Er was duidelijk bewijs dat biofeedback in combinatie met bekkenbodemspieroefeningen niet effectiever is dan bekkenbodemspieroefeningen alleen. Er was wel een positieve trend ten gunste van biofeedback in het eerste traject van behandeling, $\mathrm{nl}$. gedurende de eerste 6 behandelingen. Ten aanzien van electrostimulatie bestond er geen eenduidigheid betreffende de meest geschikte stroomvorm en de prikkelparameters. Indien de resultaten van de electrostimulatie-studies werden gecombineerd kon men concluderen dat electrostimulatie effectiever was dan placebo-electrostimulatie. Er was nauwelijks bewijs dat er verschil is tussen electrostimulatie en andere fysiotherapeutische behandelvormen. Conclusies over de effectiviteit van bekkenbodemspieroefeningen ter preventie van stress urineIncontinentie konden niet worden getrokken.

Hoofdstuk 3 bevat een gerandomiseerde effectstudie onder 40 vrouwen van 18 tot 70 jaar waarbij de rol van biofeedback als een toevoeging aan een standaard oefenprogramma met bekkenbodemspieroefeningen vergeleken werd met hetzelfde oefenprogramma zonder biofeedback bij vrouwen met stress urine-incontinentie. De resultaten van de verbandtest voor zowel de groep met de standaardbehandeling als de groep met biofeedback toonden een gemiddelde verbetering van $55 \%$ na twaalf behandelingen aan $(p<0,01)$. Deze verbetering in de groep met biofeedback werd reeds na 6 behandelingen bereikt. Na twaalf behandelingen waren in de groep met de standaardbehandeling 3 patiënten genezen $(15 \%), 14$ patiënten verbeterd $(70 \%)$ en 3 patiënten waren er slechter aan toe (15\%). In de groep met biofeedback waren deze aantallen resp. 5,14 en $1(25 \%, 70 \%, 5 \%)$.

Op basis van de resultaten van de symptoomvragenlijst was er geen verschil tussen de twee groepen na 6 en 12 behandelingen. De grootste verbetering in de groep met biofeedback ten opzichte van de groep met de standaardbehandeling was te zien na 6 behandelingen, hetgeen overeenkomt met de bevindingen van de verbandtest.

Met de gegevens van het patiëntendagboek kon onder andere het gemiddeld aantal keren urineverlies per week berekend worden. Het verschil in afname tussen de groepen na 6 en 12 behandelingen was niet significant. Er was geen verschil tussen beide groepen op basis van de gecombineerde effectmaat. Echter, als bij een lineaire regressie analyse rekening gehouden werd met het drinkgedrag en het lichaamsgewicht, bleek er na 6 behandelingen een significant verschil tussen beide groepen te zijn ten gunste van biofeedback. Dit resultaat kon niet worden bereikt na 12 behandelingen. Uit de verkregen resultaten blijkt dat een standaard oefenbehandeling met en zonder biofeedback effectieve behandelvormen zijn voor vrouwen met milde en matige vormen van stress urine-incontinentie. Biofeedback als toevoeging aan een standaard oefenprogramma had de meeste waarde tijdens de eerste 6 behandelsessies in de eerste twee weken van behandeling. Biofeedback 
zou sneller resultaat kunnen opleveren en kostenbesparend kunnen werken. In hoofdstuk 4 worden evidence-based en systematische richtlijnen voor fysiotherapie bij stress urine-incontinentie beschreven. Professionele samenwerking tussen de verwijzend arts en de fysiotherapeut is vereist om de indicatie fysiotherapie te kunnen stellen. Op basis van het diagnostisch proces blijft het vaststellen van de aard van de onderliggende pathologie waardoor stress urine-incontinentie is veroorzaakt min of meer onduidelijk. De vraag of en in welke mate fysiotherapie kan bijdragen aan het behandelen van stress urine-incontinentie kan daarom niet altijd zonder meer beantwoord worden. In zulke gevallen moet fysiotherapie als een "testbehandeling" gegeven worden.

Hoofdstuk 5 heeft als onderwerp een systematisch overzicht van gerandomiseerde effectstudies met betrekking tot conservatieve therapie voor vrouwen met urge urineincontinentie. De doelstelling van dit overzicht is het geven van inzicht in de effectiviteit van conservatieve behandeling bij volwassen vrouwen met urge urineincontinentie. In totaal werden 15 studies geïncludeerd. De methodologische kwaliteit van de studies was wederom matig. Een kwalitatieve samenvatting resulteerde in zwak bewijs dat blaastraining meer effectief is dan geen behandeling en dat blaastraining beter is dan medicatie. In geen enkele studie werd dezelfde vorm van electrostimulatie of dezelfde prikkelparameters gebruikt. Er was onvoldoende bewijskracht dat electrostimulatie effectiever is dan placeboelectrostimulatie. Momenteel is er onvoldoende onderzoek gedaan naar de effecten van bekkenbodemspieroefeningen met of zonder biofeedback en toilettraining bij vrouwen met urge urine-incontinentie.

De in hoofdstuk 6 beschreven gerandomiseerde effectstudie onder 83 vrouwen van 22-82 jaar onderzoekt de effectiviteit van verschillende behandelvormen van fysiotherapie bij vrouwen met een overactieve blaas. Het effect van electrostimulatie alleen, van bekkenbodemspieroefeningen samen met blaastraining alleen en van de combinatie van beide therapievormen werd vergeleken met een controlegroep die geen behandeling kreeg. Op basis van de in dit onderzoek gebruikte objectieve effectmaat, de Detrusor AktiviteitsIndex (DAI), leek in de praktijk en thuis uitgevoerde electrostimulatie een effectieve behandelvorm te zijn voor vrouwen met een overactieve blaas. Ook bekkenbodemspieroefeningen samen met blaastraining lieten een positieve trend in verbetering van de symptomen zien. De in dit onderzoek gebruikte combinatietherapie bleek niet effectief te zijn. Alhoewel er een positieve trend was wat betreft de subjectieve resultaten van urine-incontinentie op de dagelijkse aktiviteiten, moeten deze resultaten met voorzichtigheid beschouwd worden. Om de resultaten van dit onderzoek te bevestigen is vervolgonderzoek van hoge methodologische kwaliteit nodig.

In hoofdstuk 7 volgt een algemene discussie en conclusies met betrekking tot conservatieve behandeling van stress urine-incontinentie en een overactieve blaas. In het algemeen was de gemiddelde methodologische kwaliteit van de geïncludeerde studies in de beide systematische overzichten matig. De conclusie was dat meer gerandomiseerde effectstudies met betrekking tot fysiotherapie nodig zijn. Uit de resultaten van het systematisch overzicht en de gerandomiseerde effectstudie met betrekking tot de effectiviteit van biofeedback bij vrouwen met stress urineincontinentie bleek dat bekkenbodemspieroefeningen alleen en in combinatie met biofeedback even effectief waren. Biofeedback als toevoeging aan bekkenbodemspieroefeningen was niet effectiever dan bekkenbodemspieroefeningen alleen, behalve mogelijk in de eerste behandelperiode.

Bij vrouwen met een overactieve blaas bleek electrostimulatie, in de praktijk en thuis toegepast, effectief te zijn. Oefentherapie voor de lagere urinewegen gaf een 
positieve trend in verbetering. De combinatie van beide therapievormen gaf geen verbetering. $\mathrm{Er}$ is weinig bewijs dat blaastraining effectiever is dan geen therapie of geneesmiddelen. 


\section{Dankwoord}

Omdat ik graag een afstudeerproject bij de vakgroep urologie op wilde zetten, bezorgde een wederzijdse vriend mij een introductie bij een zekere dr. Weil. Tijdens het kennismakingsgesprek in het voorjaar van 1993 werd ik welkom geheten door deze dr. Weil met de woorden: "Ben jij een vriend van Gerard? Nou, Gerard z'n vrienden zijn mijn vrienden!" Ernest, c'est le ton, qui fait la musique.., je hartelijke ontvangst was voor mij heel belangrijk, je hebt sindsdien vele deuren voor mij opengemaakt! Heel leuk dat ook jouw promotie een feit is!

$\mathrm{Na}$ het afsluiten van mijn Doctoraal Gezondheidswetenschappen in de zomer van 1994 werd ik door Ruud Janknegt, het toenmalige hoofd van de vakgroep urologie van het azM, uitgenodigd het fysiotherapeutisch deel van een grootschalig onderzoek, het zgn. "Cure or Care"-project, op mij te nemen. Omdat mijn ervaringen tijdens het afstudeerproject met betrekking tot biofeedback bij vrouwen met stress-incontinentie bij de vakgroep urologie ronduit positief waren, heb ik meteen enthousiast toegehapt onder één "kleine" voorwaarde: de mogelijkheid tot promoveren......... Ruud, bedankt voor je vertrouwen en vaderlijke vriendschap die mij een uiterst belangrijke steun in de rug gaven bij het maken van mijn eerste stapjes op de weg van urologisch wonderland.

Mede door de hulp van Ernst van Waalwijk van Doorn kwam de strategie voor dit proefschrift tot stand. Een strategie die erop gericht was via heldere patiëntenselectie en adequate diagnostiek te komen tot een relevante therapie voor de bestudeerde gezondheidsproblemen. $\mathrm{lk}$ wil hem bedanken voor zijn inzet tijdens de opzet en uitvoering van de verschillende onderzoeken. Zoals jij zelf altijd zegt: "Nemo cognoscitur nisi per amicitiam....".

Mijn begeleider van meet af aan is Rob de Bie. Zonder hem zou mijn trektocht door wetenschapsland slechts door de sterren en de zon geleid zijn en niet door het kompas. Hij was mijn hopman tijdens de uro-scouting, mijn coach tijdens het epi-joggen. Bij Rob kon ik altijd terecht, ook al kon het niet......met al mijn vragen, problemen, ideeën, opmerkingen. Steeds verliet ik zijn kamer rijker dan bij binnenkomst. Ik ben hem ontzettend veel dank verschuldigd voor zijn onstuitbare en enthousiaste begeleiding. Zijn "Zet 'm op!' heeft mij diep geraakt, ver buiten de scope van dit proefschrift. Een dergelijke steun en toeverlaat vervult mij met respect en vriendschap en wens ik iedere promovendus toe.

Huub Verheyden was als onderzoeksassistent niet alleen de spil maar ook het rustpunt in het onderzoek "Overactieve blaas! Fysiotherapie?". Motivatie, grote inzet, relativeren, rust, actief meedenken en een grote sociale beleving zijn de ingrediënten en mélange van deze plezierige "timmerman". Ik hoop dat hij ook bij de plannen voor de toekomst deel zal uitmaken van "ons" team, want op Huub kan je altijd rekenen.

Lilian Smeets is in principe verantwoordelijk voor de aanzet tot dit proefschrift. Immers zij was degene die in onze praktijk voor fysiotherapie de eerste stapjes op de weg van de behandeling van de bekkenbodemproblematiek gezet heeft. Als behandelaar was zij betrokken bij de eerste gerandomiseerde effectstudie naar de 
meerwaarde van biofeedback. Later heeft zij samen met Helma ten Haaf de behandelingen verzorgd ten behoeve van de tweede effectstudie van dit proefschrift. Met dit team kreeg ik de beschikking over behandelaars die optima forma garant staan voor state of the art fysiotherapie. Ook jullie zijn absoluut onmisbaar bij onze toekomstplannen op het gebied van de blaas- en bekkenbodemdysfuncties.

Alle collegae van de praktijk voor fysiotherapie ben ik veel dank verschuldigd. Niet alleen was ik vaak afwezig door mijn verplichtingen in het ziekenhuis, moesten zij mij vaak vervangen als ik weer een presentatie in binnen- of buitenland mocht verzorgen, maar ook werden ze geconfronteerd met de vele veranderingen ten gevolge van dit proces. Heel in het bijzonder wil ik mijn partner Martin Koekelkoren danken voor het grote vertrouwen, opoffering, geduld en hulp tijdens de meer dan 20 jaren van onze fijne samenwerking. Met recht gold en geldt "Samen Sterk" voor onze hechte band.

De afdeling urologie, de stafleden, het poli-personeel, de verpleegkundigen van de functie-afdeling, de dames van het secretariaat wil ik bedanken voor hun gastvrijheid en collegialiteit tijdens de praktische uitvoering van de vele onderzoeken. Ik ben er trots op deel uit te maken van deze afdeling.

Alle artsen en arts-assistenten van de vakgroep urologie hebben veel moeite gedaan om de instroom van patiënten van de diverse onderzoeken te doen slagen. Van hen mocht ik vele blijken van belangstelling en adviezen tegemoet zien. Als ik om hulp verlegen zat, was er wel altijd één die mij het benodigde steuntje in de rug gaf.

Natuurlijk ben ik ook veel dank verschuldigd aan alle patiënten die vrijwillig aan de verschillende onderzoeken hebben deelgenomen. Als blijk van respect en waardering heb ik enkele bijzondere reacties van patiënten die hebben deelgenomen aan de effectstudies in het proefschrift opgenomen.

De firma's Uniphy B.V., Mölnlycke B.V., Xytron Medical B.V., Innocept Medizintechnik AG wil ik gaarne bedanken voor hun financiële en logistieke ondersteuning tijdens de gerandomiseerde effectstudies.

Een speciaal woord van dank voor Joe Lai en Michael Lansbergen voor de fijne samenwerking tijdens het onderzoek "Overactieve blaas! Fysiotherapie?". Hun deskundigheid en inzet van - vaak vrije - tijd waren onmisbaar bij de analyses van de ambulante urodynamica.

Fred Nieman moet wel bijna een puntkop gekregen hebben van de vele statistische analyses en methodologische adviezen ten behoeve van ons onderzoek. Soms leek het even of zijn leven in het ziekenhuis alleen maar bestond uit het oplossen van "statistische urologische problemen". Ik heb bijzondere waardering voor zijn deskundigheid, inzet en manier van omgang.

Mijn collegae van de commissie "Centrale Richtlijnen Fysiotherapie bij Stress-incontinentie" van het KNGF wil ik bedanken voor de vruchtbare samenwerking gedurende bijna 3 jaar. Ik denk dat we met z'n allen een moeilijke opdracht tot een heel behoorlijk eindresultaat gebracht hebben. De vele discussies en taakopdrachten verliepen onder de deskundige leiding van Nol Bernards in een fijne en vriendschappelijke sfeer. 
Erik Hendriks kan in ieder geval terugzien op een uitstekende test van zijn concept "Centrale Richtlijnen". Het doet mij bijzonder genoegen dat ook Erik één dezer dagen gepromoveerd is. Een harde werker, waarmee ik een bijzondere band ontwikkeld heb. Ik hoop dat wij in de toekomst nog vele ideeën en plannen samen mogen delen.

Mijn beide promotoren, Philip van Kerrebroeck en Piet van den Brandt, dank ik voor het in mij gestelde vertrouwen, en hun toezicht op de voortgang. Philip heeft, nadat hij het promotorschap van Ruud Janknegt ovemam, vele deuren voor mij opengezet, nauwlettend mijn voortschrijden op de "urologic highway" in de gaten gehouden. Hij staat open voor nieuwe ideeën, stimuleert creativiteit en heeft door zijn opstelling de fysiotherapie hoogst noodzakelijke support gegeven.

Piet heeft grote indruk op mij gemaakt door zijn no-nonsens instelling. Had ik hem nodig, dan klopte ik nooit tevergeefs aan, ook al kwam ik weer eens een keer "ietwat ongelegen".

Een woord van dank voor al mijn co-auteurs van de verschillende artikelen in het kader van dit proefschrift. Zonder hun bijdrage in de vorm van hulp, deskundigheid, steun, kritiek, strategie, en vriendschap, was het nooit zover gekomen!

Thum Aarts, van harte wil ik je bedanken voor de vele uren typen en lay-out die ik mocht afsnoepen van de vrije tijd met je gezin ten behoeve van dit proefschrift.

In het verloop van de enkele jaren die ik aan dit proefschrift heb gewerkt ontving ik vaak uitnodigingen voor het geven van presentaties op vele congressen, symposia en bijeenkomsten.

Letterlijk de hele wereld mocht ik in al zijn facetten bewonderen, voor of na de voordrachten. Ik leerde vele nieuwe vrienden kennen, onder bijzondere omstandigheden. Florence Jacobs en Benedicte Lagarde, beiden werkzaam voor Medtronic, wil ik in het bijzonder bedanken voor hun spontane "Franse" manier van omgang die mij altijd het gevoel gaf onder "real friends" te zijn.

Tenslotte Caroline en Hetty, door mijn aandacht voor dit proefschrift en alles wat daarmee te maken had, werden jullie daadwerkelijk vaak naar achteren geschoven. Op een zondag, ongeveer acht jaar geleden, formuleerde Caroline het zo: "Mamma, waar gaan we vandaag met z'n tweetjes naar toe?" Dit proefschrift heeft ook veel van jullie gevergd. De zonnige snoet en dito humeur van Caroline waren voor mij letterlijk een bron van jeugdige inspiratie. Ik hou van je, kleine, nu al grote meid. Roger Niël, mijn ene paranymf, heeft ooit tegen mij gezegd dat hij jou, Hetty, de meest tolerante vrouw vindt die hij ooit ontmoet heeft. Hoe waar moet dit zijn als je alle opofferingen en uren alleen zijn bij elkaar optelt. Slechts heel zelden kan iemand het geluk hebben een dergelijke persoonlijkheid naast zich te vinden. Ik heb (alweer) dat geluk! Ik ben zeer blij deze feestdag met jou en Caroline te mogen delen. Bedankt voor je grenzeloze vertrouwen, je fantastisch karakter, je liefde en begrip. Je bent een echte kameraad en schat! 
Bearijaing

"Waaron zou te dankess. als je de tited leest.

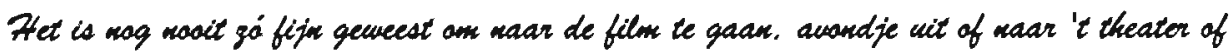
samaar een bezock

aan coriender of familie.

Want pas na thuiskonst hoor je 't getlater!'

Na ga'u 25 jaar verdiende ik de bijnaan "Zeikerd" weel.

maar dat is me niet meer in $t e d$.

Th plas weer als cen "Jonge dame".

doondat ik het artikel in de brant had gelezen.

Ben it doan Fenk mije Fisidarts doonerwezen.

Al wa 2 weleen intensicue therapie han ite de verbetering

al morken, kan ih niet gaan liggen. dave maar lopend of staand.

Daardoon bleef it 8 weken lang canseguent en cantinu.

doargaan met' 't gebliedor ex getwoei

waar le me ga goed doar woell

Lilian keeft mij oak heel goed geholpen en ardanke het croege un keek ik maar alke unijdag wit.

Flet is uandaag de dertiende en dat is juist ga leute.

Fit was ange laatste keer en mu nog cen meekje alleen.

Maar dat is geen probleem.

The meem een kope boffie met gelfgebablen taart.

dat hed it wel vordiend.

Voarkeen. word alles wat ik deed anderbroken. unant

ie gat go'n 45 keer per etmaal op de WC.

Geen druppetijes of bleine plasjes meer.

Th ga alleen mag war '" klaterende waterual maar de WC.

Ous dames doe je best. de therapie doet de rest."

Een hole danbbare patiërte:

E. 7.7 . 


\section{Authors}

LCM Berghmans, MSc RPt. Department of Urology, University Hospital Maastricht, the Netherlands

CMA Frederiks, PhD. Department of Nursing Sciences, University of Nijmegen, the Netherlands

RA de Bie, PhD MSc RPt. Department of Epidemiology, Maastricht University, the Netherlands

EHJ Weil, PhD MD. Department of Urology, University Hospital Maastricht, the Netherlands

LWH Smeets, RPt. Department of Urology, University Hospital Maastricht, the Netherlands

RA Janknegt, PhD MD. Department of Urology, University Hospital Maastricht, the Netherlands

ATM Bernards, MD. Dutch National Institute of Allied Health Professions, Amersfoort, the Netherlands

HJM Hendriks, PhD RPt, Dutch National Institute of Allied Health Professions, Amersfoort, the Netherlands

K Bø, PhD RPt EXSCIENT. Norwegian University of Sport \& Physical Education, Oslo, Norway

MHM Grupping, RPt. Dutch National Institute of Allied Health Professions, Amersfoort, the Netherlands

EJ Hay-Smith, MSc MNZSP. School of Physiotherapy, Division of Health Sciences, University of Otago, Dunedin, New Zealand

ESC van Waalwijk van Doorn, PhD DSc. Department of Urology, University Hospital Maastricht, the Netherlands

PhEVA van Kerrebroeck, PhD MD. Department of Urology, University Hospital Maastricht, the Netherlands

FHM Nieman, PhD. Department of Clinical Epidemiology \& Medical Technology Assessment, University Hospital Maastricht, the Netherlands

WMM ten Haaf, RPt. Department of Urology, University Hospital Maastricht, the Netherlands

PA van den Brandt, PhD. Department of Epidemiology, Maastricht University, the Netherlands 


\section{Articles emanating from this thesis}

Berghmans LCM, Frederiks CMA, Bie RA de, Weil EHJ, Smeets LWH, Waalwijk van Doorn ESC van, Janknegt RA: Efficacy of biofeedback, when included with pelvic floor muscle exercise treatment, for genuine stress incontinence. Neurourol and Urodyn 1996; 15: 37-52.

Berghmans LCM, Hendriks HJM, Bø K, Hay-Smith, Bie RA de, Waalwijk van Doorn ESC van. Conservative treatment of stress urinary incontinence in women: a systematic review of randomized clinical trials. Br J Urol 1998; 82: 181-191.

Berghmans Bary, Hendriks Erik, Bie Rob de, Kerrebroeck Philip van. Eletrostimulação para o tratamento da incontinência urinária de esforço. UROdinâmica 1999; 2: 133-140.

Berghmans LCM, Bernards ATM, Bø K, Grupping MHM. Guidelines for the physiotherapeutic management of genuine stress incontinence. Phys Ther Rev 1998; 3: 133-147.

Berghmans B, Bernards N, Hendriks E, Bø K. Physiotherapeutic management for genuine stress incontinence. In 'Pelvic floor dysfunction: investigations \& conservative treatment' pg. 351-369. Eds. Appell RA, Bourcier AP, La Torre F, C.E.S.I., 1999.

Berghmans LCM. Prevalentie en incidentie-cijfers van urine-incontinentie. NVFB Bulletin 2000; 8: 23-26.

Berghmans LCM, Hendriks HJM, Bie RA de, Waalwijk van Doom ESC van, Bø K, Kerrebroeck PhEVA van. Conservative treatment of urge urinary incontinence in women: a systematic review of randomized clinical trials. $\mathrm{Br} \mathrm{J}$ Urol 2000; 85: 254263.

Bo K, Berghmans LCM. Non-pharmacologic treatments for overactive bladder-pelvic floor exercises. Urology 2000; 55 (suppl 5a): 7-11. 


\section{Curriculum Vitae}

Bary Berghmans werd zo'n 45 jaar geleden op 30 maart geboren te Maastricht. $\mathrm{Na}$ het behalen van het Gymnasium- $\beta$ diploma aan het Henric van Veldeke College te Maastricht in juni 1974, vervulde hij zijn dienstplicht, o.a. aan de Koninklijke Militaire Academie te Breda. Tussen 1975 en 1979 studeerde hij fysiotherapie aan de Limburgse Opleiding voor Fysiotherapie Heerlen. Na het behalen van het diploma fysiotherapie in juni 1979, en een kort werkverband als fysiotherapeut bij Henk Reuvers te Heerlerheide, begon hij in juli 1980 samen met Martin Koekelkoren een praktijk voor fysiotherapie te Maastricht, waarin hij nog steeds parttime als fysiotherapeut werkzaam is. In 1990 ging hij Nederlands Recht studeren aan de Faculteit der Rechtsgeleerdheid van de Universiteit Maastricht, toen nog Rijksuniversiteit Limburg. In 1992 werd het diploma Propaedeuse Nederlands Recht behaald. Vanaf augustus 1992 ging hij gezondheidswetenschappen, afstudeerrichting bewegingswetenschappen, studeren aan de Faculteit Gezondheidswetenschappen van de Universiteit Maastricht. Het Doctoraal Diploma werd in augustus $1994 \mathrm{cum}$ laude behaald. Hij studeerde af op de effectiviteit van biofeedback bij vrouwen met stress urine-incontinentie. Nadien heeft hij diverse cursussen gevolgd op het gebied van bekkenbodemdysfuncties aan de Hogeschool West-Brabant te Breda. Bary volgde tevens cursussen bij professor Miettinen. Sinds 1995 is hij als wetenschappelijk medewerker, aanvankelijk als projectmedewerker, later als projectmanager, verbonden aan de Capaciteitsgroep Urologie van het Academisch Ziekenhuis Maastricht om onderzoek te doen naar de effectiviteit van conservatieve behandelmethoden bij vrouwen met urine-incontinentie. In 1996 volgde zijn registratie als Epidemioloog A. In zijn hoedanigheid als epidemioloog en fysiotherapeut was hij als inhoudsdeskundige betrokken bij de ontwikkeling van centrale richtlijnen voor fysiotherapeuten bij stress urine-incontinentie in opdracht van het Koninklijk Genootschap voor Fysiotherapie.

Bary is lid van de Werkgroep Urine-incontinentie van de Nationale Gezondheidsraad en van de Wetenschapscommissie van de Stichting Pelvic Floor Netherlands. Hij is tevens lid van de Clinical Assessment Group van de International Continence Society en van de Cochrane Incontinence Review Group. In het sociaal-maatschappelijk leven was hij in 1994 Prins Carnaval van de stad Maastricht en van 1985-1999 voorzitter van de Stichting Reünie Kombi. Sinds januari 1996 is hij voorzitter van de Stichting Maastricht 2000. 


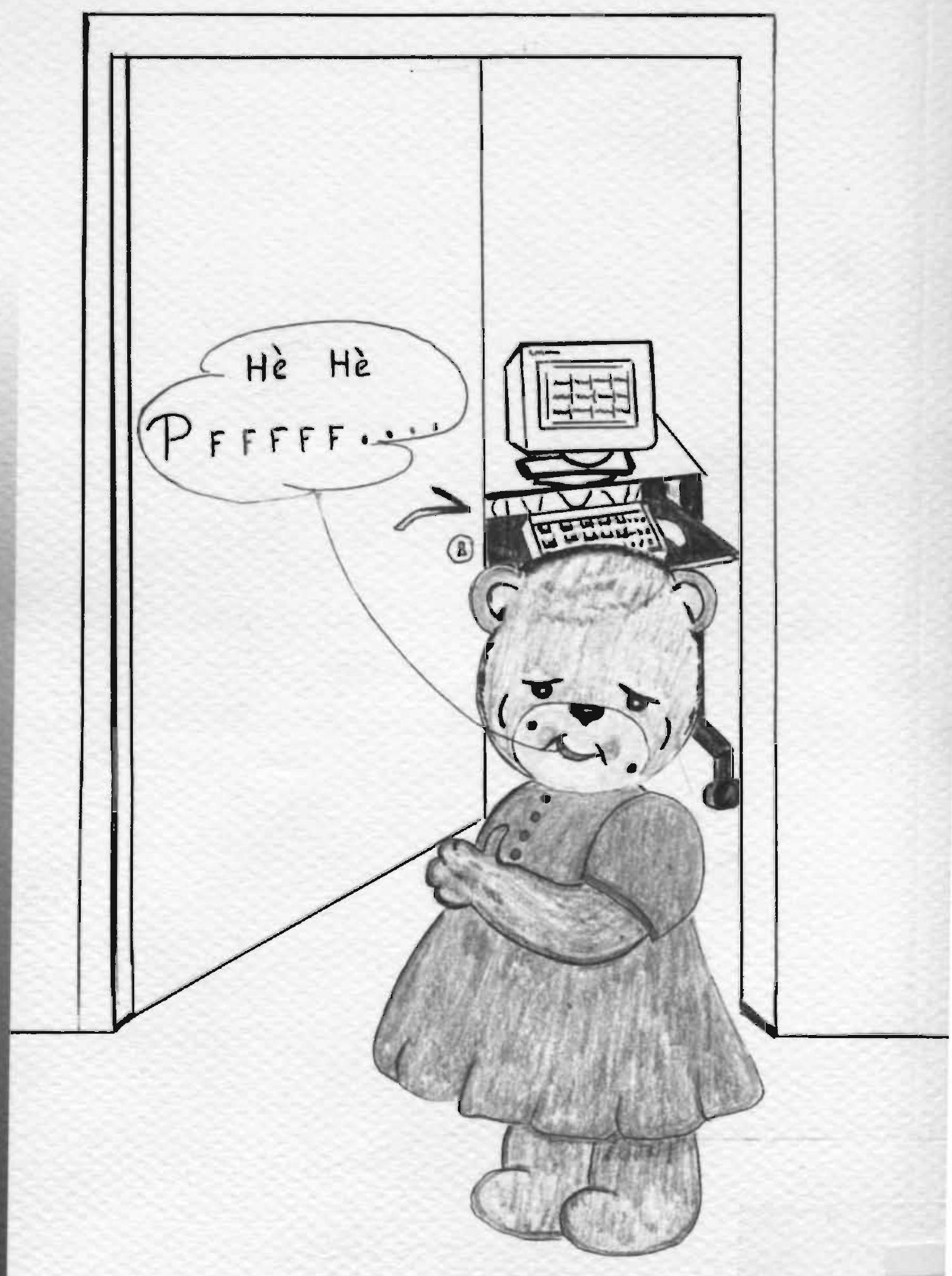

